\title{
Appalachian Bariatric Surgery Population Descriptive Analysis, Surgical Outcomes, and Food Accessibility
}

\author{
Makenzie Leanne Barr
}

Follow this and additional works at: https://researchrepository.wvu.edu/etd

\section{Recommended Citation}

Barr, Makenzie Leanne, "Appalachian Bariatric Surgery Population Descriptive Analysis, Surgical

Outcomes, and Food Accessibility" (2018). Graduate Theses, Dissertations, and Problem Reports. 5158.

https://researchrepository.wvu.edu/etd/5158

This Dissertation is protected by copyright and/or related rights. It has been brought to you by the The Research Repository @ WVU with permission from the rights-holder(s). You are free to use this Dissertation in any way that is permitted by the copyright and related rights legislation that applies to your use. For other uses you must obtain permission from the rights-holder(s) directly, unless additional rights are indicated by a Creative Commons license in the record and/ or on the work itself. This Dissertation has been accepted for inclusion in WVU Graduate Theses, Dissertations, and Problem Reports collection by an authorized administrator of The Research Repository @ WVU.

For more information, please contact researchrepository@mail.wvu.edu. 


\title{
Appalachian Bariatric Surgery Population Descriptive Analysis, Surgical Outcomes, and Food Accessibility
}

\section{Makenzie Leanne Barr}

\author{
Dissertation submitted \\ To the Davis College of Agriculture, Natural Resources, and Design \\ at West Virginia University
}

In Partial Fulfillment of the requirements for the degree of Doctor of Philosophy in Animal and Food Science

\author{
Melissa D Olfert, DrPH, RDN, Chair \\ Ida Holásková, PhD \\ Lawrence Tabone, MD \\ Stephanie Cox, PhD \\ Jennifer Walsh, PhD, RDN
}

Department of Human Nutrition and Foods

Morgantown, West Virginia

2018

Keywords: Obesity, Bariatric Surgery, Appalachia, West Virginia, Food Access

(C) Copyright 2018 Makenzie Leanne Barr 


\title{
Abstract \\ Describing an Appalachian bariatric patient population through surgical outcomes and food access
}

\author{
Makenzie L. Barr
}

Introduction. Overweight and obesity, diabetes, mental health issues, and lack of access to healthcare resources are frequent burdens among the Appalachian region of the United States. With morbid obesity, conventional behavioral interventions tend to fail. Bariatric surgery has been deemed the most successful treatment for morbid obesity and is performed regularly worldwide, however, the Appalachian population with the highest proportions of obesity and related co-morbidities has been poorly studied.

Aims. This dissertation aims to (1) provide a systematic review of the literature surrounding obesity and food access among Appalachian residents, (2) address the void in research of characterizing Appalachian bariatric surgery patients through descriptive statistics of demographic, co-morbidities, psychological scores, nutritional habits, baseline physical measures, and surgical outcomes, and (3) determine Food Access Ranking Scores of an Appalachian bariatric surgery population through Geographical Information Systems (GIS) locating patient addresses and its relationship to descriptive variables.

Methods. A retrospective chart review was performed on bariatric surgery patients who had been enrolled in a bariatric surgery program and completed gastric bypass or sleeve gastrectomy surgery between March 2013 and April 2017. Twenty-four research assistants were trained to retrieve data from over 540 bariatric patients Electronic Medical Record. Data collected from initial visit clinic questionnaires included demographics, socioeconomic status, past and current health status, family history, baseline dietary behaviors and anthropometrics. Repeated anthropometric data was recorded from patients attending one-year follow-up visits. Additional mapping of patient geographical location was conducted to identify rural locality of the population.

Results. In a systematic review, minimal research was found regarding obesity and food access within the Appalachian region were found. Within the limited findings, although conflicting, most work suggests increasing obesity is correlated with low food access. Our bariatric population was largely defined in the categories of low and moderate-low food access. Access food scores were significantly related to depression and ethnicity. Specifically, bariatric patients with lower food access scores were diagnosed with depression and were mostly non-Caucasian. Lower values of excess weight loss at one-year followup were found in patients receiving sleeve surgery type, diagnosed with diabetes, depression, or having a higher Hemoglobin A1c percentage at baseline compared to those receiving bypass surgery and without co-morbidities.

Conclusion. Minimal research has been explored among bariatric surgery patients who live in an area with the largest rates of obesity, co-morbidities and rural locality. This work aimed to fill the void in describing the Appalachian bariatric surgery patient population along with their lifestyle behaviors and health history prior to surgery and how it correlates to their food access and impact surgical outcomes. Findings suggest weight loss surgery in residents of the Appalachian region is successful but, lessen in the conjunction with co-morbidities. Consideration and additional education and support should be given to those diagnosed with diabetes or depression. This research intends to inform future interventions in an Appalachian bariatric population. 


\section{Table of Contents}

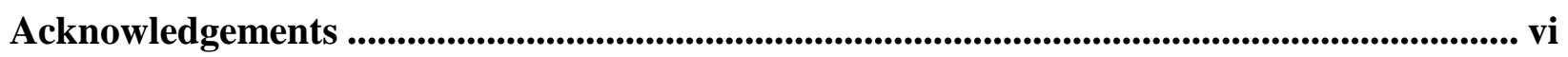

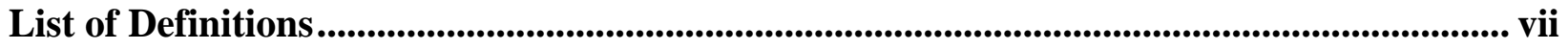

List of Figures.................................................................................................................................. ix

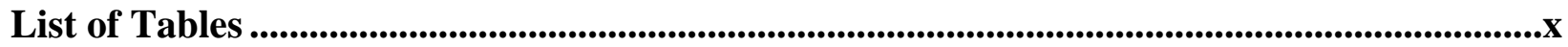

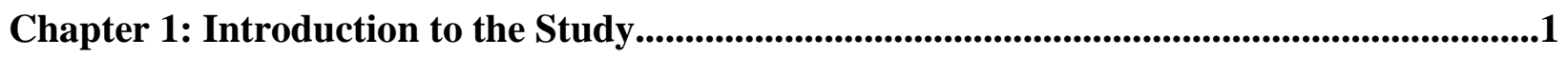

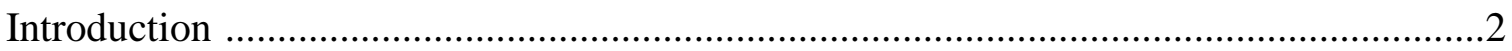

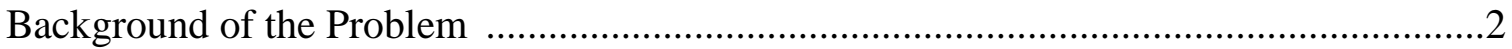

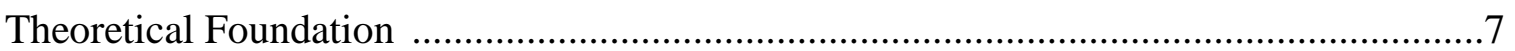

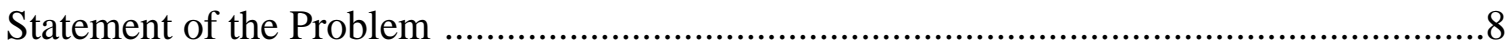

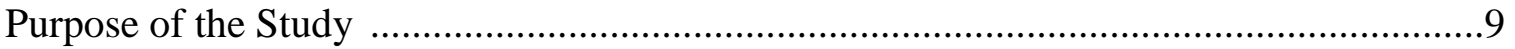

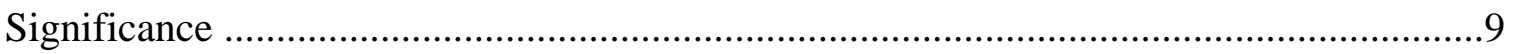

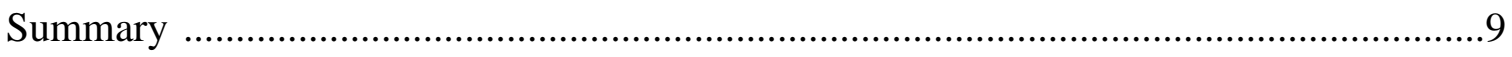

Chapter 2: Additional Background Literature .................................................................................11

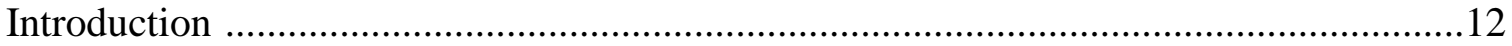

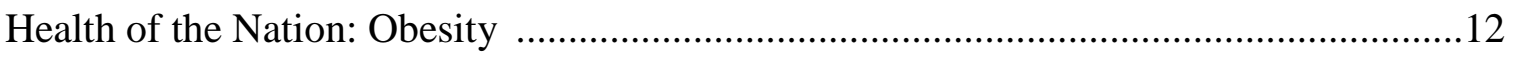

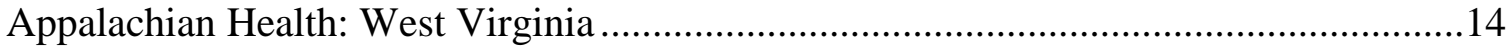

Obesity related Co-Morbidities: Nationwide, Appalachia, and West Virginia .................15

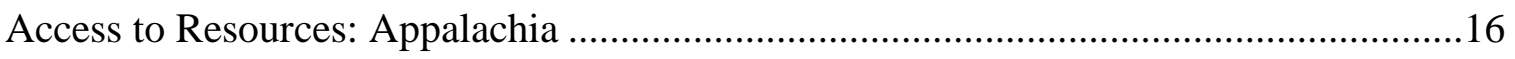

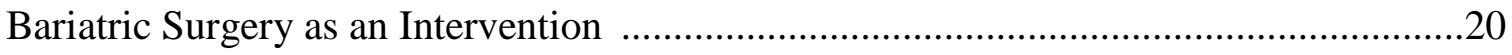

Chapter 3: Study Design and Statistical Analyses .............................................................................24

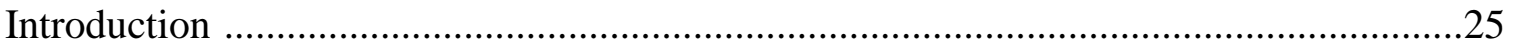

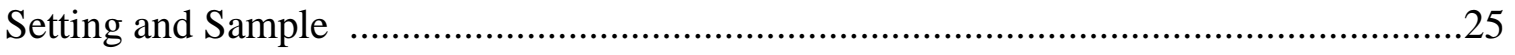

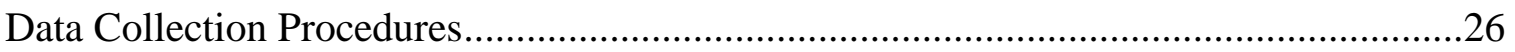

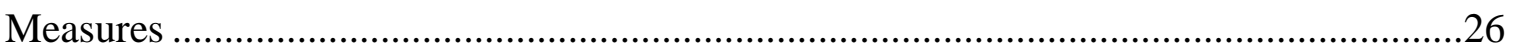

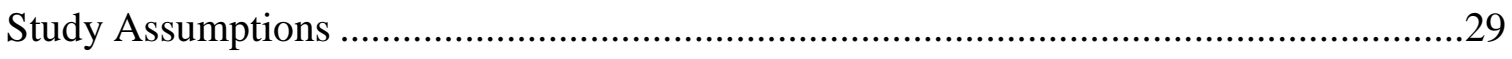

Dissertation Aims and Objectives/Hypotheses .......................................................29

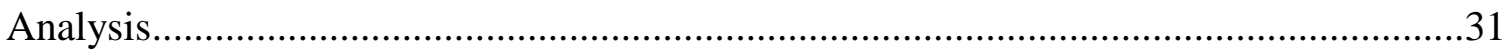

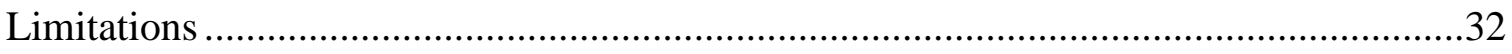

Chapter 4: Food Access and Obesity in the Appalachian Region: A Systematic Review ....34 


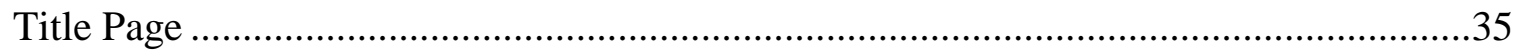

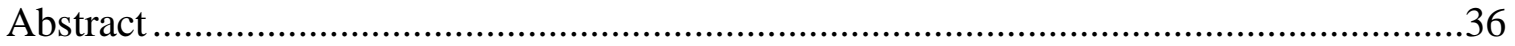

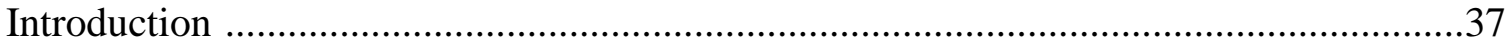

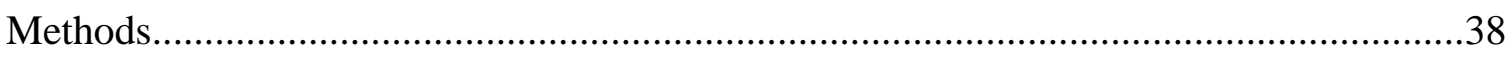

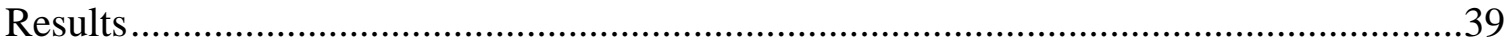

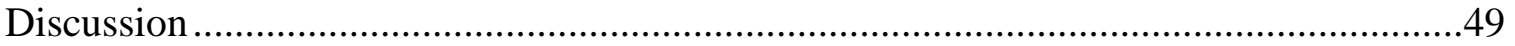

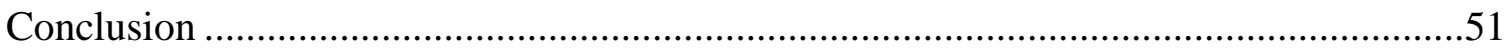

\section{Chapter 5: Descriptive Analysis and One-Year Bariatric Surgery Outcomes of an}

Appalachian Centered Hospital ............................................................................................................53

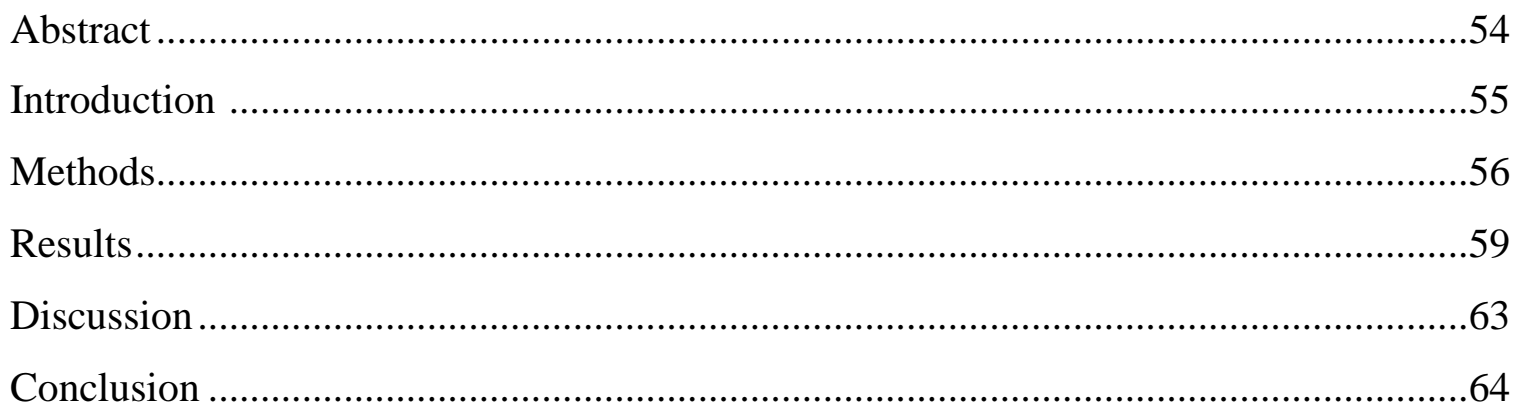

Chapter 6: Food Access Ranking Among a West Virginia Population Completing Bariatric

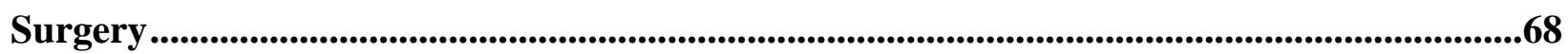

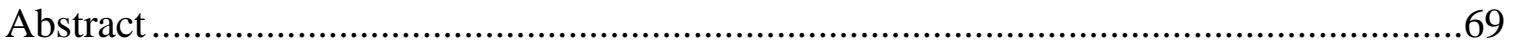

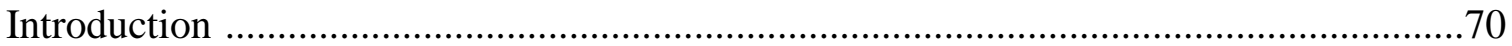

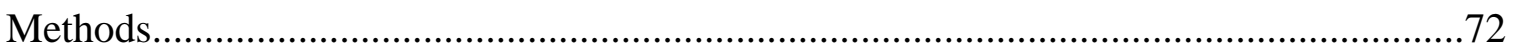

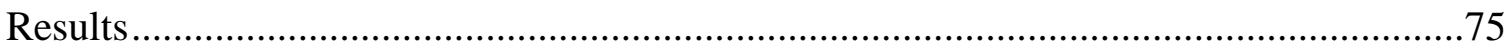

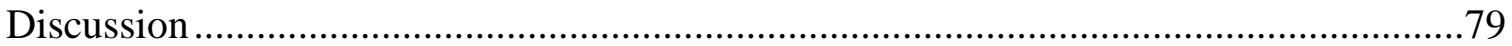

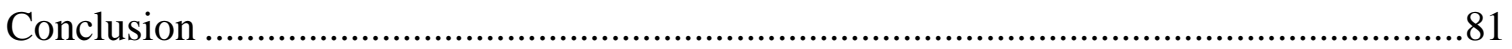

Chapter 7: Conclusions and Future Research ........................................................................83

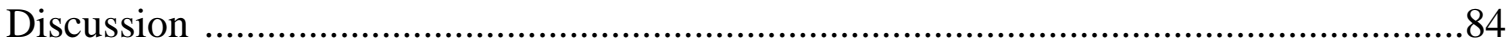

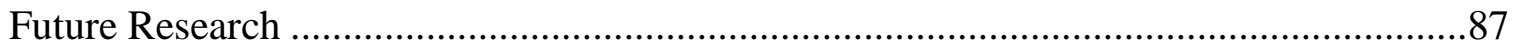

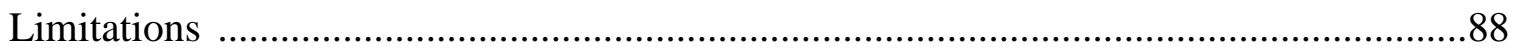

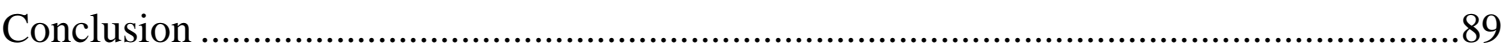

References ......................................................................................................................................................90

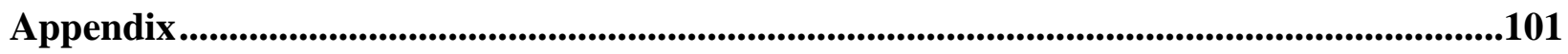

Institutional Review Board Approval ............................................................ 102 


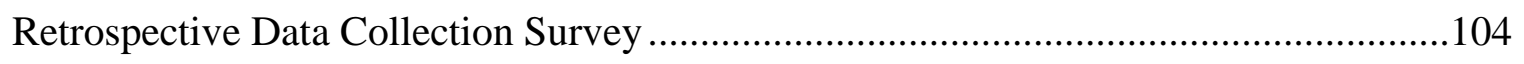

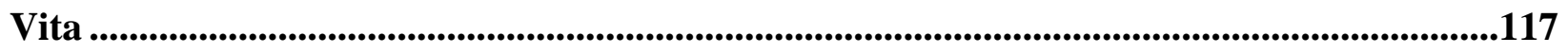




\section{Acknowledgements}

Never in my dreams did I think I would end up here, but having a great mentor who pushes you helps. Dr. Melissa Olfert, thank you for taking me under your wing and into your lab during my undergraduate career. I could never express my gratitude for the opportunities and experiences I have gained from being your student. The skills I have gained from my graduate career have prepared me for life after this degree and I am extremely grateful.

To my committee members. Dr. Ida Holásková, the guidance and training you have given me through all my years in graduate school have made me a better researcher. Thank you for the hours you've allowed me to spend in your office and all of the chocolate. Dr. Lawrence Tabone, this project may never have come to life if you hadn't have allowed me to complete dietetic internship hours in the bariatric clinic. That rotation was, by far, my favorite and the knowledge I've gained from you and your staff is invaluable and I'm very grateful. Dr. Stephanie Cox, thank you for allowing me to come sit in your office and learn your process with patients and the importance of psychological screening in this population. I appreciate your willingness to share your knowledge and always be a smiling face during this journey. Last, but certainly not least, Dr. Jennifer Walsh. Thank you for your willingness to be a part of this committee even from afar. Technology and paperwork were no battle for us and I appreciate your flexibility with me and your support.

To my friends. We all know I'm not great with words or feelings, but there is no possible way in this world to share with each of you how much I've appreciated you all keeping my head on straight and pushing me. Remi, Jade, Becca, Lindsay, I'm so thankful for your friendship and tough love when needed. I promise to return the favor, somehow.

To my family. You are the greatest gift God has ever given me. I know that you've always thought I was just going to go to school for the rest of my life, good thing I've finally proved you wrong. Thank you for standing beside me through all these years and supporting this goal. 


\section{List of Definitions}

Appalachia. An area of the United States relating to the Appalachian Mountains region, its population, or cultural aspects.

Body Mass Index (BMI). Body Mass Index categorized as a standard measure of health that utilized weight in kilograms divided by the height in meters squared. BMI categories include: underweight $<18.5 \mathrm{~kg} / \mathrm{m}^{2} ;$ normal $=18.5-24.9 \mathrm{~kg} / \mathrm{m}^{2} ;$ Overweight $=25.0-29.9 \mathrm{~kg} / \mathrm{m}^{2} ;$ Obese $=$ $30.0-39.9 \mathrm{~kg} / \mathrm{m}^{2}$; Morbid Obesity $\geq 40 \mathrm{~kg} / \mathrm{m}^{2}$.

Bariatric Surgery $(B S)$. Surgical procedures that reduce stomach size, thus reducing caloric intake, in individuals with obesity to aid in weight loss. Criteria for receiving bariatric surgery include a BMI of $\geq 40 \mathrm{~kg} / \mathrm{m}^{2}$ or $\geq 35 \mathrm{~kg} / \mathrm{m}^{2}$ with other obesity-related morbidities.

Laparoscopic Roux-en-Y Gastric Bypass (LRYGB) [1-3]. A restrictive-malabsorptive procedure where a small stomach pouch, approximately one ounce or 30 milliliters in volume, is created by dividing the top of the stomach from the rest of the stomach. Next, the first portion of the small intestine is divided, and the bottom end of the divided small intestine is brought up and connected to the newly created small stomach pouch. The procedure is completed by connecting the top portion of the divided small intestine to the small intestine further down so that the stomach acids and digestive enzymes from the bypassed stomach and first portion of small intestine will eventually mix with the food.

Laparoscopic Sleeve Gastrectomy (LSG) [1-3]. A restrictive procedure performed by removing approximately 80 percent of the stomach. The remaining stomach is a tubular pouch that resembles a banana. The new stomach pouch holds a considerably smaller volume than the normal stomach and helps to significantly reduce the amount of food (and thus calories) that can be consumed.

Percent Excess Weight Loss (\%EWL). Percent excess weight loss determined by excess body weight loss one-year post bariatric surgery. Literature loosely defines "success" of surgery by a $50 \%$ EWL.

Food Access. Residing in an area with limited quality and quantity supermarkets, supercenters, grocery stores, or other sources of healthy and affordable food further exacerbated by lowincome and lack of vehicle access.

United States Department of Agriculture (USDA). The USDA is a government agency that strives to support food, agriculture, natural resources, rural development, nutrition, and related issues based on public policy, the best available science, and effective management.

Census Tracts. As defined by USDA, census tracts are relatively permanent subdivisions of a county typically with between 2,500 and 8,000 people. Spatial size of census tracts varies widely depending on population density. Census tracts do not cross county lines and are designed to be 
homogeneous with respect to population characteristics, economic status, and living conditions. Census tract boundaries are established to be relatively stable to allow for comparison. 


\section{List of Figures}

\section{Chapter 2:}

Figure 1: Trends in United States Overweight, Obesity, and Extreme Obesity among men and women aged 20-74: 1960-1962 through 2013-2014.........................13

Figure 2: United States Appalachian Region and Subregions........................14

Figure 3: 2012 Rate of Obesity, Diabetes, and Bariatric Surgeries per 100,000 population

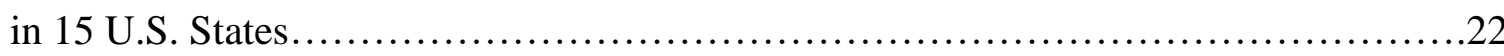

\section{Chapter 4:}

Figure 1: Preferred Reporting Items for Systematic Reviews and Meta-Analyses flow diagram of food access and obesity within the Appalachian region....................41

\section{Chapter 5:}

Figures 1-3: ANOVA Model graphs of surgery (Model 1), diabetes (Model 2), and depression (Model 3) on \%EWL outcome.....................................66

Figures 4 and 5: ANCOVA model building and figures of surgery, HbA1c (Model 4), and depression (Model 5) relationship with \%EWL outcome...

\section{Chapter 6:}

Figure 1: WV FOODLINK map of food access among West Virginia.................74

Figure 2a: High and Low FARS Quartiles by Ethnicity/Race.......................82

Figure 2b: High and Low FARS Quartiles by Family History of Obesity..............82

Figure 2c: High and Low FARS Quartiles by Diagnosed Depression.................82 


\section{List of Tables}

\section{Chapter 4:}

Table 1: Descriptive characteristics of peer-reviewed and gray literature examining food access and obesity in Appalachia

Table 2: Reviewed articles examining food access and obesity among an Appalachian population

\section{Chapter 5:}

Table 1: Descriptive Statistics

Table 2: Spearmen rho correlation table for entry into \%EWL ANOVA and ANCOVA model building

Table 3: ANOVA and ANCOVA Models of surgery (Model 1), diabetes (Model 2), and depression (Model 3) on \%EWL outcome. .66

Table 4: ANCOVA model building and figures of surgery, HbA1c (Model 4), and depression (Model 5) relationship with \%EWL outcome.

\section{Chapter 6:}

Table 1: Food Access Ranking Score Variable Description........................73

Table 2: Descriptive characteristics of West Virginia residing bariatric patients between

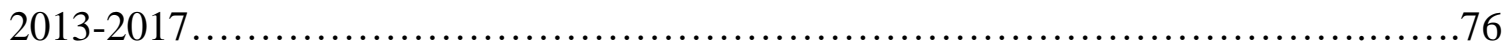

Table 3: Nutrition and lifestyle behaviors between surgery patient groups at baseline...77

Table 4: Categorical FARS by Surgery Type................................ 77

Table 5: Correlation Table of FARS by Variables of Interest......................78

Table 6: Categorical FARS by Quartiles...................................... 78

Table 7: Correlation Table of low vs high FARS ............................... 78 
Chapter I: Introduction to the Study 


\section{Introduction}

“The U.S. can't be healthy as a whole if we are leaving whole regions behind", a quote from Hillary Heishman, senior program officer of the Robert Wood Johnson Foundation in a recent Appalachian Regional Commission press release entitled, Appalachian Region Endures Dramatic Health Challenges Compared with the Nation, New Research Shows [4]. Health among the Appalachian region (New York, Pennsylvania, Ohio, West Virginia, Kentucky, North Carolina, South Carolina, Maryland, Virginia, Tennessee, Georgia, Alabama, and Mississippi) has trailed behind the health of the nation as a whole. This underrepresented, and health disparate population not only lacks resources and access to a vast array of healthcare, but specific areas of research supporting the understanding of this population is lagging as well. The foci of this dissertation will delve into the bariatric surgery patient population in centralized Appalachia. This document aims to provide background and insight into the literature surrounding obesity, Appalachia, and food access to describe this population and their metabolic outcomes of surgery as it relates to healthy dietary patterns. Across the following chapters, a summation of the literature behind Appalachia, bariatric surgery, and food access will be explained.

\section{Background of the Problem}

Overweight is classified as having a body mass index (BMI) between 25.0 and 30.0 $\mathrm{kg} / \mathrm{m}^{2}$ and obese classification is having a BMI of $30 \mathrm{~kg} / \mathrm{m}^{2}$ or higher [5]. Specifically, within the obesity classification, there are three subgroups: Class I Obesity is a BMI of $30-35 \mathrm{~kg} / \mathrm{m}^{2}$, Class II Obesity is a BMI of $35-40 \mathrm{k} / \mathrm{m}^{2}$, and Class III Obesity is a BMI of $40 \mathrm{~kg} / \mathrm{m}^{2}$ or higher [5]. Within the United States, more than one third of adults are considered obese [6]. Class 3 obesity, or morbid obesity, is found to be present among $7.7 \%$ of the U.S. population [6]. When examining the health of the nation, the Appalachian region is often scrutinized for various health 
conditions including leading the nation in diabetes and cardiovascular disease as well as claiming the highest rates of overweight and obesity. Contained by the Appalachian area, West Virginia is the only state that is entirely encompassed in the region. Per the State of Obesity, $35.6 \%$ of West Virginia adults were considered obese in 2015, increasing to $37.7 \%$ of adults in 2016 placing the state first in the nation for percentage of adults with obesity [7, 8]. Common obesity related comorbidities are not surprisingly, also elevated among this population. West Virginia adults specifically placed highest among rates of diabetes (15\%), depression (23.8\%) and hypertension $(42.7 \%)[7,9]$. Due to these multi-morbidities that accompany each other, along with the hefty economic burden that obesity causes [10-12], nationwide calls for research and interventions in the realm of obesity have had a long standing in the literature among all ages and regions. However, in the upper classes of obesity, dietary and physical activity interventions tend to fail at disarming the burden excess weight brings.

The current, most effective solution for alleviating extreme weight and consequent health issues is through metabolic surgeries [13]. Between 2011 and 2016 bariatric surgery procedures in the United States have risen from 158,000 to 216,000 annually $[3,14-16]$. Surgical options have become less invasive over the years to typically being performed laparoscopically. The most common types of surgeries in the United States include laparoscopic roux-en-y gastric bypass (LRYGB), laparoscopic sleeve gastrectomy (LSG), laparoscopic adjustable banding (LAB), and biliopancreatic diversion with duodenal switch (BPD-DS). Surgical procedures are typically determined through careful consideration of health history and specific patient need by the surgical team and patient. To achieve significant, and expectantly, long-term weight loss these surgical interventions are comprised of procedures that cause malabsorption and/or restriction of food intake [2]. Most insurance companies, for coverage of bariatric surgeries, 
require candidates to have a BMI of $\geq 35 \mathrm{~kg} / \mathrm{m}^{2}$ with at least one or more co-morbidities (type II diabetes, hypertension, sleep apnea or other respiratory disorders, non-alcoholic fatty liver disease, osteoarthritis, lipid abnormalities, gastrointestinal disorders, or heart disease) or a BMI of $\geq 40 \mathrm{~kg} / \mathrm{m}^{2}$ or 100 pounds overweight without co-morbidities [3]. However, not only do comorbidities impact a patients' eligibility for surgery, these conditions can impact surgical outcomes post-operatively. Because behavioral health, including nutritional and mental health, is vital to optimal outcomes after bariatric surgery, the research included in this dissertation is of value. Conditions that often accompanies extreme weight are mental health issues [17]. Patients with morbid obesity tend to have lower self-esteem and body dissatisfaction from carrying extra weight. A model proposed by Marks et al. depicts the reciprocal relationships among weight/obesity, body dissatisfaction, energy-dense consumption and their negative affect that becomes a cyclic process and downwards spiral of health [18, 19]. Specifically, having a BMI over 40 increases chances of having depression. When examining the relationship among depressive disorders and obesity, some large cohort studies have identified over $40 \%$ of patients who undergo a bariatric program have a depressive disorder [20, 21]. Consideration of these multi-factorial conditions play a role in individualized treatment both pre-operatively and postoperatively. To provide a holistic approach encompassing all health conditions, it is important to involve a multi-disciplinary team of professionals in each bariatric patient's program. As recommended by the American Society of Metabolic and Bariatric Surgery (ASMBS), nursing, surgery, nutrition, and psychology, all play an important role in each patient's trajectory and clearance for surgery in a typical bariatric program. For a health disparate population that has large percentages of unhealthy dietary patterns and related co-morbidities such as mental health conditions and type II diabetes, a multi-disciplinary team can be vital to success in a central 
Appalachia and West Virginia population. Nonetheless, it is unknown how this population responds to surgery and how their personal health and habits at baseline are playing a role in their surgical weight loss.

In conjunction with the Appalachian region leading in chronic diseases, residents also tend to have lower income, limited resources and poorer educational attainment [22] that only exacerbate the impact obesity and its co-morbidities produce [23-25]. When specifically examining the Appalachian region, rural areas, or West Virginia as centralized Appalachia, bariatric surgery is minimally utilized compared to the quantity of individuals who are eligible. Consideration of health history, insurance availability, support from family, or even health literacy can effect utilization of bariatric surgery as a tool for weight loss. In a 2017 study examining rural bariatric patients, Bergmann et al. finds that rural status was a significant predictor of surgery completion with rural patients being less likely to undergo surgery than their urban counterparts, though when placed in a model controlling for insurance type, rural status was no longer a significant predictor [26]. However, rural dwellers were more likely to be unemployed or disabled, have co-morbidities, and have West Virginia Medicaid. Furthermore, those completing the surgery program were more educated and employed full time. When predicting outcomes in relation to rural status, authors found that rural status did not significantly predict BMI at 6 months follow up or with follow up attendance [27]. In the understanding of the literature, this is the first study analyzing a rural Appalachian population, however, contains only minimal focus on the surgical outcomes. This initial study provides minimal baseline analysis to place grounds for approaching further research examining this population and designing future prospective interventions. 
In order to better equip Appalachian patients with the best care during their pre and postoperative bariatric program, investigation of an Appalachian centered surgical program is warranted. Likewise, the examination of the environment is important when changing or intervening on health of a population. An aspect of the environment that this document will focus on will be food access of the residents within West Virginia. Access to affordable, nutritious food is a difficult feat for many residents in this area due to their rurality, limited income, or even vehicle access. Access to healthy foods is vital for changing dietary behavior, specifically, in a post-operative bariatric patient who should be following a specific dietary regimen.

Currently, there is a large void in the research identifying bariatric surgery outcome status of Appalachian and rural bariatric patients. Likewise, literature is lagging among food access and bariatric surgery and further, bariatric surgery and obesity within the Appalachian region. Of the population of patients who receive weight loss surgery in West Virginia, there may prove to be aspects of rural locality that hinder their process toward a healthier lifestyle as well as their clinical and weight outcomes post-surgery.

Of the previously mentioned disparities among the Appalachian region, specific issues to be focused on throughout this dissertation are the areas lack of resources and influence of comorbidities that are among the highest. Due to the large rurality and low income of the area, the population faces a lack of health care resources, and even adequate, affordable, nutritious foods that would aid in a healthier lifestyle pattern. Research surrounding food access and obesity identify significant correlations within United States populations. Within the Appalachian region, research is lacking. This dissertation aims to provide insight and add to the limited existing literature in into this research void among the Appalachian population and begin formative investigation in the area. 


\section{Theoretical Foundation}

Although a prospective study is not included in the current dissertation, the research proposed will be grounded in the foundation of the Social Cognitive Theory and the Social Ecological Model [28-31]. The Social Cognitive Theory (SCT), previously the Social Learning Theory, employs the idea that human behavior, cognition, and other personal factors have a reciprocal relationship with the environment around them, which allows them to continuously influence each other [28-31]. Further, it identifies that behavior is also influenced by reinforcement and observing others, such as family members influencing health and dietary behaviors. Specifically, the SCT is made up of 9 concepts based on the reciprocity of individual, behavior, and environment: reciprocal determinism, outcome expectancies, self-efficacy, collective efficacy, observational learning, incentive motivation, facilitation, self-regulation, and moral disengagement [30, 31]. Overall, the SCT is based upon idea that individuals can shape their environment to suit the purpose they frame for themselves [30, 31]. This idea specifically, "reciprocal determinism", explains human action, motivation, and emotion by the person, their behavior, and their environment all working equally on each other [31]. In this intervention, individuals have already invested in receiving bariatric surgery and, the belief is that they will also be invested in changing their current routine to fit the new lifestyle required after surgery. Specific research in the field of behavior change in obesity or dietary change has employed the SCT constructs of goal setting, self-efficacy, and social support. These constructs, as well as observational learning, incentive motivation, and facilitation, will be in the forefront of thought during this retrospective study to aid in forming a thoughtful, future intervention.

The Social Ecological Model (SEM) will also be kept in mind to understand the impact the environment plays on an individual and their health outcomes. Specifically, when utilizing 
SEM in this retrospective study, our focus will be on the environment of the patients through food access. The SEM describes how each system impacts a certain aspect, such as obesity or surgical outcomes [30, 32]. Nested systems in place in the SEM include (1) Individual, (2) Interpersonal, (3) Institutions/Organizations, (4) Community, and (5) Structure, Policies, and Systems [30, 32]. This model will provide the framework to look beyond individual level factors influencing health by acknowledging the interactions of the environment, relationships, and economic factors that play a role in individuals' lifestyle and health decision making. Food environments play a significant role in the decisions individuals make pertaining to their diet [33, 34]. Populations living in an area with poor access to food can lead to inadequate dietary choices or further exacerbate other co-morbid conditions. We aim to examine the food environment of patients to inform if future prospective studies considering food access knowledge and resources are warranted.

\section{Statement of the Problem}

Despite the deteriorated health status in much of the Appalachian region of the United States, examining the impact of a successful weight loss treatment such as bariatric surgery outcomes have yet to be fully explored. Although different patients see diverse results after metabolic surgery there is limited understanding overall outcomes among an Appalachian population. As Appalachian individuals are exposed to a variety of factors influencing their health, such as access to healthcare, greater frequency of co-morbidities, and inadequate food access, understanding the effectiveness of surgery and variables impacting these outcomes in this region is important. This dissertation aims to provide insight and formative examination into Appalachian health, surgical outcomes, and environmental factors to inform and begin the understanding of this population in the literature. 


\section{Purpose of the Study}

The objectives of the current dissertation are to (1) provide a systematic review of the literature surrounding obesity and food access among Appalachian residents, (2) address the void in research of characterizing Appalachian bariatric surgery patients through descriptive statistics of demographic, co-morbidities, psychological scores, nutritional habits, baseline physical measures, and surgical outcomes, and (3) determine Food Access Ranking Scores of an Appalachian bariatric surgery population through a novel Geographical Information Systems (GIS) approach to assessing food access in the region by locating patient addresses. The overarching goal will be to describe this overlooked population and inform future research on factors to consider when planning prospective interventions.

\section{Significance}

Understanding regions of the United States that are lagging in health is essential to improving health nationwide. The Appalachian region is one of these health disparate regions. An array of literature has examined obesity, rural or Appalachian regions, and food access singularly or in minimal combinations. However, examining all of these important topics together in bariatric surgery patients is a novel and unique approach. This dissertation delves into uncharted territory combining these topics to shed light on the impact Appalachian living makes on individuals who seek and complete bariatric surgery. We hope to fill a gap in knowledge regarding this population and the considerations needing to be taken to further aid in developing future interventions for this underrepresented population during their bariatric program.

\section{Summary}

Obesity among the nation is not only a public health concern but has stemmed into an economic concern as well. Furthermore, when in higher classes of obesity, these resulting factors 
are intensified. Among a health disparate and underserved Appalachian region of the United States, obesity exacerbates its related co-morbidities due to inadequate income, education, and access to healthy foods when compared to the nation. The treatment intervention was selected naturally occurred for this dissertation is bariatric surgery. Within this document Chapter 2 delivers a literature review that will provide a thorough background to support the subsequent studies. The research design and statistical analyses is described in Chapter 3 to provide insight to the processes involved in the approval and data collection of this project. These chapters are followed by three manuscripts that aim to respond to the lack of research in the areas of Appalachian bariatric surgery patients, their surgical outcomes, and food environments. Chapters 4-6 include: A Systematic Review of Food Access and Obesity in the Appalachian Region (Ch. 4), Population and Surgical Outcome Description of an Appalachian Bariatric Patient Population (Ch. 5), and A Novel approach to classifying Food Access among West Virginia Bariatric Surgery Patients (Ch. 6). These manuscripts taken together provide formative research to shed light on underrepresented Appalachia, bariatric surgery patients. Through the vast amount of research separately capturing bariatric surgery outcomes, the Appalachian region and food access, this dissertation aims to merge the three in a methodical arena. This document is concluded by a discussion and suggestions for future research. 


\section{Chapter II: Additional Background Literature Review}




\section{Introduction}

The current chapter provides background for the studies through a literature review based not only on bariatric surgery among the nation and Appalachian region specifically, but also the health of this disparate area and the barriers to healthy living that may be present. Further literature review is provided in each manuscript background and introduction (Chapters 4-6). These reviews together provide comprehensive understanding of the literature, identify the gaps, and bring about awareness as to support the significance of this effort.

Literature provided in this review was obtained through various databases provided through West Virginia University Libraries. No year restrictions were placed on literature review however, obesity, diabetes and mental health prevalence statistics were restricted to the most recent years for comparison. Databases utilized included PubMed, Google Scholar, CINAHL, ScienceDirect, and WorldCat.org. Search terms included: Appalachia, rural, obesity, diabetes, bariatric surgery, bariatric, psychology, mental health, food access, food systems, behavioral health, perioperative care, and surgery outcomes.

\section{Health of the Nation: Obesity}

Health, United States, 2016: At a Glance provides an overlay of the morbidity and risk factors at present day in the nation [35]. Heart disease leads the 2015 mortality list with 168.5 deaths per 100,000 age-adjusted population, followed by cancer (158.5), chronic lower

respiratory disease (41.6), unintentional injuries (43.2), stroke (37.6), Alzheimer's disease (29.4), diabetes (21.3), influenza and pneumonia (15.2), nephritis, nephrotic syndrome, and nephrosis (13.4), and suicide (13.3) [35].

Modifiable risk factors targeting these diseases consist of high blood cholesterol, poor dietary habits, physical inactivity, smoking, non-familial hypertension, and obesity [36-38]. 


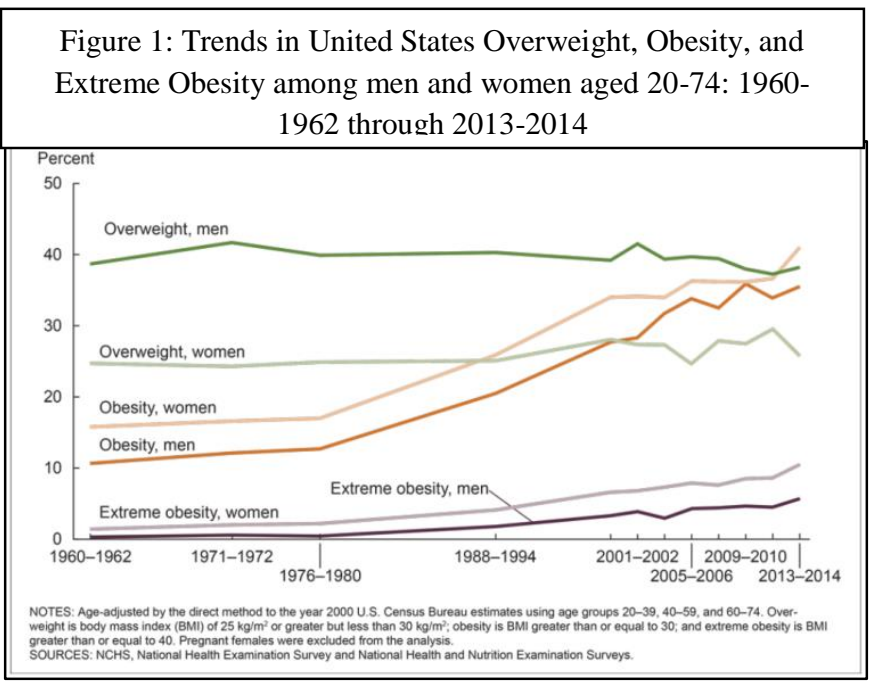

Obesity, as a major factor in associated comorbidities has been a major public health concern for years [39]. Overweight is classified as having a body mass index (BMI) between 25.0 and $30.0 \mathrm{~kg} / \mathrm{m}^{2}$ and obese classification is having a BMI of 30 $\mathrm{kg} / \mathrm{m}^{2}$ or higher [5]. Within the obesity classification, there are three subgroups:

Class I Obesity is a BMI of $30-35 \mathrm{~kg} / \mathrm{m}^{2}$, Class II Obesity is a BMI of $35-40 \mathrm{~kg} / \mathrm{m}^{2}$, and Class III BMI of $\geq 40 \mathrm{~kg} / \mathrm{m}^{2}$. Centers for Disease Control and Prevention (CDC) state that within the United States more than one-third, or 36.5\%, of adults are classified as obese [6, 40]. Further, rates of 'extreme' or 'severe obesity' (Class III) are found among 6.4 percent of the adult population in 2011-2012, and increased to $7.7 \%$ among 2017 State of Obesity data [41, 42]. In Figure 1, National Health and Nutrition Examination Survey rates of extreme obesity in women and men have been increasing specifically around 1980 [43, 44]. The steep obesity trajectory has softened over the last few years, however, it still poses a threat to the nation and the risk of acquiring additional co-morbidities. Individuals more likely to be overweight or obese include women, racial or ethnic minorities, and persons of lower income or educational attainment [6]. The Department of Defense estimates that $\$ 1.5$ billion annually is spent on obesity-related health care costs with billions also being lost in work productivity [45]. Furthermore, $\$ 1,429 /$ year are spent in additional costs for individuals who are obese compared to their normal weight counterparts [45]. This leads to a demand in further funding of epidemiological studies to combat obesity. When targeting high risk areas, regions of the United States that are low income or rural 
are found to have higher rates of health disparities. Due to their lack of resources, vehicles, and environmental structure, health among residents tends to be inferior compared to other regions [23]. These areas are densely found among the Appalachian region of the United States [23].

\section{Appalachian Health: West Virginia}

The Appalachia region (Figure 2)

ranges across portions of thirteen states, encompassing 420 counties, and 205,000 square miles from southern New York down to northeastern Mississippi [46].

Within this cluster of counties, there is total encompassment of only one entire state, West Virginia. The regions wellknown history has strong family ties, coal mining, agriculture, and a large rural population [23, 47]. Compared the national average of $20 \%$ of the

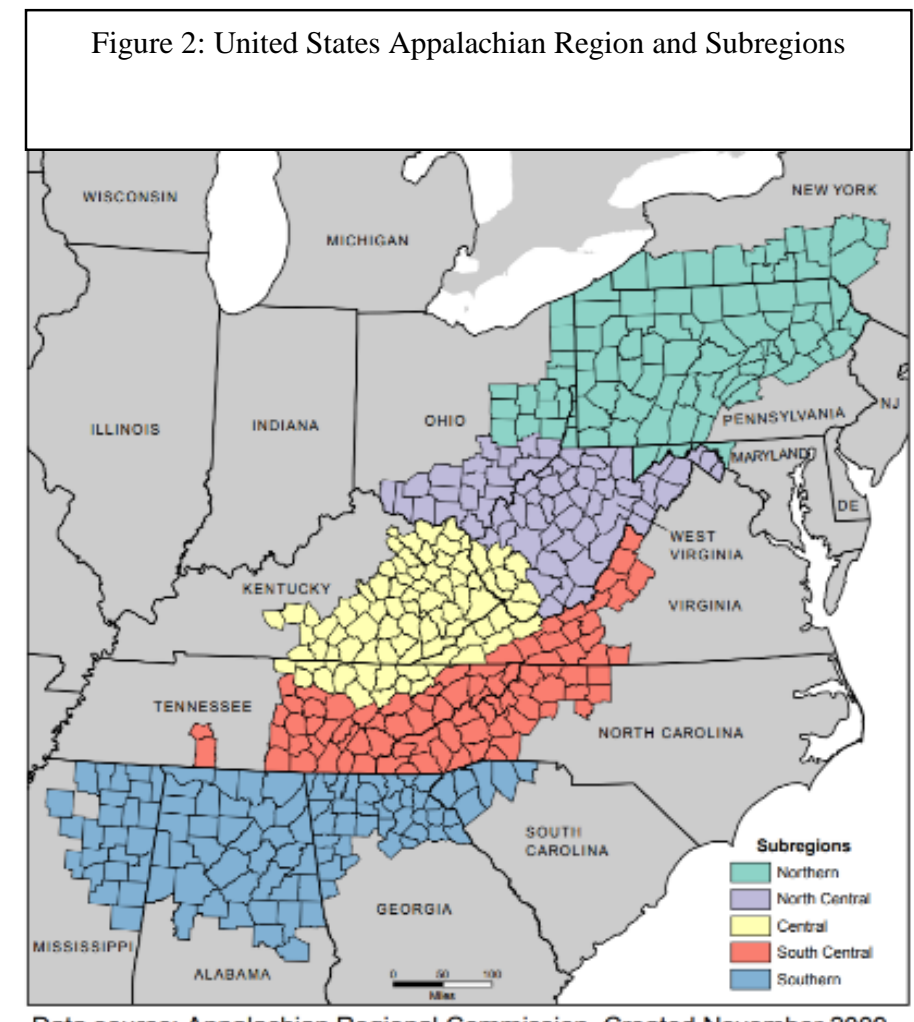

Data source: Appalachian Regional Commission, Created November 2009 population being classified as rural, $42 \%$ in the Appalachian region are considered rural [46]. This rural region, unfortunately, is also known for its vast amount of health and economic disparities. The formation of the Appalachian Regional Commission has aided in improving economic opportunities, workforce readiness, critical infrastructure, natural and cultural assets, and leadership and community capacity among the region [48]. Although the region has made strides over the past five years, challenges still remain. Educational attainment [22], poverty [22, 23], access to healthful foods and quality healthcare [22], as well as lower health literacy [49] are 
exponentially greater than that of the United States. Of the region, the most health disparate areas are found within central and north central Appalachia, which specifically includes the entire state of West Virginia [22]. 2017 reports show all-cause mortality rates in the Appalachian U.S. are increasing at a greater rate than those non-Appalachian regions (1999 to 2014) [50] with West Virginia and Kentucky leading those mortality rates for Appalachia [50].

Likewise, it is recognized that the Appalachian region leads the United States in a variety of modifiable health risk factors, which could be alleviated by a healthful diet and physical activity [51-55]. The region in general leads with higher amounts of physically and mentally unhealthy days than that of the nation as a whole, and those in rural areas are among the highest [56]. Health concerns more prevalent in the area compared to the nation include higher risk of mortality from heart disease, cancer, COPD, injury, stroke, diabetes, drug overdose, and others [4, 56-58]. Particularly, West Virginia has been at the forefront of those lists for over the last decade for conditions including obesity, hypertension, depression and diabetes [7, 9].

According to 'The State of Obesity: Better Policies for a Healthier America', West Virginia's adult obesity rate has increased to $37.7 \%$ as of 2016 , making the state number one in obesity rates [8]. This rate is compared to $35.7 \%$ obesity in $2015,32.3 \%$ in 2010 , and $23.9 \%$ in 2000 [42]. Among West Virginia rates of Class II obesity, 2013 data place $17.6 \%$ of adults in this classification [59] while 2008 data place $4.9 \%$ of adults in Class III obesity [9]. With this outdated data and the pronounced increase in obesity within the last decade, updated obesity data within the state specifically is merited.

\section{Obesity Related Co-morbidities: Nationwide, Appalachia, and West Virginia}

Obesity is taxing on the body and can extend to many other aspects of an individual's life including, general quality of life, health, self-esteem, and even the addition of other co- 
morbidities [60]. Individuals with obesity are at an elevated risk for developing insulin resistance and type 2 diabetes, sleep apnea, cardiovascular disease, hypertension, certain cancers, and many other conditions [60]. These co-morbidities are of higher proportions in the Appalachian region, with its total state of West Virginia leading the statistics. Other co-morbidities positioning West Virginia as the top state in the nation include $15 \%$ of adults with diabetes compared to the nation's $12.7 \%$ (2013-2014 data), and 42.7\% adults with hypertension compared to the nation's $33.5 \%$ (2016 data) $[4,9,56]$. Along with related co-morbidities such as diabetes and hypertension, those with excess weight can be found to have additional related psychological complications [61-63]. West Virginia Behavioral Risk Factor Surveillance Survey (BRFSS) examines depression rates within the state. A 2016 report places the state second for percentage of adults diagnosed with depression (23.8\%) [9]. Clinically diagnosed depression has found to be related to increasing obesity [64-66] and is another avenue demanding consideration when treating obesity.

Reviewing the long standing relationship of obesity to these common co-morbidities, it is unsurprising that these conditions are higher among West Virginia residents as well. These disparities found in the Appalachian region, specifically West Virginia, can be factors in the further exacerbating decline of health in the region. When explaining reasoning behind the unhealthfulness of the area, consideration of multi-factorial diseases and rural locality of the state can be influential [67].

\section{Access to Resources: Appalachia}

Among the population who reside in the Appalachian region, location has impacted its health, economy, and resources. Poverty has declined since 1960 (295 counties above 1.5 times the U.S. poverty rate) to currently 87 counties in high poverty regions (although remaining 1.5 
times the U.S. poverty rate) [56]. It is estimated that 700,261 people living in rural areas in West Virginia [68], have a poverty rate of $17.9 \%$ [69], annual per-capita income of $\$ 24,002$ [69], and 17.6\% have not completed high school. A similar 2017 Appalachian Regional Commission report comparing the region to the nation averages places the Appalachian region 19\% lower median household income, nearly $2 \%$ higher poverty rate, over $6 \%$ less post-secondary education, and nearly $2 \%$ more receiving disability benefits [56].

Coincidentally, while health among Appalachian populations is markedly poorer than that of the nation, health care resources are also scarce. According to Health, United States, 2016: At a Glance, adults in the South (including West Virginia), had the greatest difficulty accessing medical care due to cost in 2015 [35]. A mixed methods study by Gutschall et al. found the number one barrier to good health expressed by Appalachian residents was access and resources [70]. A similar examination of Appalachian individuals with multi-morbidities found that these participants were concerned that they were concerned with their ability to meet dietary and medication requirements for their conditions [71]. Participants were further concerned on missing work days or be fired due to their health, expressing that this can eventually leads to loss of benefits, income, or even onset of depression [71]. Furthermore, this subsequent increase in cost associated with medications or travel to clinics tend to deter individuals from receiving proper care or primary prevention measures to ensure adequate health [25, 57]. In addition to these concerns, the Appalachian Regional Commission reports the region preforms lower than the nation in number of available primary care physicians, mental health professionals, specialty physicians, and dentists overall $[4,46,57,68]$.

Equally, access to affordable, nutritious food is a difficult feat for many residents. Food insecurity, defined as inadequate access at all times to sufficient amounts of food for a 
sustainable, active life, is a contributing factor to health disparities in the region [72]. Food insecurity rates in American adults were over 14\% in 1995-2012 data and has been labeled as a public health concern (Pheley, et al. 2002). USDA data on food insecurity in West Virginia found $14.9 \%$ of households to be food insecure and $6.2 \%$ very food insecure [46]. The Appalachian Regional Commission report on health disparities and resources in Appalachia identified the region has $14 \%$ fewer grocery stores per 100,000 population than the nations average [56]. The burden of limited income to purchase necessities can be alleviated by programs such as Women, Infants and Children (WIC) or Supplemental Nutrition Assistance Program (SNAP). In West Virginia, WIC clinics serve approximately 42,000 people each month, or $80 \%$ of eligible individuals including 3 of 5 infants born in the state [73]. Likewise, SNAP provides food benefits to over 367,000 West Virginians monthly [73]. In a 2016 study by Andress and Fitch, low income WIC participants took part in focus groups to identify feelings regarding food access in their communities of rural West Virginia [74]. Themes that emerged from focus groups included concerns regarding (1) structural environment including distance to retailers and transportation, (2) personal and household determinants of food including purchasing healthy options that are available and affordable, and (3) social and cultural aspects of the environment including stores meeting needs and products that were unacceptable [74].

While food security takes into account the ability to acquire enough food predominately, by terms on monetary value, the environment surrounding these individuals in access to food is of another question. The USDA defines a food desert as "areas of the country void of fresh fruit, vegetables, and other healthful whole foods" $[75,76]$. This definition specifically uses lack of grocery stores, farmers' markets, and healthy food providers as evidence of these food deserts $[75,76]$. These data are combined with US Census data to define areas of food deserts in the 
United States. Criteria for these measured areas of food deserts include low income areas (median household income $<80 \%$ of state median income or poverty rate of $\geq 20 \%$ ) and low access areas (proximity to a grocery store such as 1 mile in urban areas and 10 miles in rural areas) [75-79]. The USDA defines a grocery store with the minimal criteria as one that sells a wide variety of products [75-79]. Additionally, low access communities are areas also defined by at least 500 persons or $33 \%$ of a census tract's population live more than one mile from a supermarket (10 miles if nonmetropolitan tract) [75-79]. All of these criteria are used to create binary sets for each census tract to determine if an area is deemed a food desert or non-food desert. Among West Virginia residents, it is estimated that $42 \%$ of census block groups have low or very low access to a grocery store that carries sufficient amounts of fresh or healthy foods [80].

In 2017, Andress and Hallie used a community-based participatory research approach to photovoice narratives with elderly rural dwellers in West Virginia [81]. Although Appalachia is noted to have $14 \%$ fewer grocery stores per 1,000 population than the national average [56], residents indicate that they have grown accustom to the distance required to obtain food. Yet, when traveling to food stores, options available usually fall short to buyers standards [81].

When investigating both obesity and food access among Appalachian areas, there is a miniscule body of research. Previous literature among other rural regions of the United States have seen correlations of poorer health with lack of quality, affordable, nutritious foods [72, 82]. In conclusion of the limited studies in Appalachia surrounding obesity and food access, the majority of studies found higher rates of obesity with limited food access in the region [83-87]. Most data reviewed were cross-sectional studies or observational data with only correlational 
analyses. This limited data does not allow for a meta-analysis but supports future research endeavors in examining obesity and food access relationship in Appalachia.

\section{Bariatric Surgery as an Intervention}

To date, the most effective treatment for decreasing morbid obesity efficiently and longterm, is bariatric surgery [13, 88, 89]. Between 2011 and 2015 bariatric surgery procedures in the United States have risen from 158,000 to 196,000 [16]. With up to 196,000 bariatric surgeries performed annually, typical surgical procedures include laparoscopic Roux-en-Y gastric bypass (LRYGB), laparoscopic sleeve gastrectomy (LSG), biliopancreatic diversion with duodenal switch, and adjustable gastric bands [2]. These surgeries are comprised of procedures that aid in malabsorption and/or restriction of food intake to achieve weight loss [3, 90]. Most physicians providing surgery or insurance companies paying for bariatric surgeries typically have criteria including patient BMI of $\geq 35 \mathrm{~kg} / \mathrm{m}^{2}$ with at least one of its associated co-morbidities (type II diabetes, hypertension, sleep apnea or other respiratory disorders, non-alcoholic fatty liver disease, osteoarthritis, lipid abnormalities, gastrointestinal disorders, or heart disease) or a BMI of $\geq 40 \mathrm{~kg} / \mathrm{m}^{2}$ or 100 pounds overweight without co-morbidities [1,3]. Surgeries performed largely in the United States include LRYGB (18.7\%) and LSG (58.1\%). The LRYGB has well established effectiveness in patients within the literature however, LSG is noted to be a less demanding operation than LRYGB, and an effective alternative [91]. Research comparing the two surgeries has been found to be conflicting by outcomes of weight loss [92-94]. These results typically show LRYGB achieving significantly higher amounts of excess weight loss. Recent studies by Peterli et al. $(2017,2018)$ and Salminen et al. (2018) showed similar loss in LRYGB and LSG up to 5-year post-operatively [95-97]. LSG and LRYGB displayed percent excess 
weight loss (\%EWL) outcomes of $>49 \%$ and $>57 \%$ respectively [95-98]. This places both surgical procedures near the loose definition of $>50 \%$ excess body weight loss as success.

Commonly associated with, and frequently exacerbated among upper classifications of BMI, are obesity related co-morbidities [88]. Conventional dietary, lifestyle and behavior change interventions for significant weight reductions, likely fail in comparison to surgical weight loss interventions [99]. Not only effective in significant weight reduction, bariatric surgeries have been found to reduce severity or appearance of co-morbidities entirely after surgery $[100,101]$. Literature supports remission of type 2 diabetes or reduction in blood glucose after surgery [102]. Brethauer et al. found remission of type 2 diabetes after bariatric surgery in nearly $30 \%$ of patients after 5-years [102]. Those more likely to achieve remission included patients with a shorter lifetime duration of diabetes and higher long-term excess weight loss [102]. Individuals likely to have reoccurrence of diabetes after remission, were those having a longer lifetime duration of type 2 diabetes, less excess weight loss, and regain of weight after largest loss postsurgery [102]. Likewise, among psychological conditions, increasing weight is found to be correlated with co- morbid. In bariatric patients, literature has found that patients have an array of mental health issues with depression as a main condition [103-106]. Of these individuals receiving surgery, preoperative depression scores and diagnoses predict lesser weight loss outcomes compared to non-diagnosed, lower depressive scoring individuals [107, 108]. Although conflicting results remain in the literature, mental health issues such as depression have seen to be lessened with bariatric surgery [109-111]. In a study by Booth et al., authors found that an average reduction of $4 \%$ of clinical depression in patients was seen at 2-years postoperation, however at the seventh year post-operation, depression had increased to $1 \%$ greater than baseline $[110,112]$. 
Among the Appalachian region, the question arises of 'success' among bariatric surgery patients who reside in the Appalachian region. When analyzing literature regarding health disparities in the Appalachian region, many previously mentioned factors among the population can be antagonistic toward weight loss such as environmental influences, health literacy, access to resources, and co-morbid conditions.

To date, minimal number of

studies have examined

Appalachian populations of

bariatric surgery patients.

Although there are nearly

200,000 bariatric surgeries

performed annually, this is

noted to be a mere $1 \%$ of the

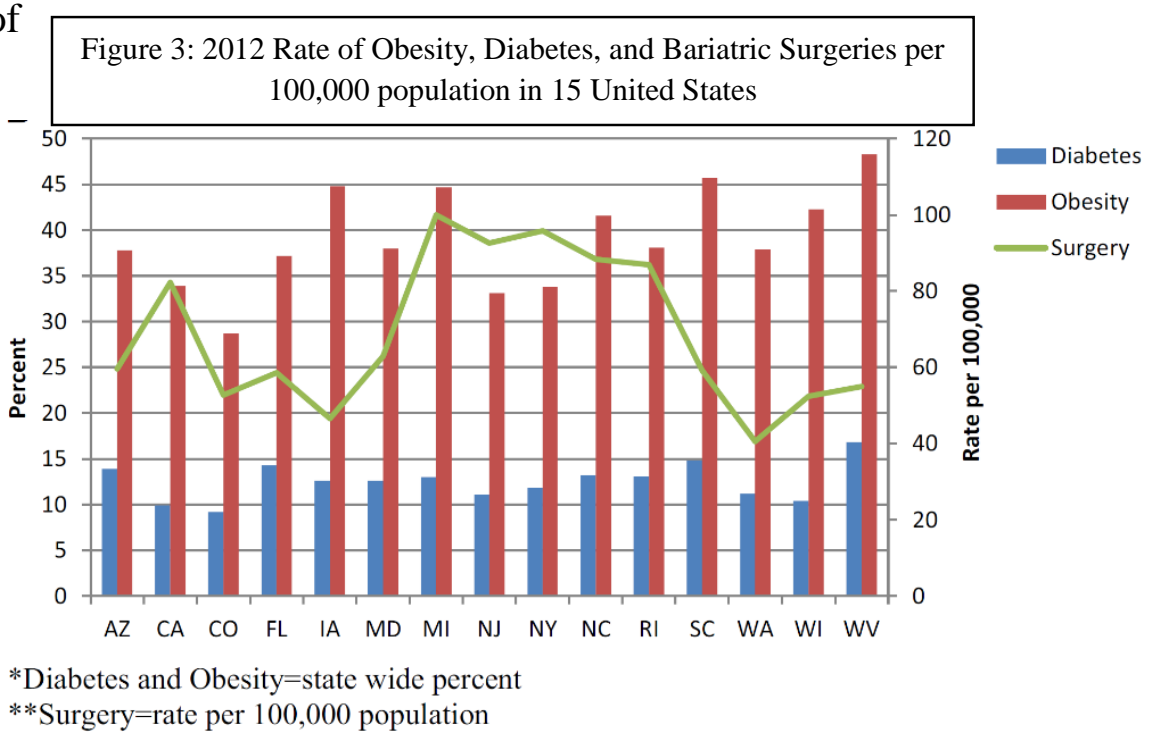

eligible United States population who actually take advantage of this intervention [113]. In

Figure 3, rates of diabetes, obesity, and surgeries performed in 2012 per 100,000 population are depicted [114]. Specifically, when examining West Virginia, both diabetes and obesity are of the highest rates, while bariatric surgery is among the lowest rates, similar to those of Colorado (lowest rates of diabetes and obesity). However, patient understanding of the need for lifestyle change remains the precursor for true health behavior change and utilization of interventions such as metabolic surgery. In a study examining self-reported and perceived health in Appalachian residents, participants reported themselves as being "healthy" while simultaneously reporting themselves as sedentary, hypertensive, overweight, or hyperlipidemic [115]. Over half of the individuals reporting being healthy, also had at least two disease conditions or poor health 
behaviors [115]. This examination of perceived health in Appalachia may lend interesting insight into the inferior health of the region. Equally, if Appalachian individuals have inadequate awareness of their poor health and limited understanding of the impact an unhealthy lifestyle can make, an increased number of residents approaching procedures like bariatric surgery may be unlikely. However; of those individuals who do reach out for bariatric surgery interventions residing in the Appalachian region, there is a large void in the literature describing the population, their journey, surgical outcomes and factors influencing those outcomes. 


\section{Chapter III: Research Design and Statistical Analyses}




\section{Introduction}

The following chapter provides a description of the study methodology used to address research questions for this retrospective medical record review of bariatric surgery patients at West Virginia University Hospital. Data collection methods are described in further detail along with associated hypothesis. Study design, data gathering, instruments, variables measured, and data analyses is explained.

\section{Setting and Sample}

Retrospective data consisted of individuals who took part in the bariatric surgery program at West Virginia University Hospitals. Inclusion criteria for analyses included individuals 18 years or older who completed a surgery program and received LSG or LRYGB surgery between 2013-2017. Candidates for surgery were cleared by surgeon, dietitian, psychologist, cardiologist, and pulmonologist. Weight criteria for surgery included a BMI of $\geq 40 \mathrm{~kg} / \mathrm{m}^{2}$ or BMI $\geq 35 \mathrm{~kg} / \mathrm{m}^{2}$ with at least one co-morbidity (type II diabetes, hypertension, sleep apnea or other respiratory disorders, non-alcoholic fatty liver disease, osteoarthritis, lipid abnormalities, gastrointestinal disorders, or heart disease).

WVU Medicine Bariatric program has collected data on bariatric patients at initial clinic visit and at each attended follow-up visit. A query was completed on patients who have finished surgery between 2013-2017 ( $\mathrm{n}=599)$. Patients who received gastric banding surgery or had a revision of a previous bariatric surgery were removed from data set as they were a limited sample and metabolic outcomes may differ. Baseline descriptive statistics were available on a total of 547 patients. Sample sizes differ among analyses due to incomplete/missing data in patient charts. Qualitative and quantitative data were collected via Electronic Medical Record 
(EMR) and are described below. Baseline measures were collected from initial visits at bariatric and psychology clinics.

\section{Data Collection Procedures}

Approval to conduct research was obtained via West Virginia University Institutional Review Board (1611355277) in March 2017. All researchers completed HIPAA training, contracts, and Collaborative Institution Training Initiation course certificates. Research assistants on the project were trained to retrieve information from patient charts for the study. Assistants included graduate students $(n=7)$, medical students $(n=13)$, and undergraduate students $(n=4)$. Students were trained over April and May of 2017. Data was retrieved April through September 2017 via WVU Hospitals secure server, Citrix, and entered into a secure, HIPAA compliant, RedCap survey. Trained students viewed patient EMR and collected information from clinician notes, uploaded PDF documents, and laboratory values that were available.

Data was downloaded onto a secure server on university hard drives for cleaning and analyses. Data was cleaned and outliers were removed prior to analyses in Chapters 5.

\section{Measures}

A baseline Bariatric Program Questionnaire was completed by each surgical patient prior to their initial bariatric visit. This questionnaire includes demographics, behavioral variables, health history, and a nutritional questionnaire. Follow-up anthropometrics were captured at each follow-up appointment patients attended (3 month, 6 month, 9 month, 1 year, 18 month, and 3 year possible). Lastly, Geographical Information Systems (GIS) were used to locate patient address through WV GIS Technical Centers' WV Address Locator Services [116]. Measures specifically used in this dissertation are as follows: 
Bariatric Program Questionnaire. This comprehensive 168 item questionnaire designed by the WVUH bariatric program identified variables including demographic information including age, gender, race, relationship status, education attainment, occupation, and insurance type. Social history questions include drug and alcohol use or any rehab or additions. Family health history and well as personal health history (endocrine, pulmonology, cardiology, neurological, gastrointestinal, bladder/kidney, psychological, and females were given fertility and PCOS) was included. Form was scanned and uploaded as a PDF into patient chart.

Nutrition Questionnaire. Baseline dietary behaviors captured in an 86 item self-reported survey completed by patients for their initial bariatric visit. Variables included weight history, dietary patterns, sleep, stress, physical activity, vitamin and mineral use, and a self-reported 24-hour dietary recall. Form was scanned and uploaded as a PDF into patient chart.

Follow-up Anthropometrics. Repeated anthropometrics used for major outcome measures were retrieved at each attended follow-up visit. Measures included weight, BMI, and excess body weight (EBW). Percent excess weight loss (\%EWL) was calculated as (initial weight - 1-year follow-up weight) / (initial weight - weight at BMI of 25) x 100.

Geographical Information Systems (GIS). WV address Locator Service used is in collaboration with WV Statewide Addressing and Mapping Board (WVSAMB) and the WV Division of Homeland Security and Emergency Management (WVDHSEM). Patient address was located, and mapped by WV FOODLINK experts' Food Accessibility Map [117, 118]. This Food Accessibility Map uses four weighted variables to illustrate the barriers that households face in accessing food and calculates food accessibility. The factors used to calculate food accessibility included, (a) the quality of retailers, (b) the quantity of retailers, (c) income, and (d) vehicle access. 
Food Accessibility. The current study utilizes a novel food access ranking score (FARS) developed by WV FOODLINK GIS experts [117, 118]. Utilizing both USDA census-data and unique indicators of food access (quality of food retailers), this approach provides a more refined understanding of food deserts in West Virginia. Due to the exclusiveness of the map to the state of West Virginia, only patients residing in the state were included. FARS is based on four weighted variables to illustrate the complexity of food access. This map utilizes census block group scales to calculate food access as compared to the USDA census tract usage. The four variables included in the Food Access Ranking Score (FARS) are (1) Quantity of Retailers, (2) Quality of Retailers, (3) Income, and (4) Vehicle Access.

- The quantity variable calculated a score for each census block group based upon the presence of absence of retailer types and was also normalized to create a weighted variable between 0 and 1 .

- The quality variable was calculated by multiplying the number of retailers in each category by the quality of the foods available, normalized statewide via a weighted variable between 0 and 1 .

- The income variable was calculated based upon the median national household income to more accurately reflect household purchasing power in relationship to other parts of the country. Census block groups were given a score of 0 or 1 based upon whether they were above or below $80 \%$ of the national income median.

- Finally, the vehicle variable was drawn from the USDA data and disaggregated from the census tract to the census block group scale. Tracts that had high vehicle access were given a 1 and tracts with low vehicle access were given a 0 . 
The FARS was then calculated by summing the weighted variables into a final access score between 0 and 4 . Block groups that scored a zero have little to no food access (do not have access to a quality store of any kind, they have low incomes and low vehicle access), areas in moderate range of 1 to 2 , and groups that scored between a 3 and 4 (have each type of quality store, more than one of some of them have household incomes above the national median, and have access to a vehicle).

\section{Study Assumptions}

The current bariatric program in which study participants participated, required prospective patients to complete a written questionnaire and return it back to the clinic at their initial bariatric program visit. These questionnaires were predominately self-reported measures. It is assumed throughout these studies that patients had completed questionnaires honestly and to the best of their ability.

\section{Dissertation Aims and Objectives/Hypotheses}

Specific Aim 1: Systematically review literature regarding food access and obesity among the Appalachian region of the United States. Minimal literature examines the Appalachian regions food access and relationship to obesity.

Objective: Summarize available literature on an populations with obesity and their food access among the Appalachian region to inform future studies and potential prospective interventions.

Specific Aim 2: Provide insight into formative research characterizing Appalachian bariatric surgery patients through descriptive statistics of demographic, co-morbidities, nutritional habits, and baseline physical measures. Describe bariatric surgery success outcomes of Appalachian patients through body weight loss percentage, BMI, and their 
relationship to patient demographics, health conditions, and dietary behaviors. The environment within the Appalachian region is less than conducive to maintaining a healthy lifestyle. This can impact the outcomes or success a bariatric surgery has on those residing in this area. The work proposed in Aim 2 provides informative data on the success after bariatric surgery in a health disparate population. Analysis will lead to discussion and interpretation to implement qualitative research designs to identify barriers in place with these individuals and thus, future interventions to overcome them.

$\underline{\text { Research Hypothesis: }}$ Those patients with less successful surgical outcomes at 1-year follow-up (<50\% EBWL) will have higher initial weight/BMI/EBW, multiple morbidities, poorer nutritional behaviors, and poorer family history. Further, patients within our population will have lower \%EWL than described in the literature among other bariatric surgery cohorts.

\section{Specific Aim 3: Determining Food Access Ranking Scores of an Appalachian bariatric} surgery population through Geographical Information Systems (GIS) locating patient addresses and its relationship to descriptive variables. Specifically, with bariatric surgery patients and food access, little work has been completed to examine the relationship or impact they have on each other. The approach taken here, defining this bariatric population and utilizing a GIS location to identify food access scores, will provide valuable insight for future research interventions to ensure better understanding how conducive residents' food environments will be prior to or after surgery.

Research Hypothesis: It is hypothesized that the largest proportion of food access ranking among a West Virginia bariatric population is in the low and moderate-low food 
access score. Further, those patients with lower food access would have poorer surgical outcomes (i.e lower \%EWL).

\section{Analysis}

In Aim 1 a systematic review of the literature was performed regarding obesity and food access in the Appalachian region. No specific statistical analyses were utilized due to the lack of comparability of study measures. Study locations, and a general population demographics are combined from studies original data.

General descriptive statistics to define the population are described in Chapter 5. Differences among LRYGB and LSG baseline descriptors was utilized in Chapter 5, Table 1. Examining outcome measure of \%EWL to identify characteristics differences among those patients achieving more or less success was initiated with a priori selection of variables. Initial variables included for relational screening included gender, age, ethnicity, surgery type, marital status, baseline diabetes, hypertension, high cholesterol, diagnosed depression, and cooking responsibilities.

Independent t-test was used for assessing association between \%EWL and variables with two groups (Surgery type, Gender, Ethnicity, Education level, State, Marital Status, Diabetic, Diagnosed Hypertension, Diagnosed Depression). ANOVA was used testing for testing hypothesis f equality among more than two groups of categorical variables (education and marital status), and Spearman's Rho was used for examining correlation of \%EWL with continuous variables (age, \% Attended follow-up, Systolic Blood Pressure, Diastolic Blood Pressure, HbA1c and BDI). Fisher's Exact test was used for cell sizes < five. Significant correlations of $\mathrm{p}<.05$ were included in next step of building ANOVA and ANCOVA models to test relationship between \%EWL and categorical and continuous predictor variables. Model 
assumptions of homoscedasticity, normality, and lack of multicolinnearity were assessed. Cook's D influence was set at 0.0227 (4/n). Data with an influence greater than Cook's D were removed from analysis $(n=7)$. Effect size in models were assessed by change in adjusted $\mathrm{R}^{2}$ values to calculate variance of each variable when placed in the model.

Aim 3 targeted understanding food access among West Virginia cohort of patients. Hypothesis stated that those with lower food access scores would display less successful \%EWL. Wilcoxon Rank Sum test was used to examine relationship between continuous FARS scores and binary variables and Kruskal-Wallis test was used for examining if FARS depended on continuous variables. Fisher's Exact test was used for categorical variables when cell sizes were less than five. FARS shown in categories of 1 through 4 for visualization, utilized on a continuous scale for initial analyses and adapted into quartiles for further analyses to compare differences in the extreme low and high food access areas. Pearson's Chi-Square test was used for testing association of FARS categories (quartile 1: low and quartile 4: high) with binary categorical variables and Kruskal-Wallis was used for comparing the continuous variables between the two FARS quartile categories.

\section{Limitations of the Study}

Utilizing a retrospective cohort study design brings about potential issues in the data collection phase. Within each bariatric patient chart across time, there were changes with surgeons and style of written notes and communication regarding patients. Most of the data collected on each patient were provided in the form of scanned PDF documents into their chart. This may have led to questionnaires not entirely completed by the patient, illegible writing, or patient was seen previously by another physician and documentation wasn't required (i.e. some 
patients were cleared by other behavioral medicine physicians and psychological questionnaire scores weren't available). Further limitations of the overall studies are described in Chapter 7. 


\section{Chapter IV: Food Access and Obesity in the Appalachian Region: A Systematic Review}




\title{
Submitted Manuscript for Review:
}

\section{Food Access in the Appalachian Region and Obesity: A Systematic Review}

\author{
ML Barr ${ }^{1}$, RL Hagedorn ${ }^{1}$, MD Olfert ${ }^{1}$
}

${ }^{1}$ West Virginia University, Davis College of Agriculture, Natural Resources and Design, Division of Animal and Nutritional Sciences, Department of Human Nutrition and Food

\section{Authors Email Addresses:}

mbarr6@mix.wvu.edu; rlhagedorn@mix.wvu.edu; melissa.olfert@mail.wvu.edu

\section{Correspondence:}

Melissa D. Olfert, DrPH, RDN

Associate Professor, Human Nutrition and Foods

Division of Animal and Nutritional Sciences

Davis College of Agriculture, Natural Resources, and Design

West Virginia University

G25 Agriculture Sciences Building

333 Evansdale Dr.

Morgantown, WV 26506

(304) $293-1918$

(304) 293 - 2232 (Fax)

Melissa.olfert@mail.wvu.edu (E-mail) 


\begin{abstract}
Studies examining food access and food deserts among United States populations are widely found within the literature in both rural and urban areas. Research focusing on health disparate, high obesity, and low access areas such as Appalachia, however, are limited. The objective of the current study was to complete a systematic review of food access and obesity among Appalachian regions of the United States. Search terms used were Appalachia, rural, obesity, food access, food systems, and food deserts. 487 articles were searchable through peer-reviewed databases. Seven remaining articles were found to meet all inclusion criteria. Five of the seven studies identified that residing in a rural or food desert area had positive associations with obesity prevalence. The remaining two studies had examined urban neighborhoods and all United States counties to find no changes in dietary quality or BMI and no association of obesity prevalence with residing in a food desert. Food access and obesity among a health disparate region such as Appalachia is poorly understood. However, with limited studies and conflicting results, a clear comparability of studies was unobtainable. Future research and examination of intervention effectiveness is warranted in this underrepresented Appalachian region.
\end{abstract}

Keywords: food access, obesity, Appalachia, rural, food desert 


\section{INTRODUCTION}

Appalachia, consisting of portions of 12 states, and the entirety of West Virginia contain the Appalachian Mountain Range along with a long standing reputation of health disparities [23, 119-123]. The area is consistently among the highest rates of hypertension, diabetes, obesity, mental health issues, and lack of access to care [23, 124, 125]. Among the highest conditions in this region, overweight and obesity rates have spiked and remained elevated among these individuals $[4,6,40,46,126-132]$. Various research has been employed examining the relationship of overweight and obesity among the Appalachian region and culture [132, 133]. The rural nature among the region lends a hand to the continued health disparities among the area: $[4,46,134]$ distance to higher resource areas increases travel time or time off of work, low income and inadequate insurance coverage discourages seeking of preventative care, infrastructure barriers, lower educational attainment, poor health literacy and lower confidence lower the ability to acquire and utilize new health knowledge for their personal care $[135,136]$. Because of these barriers, encouraging a population to improve their health and dietary habits is impacted by how affordable and available these healthy, nutritious foods are [137, 138].

Interestingly, current literature identifies a lack of access to affordable, healthy, nutritious foods has been found with correlate to obesity rates in rural settings throughout the United States [137, 138]. Food access is typically determined through various avenues including the United States Department of Agriculture's (USDA) Food Access, USDA Census-tract data (smaller areas than county data) $[75,76]$, county-level data, participant self-reporting and Geographical Information Systems (GIS) locations [137, 139, 140]. Likewise, overweight and obesity is determined through variations of measurements such as county-level data, self-reported measures, anthropometrics and body mass index $[6,40,43]$. These techniques of determining access and 
obesity have been used nationwide for various purposes, however utilizing them together in a streamline fashion is warranted. This work is specifically necessary in regions that are rural and have high rates of obesity. In our target population of Appalachia, there has been minimal work focusing on this specific health disparate population, food access, and obesity, simultaneously.

The objective of the current study was to systematically review both peer-reviewed and gray literature to synthesize and capture understanding of obesity and food access in a health disparate region such as Appalachia. To our knowledge, this is the first review to obtain an examination of both obesity and food access (FA), specifically in the Appalachia region.

\section{METHODS}

To provide a complete picture of FA and obesity in Appalachia, a systematic review was conducted in accordance with the Preferred Reporting Items for Systematic Reviews and MetaAnalyses (PRISMA) guidelines [141]. Databases utilized included PubMed, CINAHL, ScienceDirect, and WorldCat.org. Google Scholar was utilized outside the normal databases to capture any overlooked or gray literature including dissertations and conference proceedings. Search terms included: Appalachia, rural, obesity, food access, food systems, and food deserts. Date restrictions weren't used as all articles were 2006 and later. Language restrictions of English were used. Excel spreadsheets and citation managers were used to extract and assess articles.

\section{Selection Criteria}

Citation manager was used to identify duplicates. Articles were extracted into an excel spreadsheet and were independently screened for eligibility. Titles, abstracts, and full text portions were reviewed to determine final articles for analysis. Food access variables were determined by inclusion criteria of studies to use measurable Geographic Information System 
(GIS) locations of individuals in proximity to nearest food stores or determined through personal accounting of community access. Obesity related criteria for study variables were determined through census data, physical measurements, county data, or self-report. Appalachian region was determined from the study or from current authors examining study location.

\section{Data Extraction}

Authors MLB and RLH reviewed all full-text for final inclusion. MDO reviewed final decisions for tie breakers. All relevant peer-review literature to extract the following: objective, data collection time frame, study design and approach (eg. obesity and food access measurements), results and conclusions. Results were compiled and assigned into the following categories: prevalence of access, impact of demographic factors, obesity factors, and other influential factors.

\section{RESULTS}

From selected search terms, a total of 487 articles were searchable through peerreviewed databases $(n=377)$ and Google Scholar searches $(n=110)$. All citations were compiled into EndNote citation manager and duplicates $(\mathrm{n}=18)$ were removed. Titles were reviewed to remove a further 227 citations that did not meet the inclusion criteria (not measuring food access, not measuring obesity, not in the Appalachian region, or a
Table 1: Descriptive characteristics of peerreviewed and gray literature examining food access and obesity in Appalachia

\begin{tabular}{|l|r|}
\hline Description & $\begin{array}{r}\text { Peer Reviewed and } \\
\text { Gray Literature }\end{array}$ \\
\hline n (\%) \\
\hline Necation York \& Pennsylvania & $1(14.3)$ \\
\hline Pennsylvania & $2(28.6)$ \\
\hline West Virginia & $1(14.3)$ \\
\hline Kentucky & $1(14.3)$ \\
\hline Alabama & $1(14.3)$ \\
\hline United States & $1(14.3)$ \\
\hline Demographic & $1(14.3)$ \\
\hline Predominately White & $2(25.0)$ \\
\hline Predominately Black & $0(0)$ \\
\hline Mixed & $4(57.1)$ \\
\hline Unknown & \\
\hline Locale & $5(71.4)$ \\
\hline Rural & $1(14.3)$ \\
\hline Urban & $1(14.3)$ \\
\hline Mixed &
\end{tabular}
combination) for this review. The remaining 242 abstracts were assessed removing 197 articles 
for failure to meet inclusion criteria of study completion in the Appalachian region or measuring food access and obesity. The remaining 45 articles were full-text reviewed. PRISMA flowchart of article selection in Figure 1. After full text review, 38 articles were removed for incomplete inclusion criteria of either not measuring obesity $(\mathrm{n}=8)$, not measuring food access $(\mathrm{n}=16)$, not within the Appalachian region $(n=9)$, or not meeting a combination of the three $(n=5)$. The remaining 7 articles were found to meet all inclusion criteria (measuring food access, obesity and in the Appalachian region) to be included in qualitative analysis. One article as gray literature, the remaining 6 were peer-reviewed.

\section{Description of Study Locations}

Of the 7 articles reviewed, all were included in portions of the Appalachian region with one including the entire state of West Virginia $(n=1)$ [83], Pennsylvania counties ( $n=2)[86,142]$, one including Pennsylvania and New York counties (n=1) [143], Kentucky counties ( $n=1)$ [84], Alabama counties $(\mathrm{n}=1)$ [85], and all United States counties (stating disparities among Appalachia described in Table 1) ( $\mathrm{n}=1)$ [87] (Table 2).

\section{Study Samples}

Average sample size across all articles utilizing individual participants was $n=909$. Studies with individual participants ranged from 613 participants in an Alabama county school [85] to 1,372 in two Pennsylvania neighborhoods [86]. Studies focusing on county data ranged from 55 in West Virginia counties [83] to 3,109 counties in 48 United States [87]. Age ranges of the studies typically ranged within adults 18 years or higher $[83-85,87,142,143]$, however, some varied including school district data of individuals 2-20 years old [86]. 


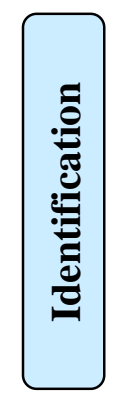
Records identified through database searching
$(\mathrm{n}=377)$
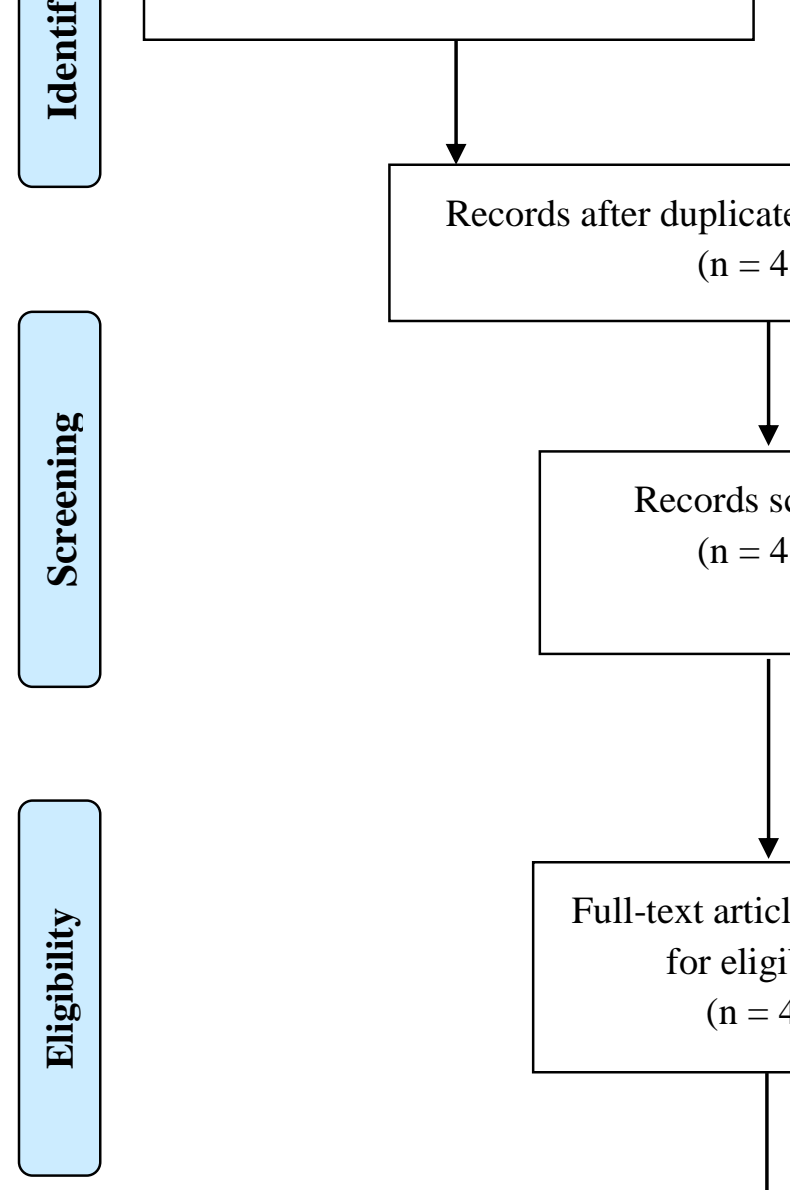

Records after duplicates $(\mathrm{n}=18)$ removed

$$
\text { ( } \mathrm{n}=469)
$$
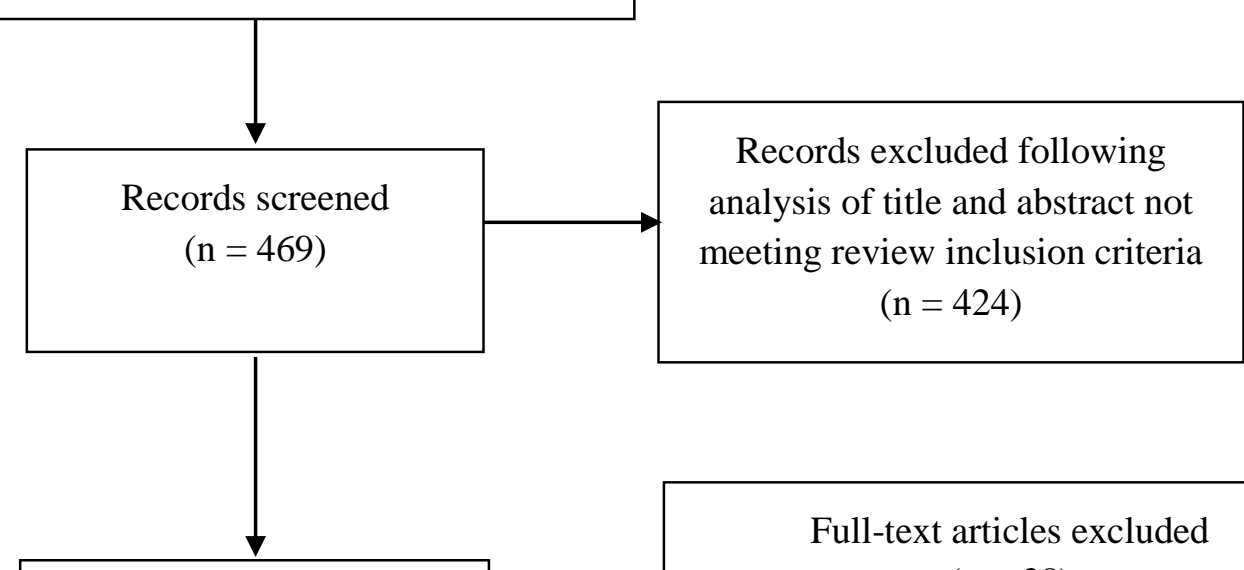

Full-text articles assessed for eligibility

$$
(n=45)
$$
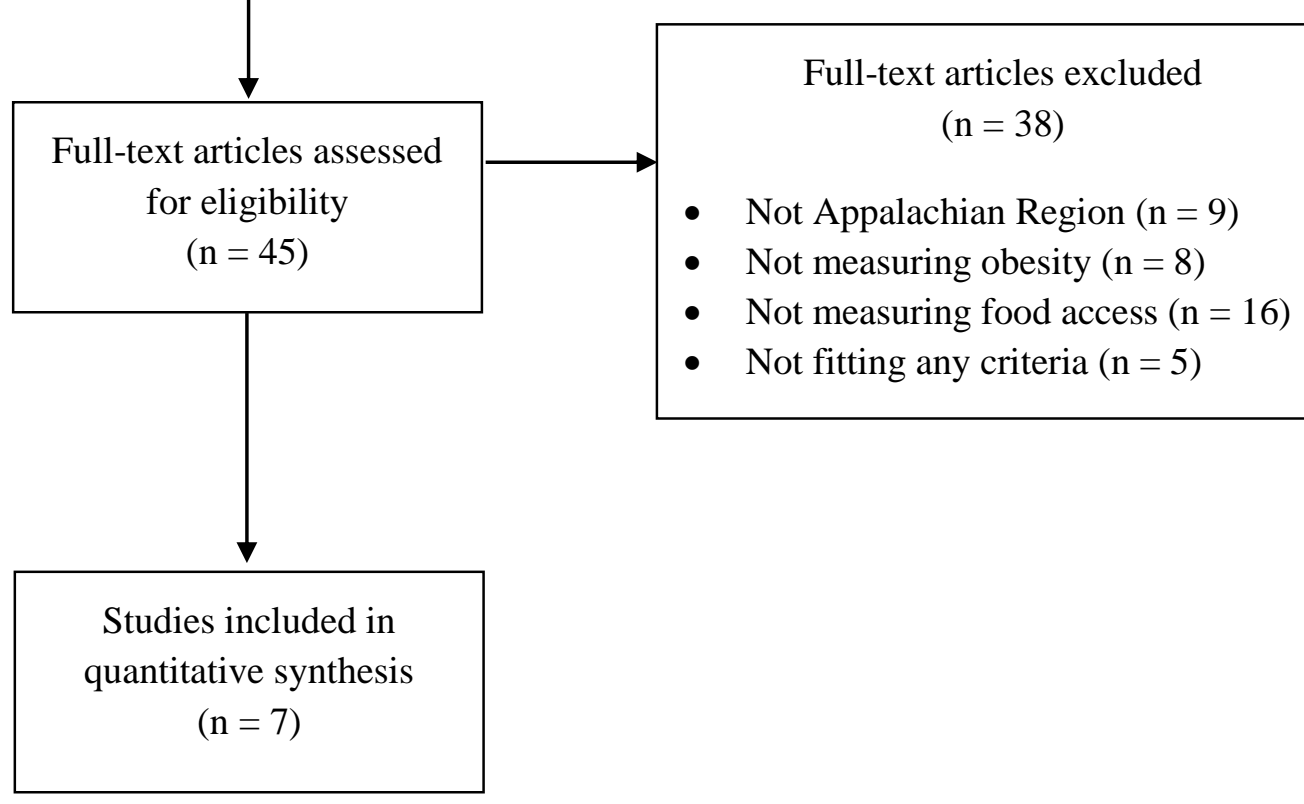

- Not fitting any criteria $(\mathrm{n}=5)$

\section{Studies included in quantitative synthesis}

$$
(n=7)
$$

Figure 1: Preferred Reporting Items for Systematic Reviews and Meta-Analyses flow diagram of food access and obesity within the Appalachian region 
Table 2: Reviewed articles examining food access and obesity among an Appalachian population

\begin{tabular}{|c|c|c|c|c|c|}
\hline Authors & $\begin{array}{l}\text { Data } \\
\text { collection } \\
\text { time } \\
\text { frame }\end{array}$ & Setting & $\begin{array}{l}\text { Sample } \\
\text { demographics }\end{array}$ & $\begin{array}{l}\text { Study design and } \\
\text { approach }\end{array}$ & $\begin{array}{l}\text { Food access } \\
\text { measures }\end{array}$ \\
\hline $\begin{array}{l}\text { Amarasinghe A, } \\
\text { et al. } 2006\end{array}$ & $\begin{array}{l}1992 \text { and } \\
1997\end{array}$ & $\begin{array}{l}\text { West } \\
\text { Virginia } \\
\text { counties }\end{array}$ & $\begin{array}{l}\mathrm{N}=55 \text { counties; } 94.66 \\
\text { people per square } \\
\text { mile (rural); } \\
\text { Obese: } 18.92+4.2 \% \text {; } \\
\text { Below poverty line: } \\
\text { 20.32+6.36\%; } \\
\text { Completed college: } \\
11.1+4.57 \% \text {; Percent } \\
\text { unemployment: } \\
7.57+3.03 \% \text {; Annual } \\
\text { wages: } \\
\$ 20,915.87+4076.85 ; \\
\% \text { population who } \\
\text { smoked: } \\
26.01+5.60 \% ;\end{array}$ & $\begin{array}{l}\text { Cross-sectional; } \\
\text { Secondary county } \\
\text { data; } \\
\text { Inclusion criteria: All } \\
\text { counties with } \\
\text { available data; Panel } \\
\text { Data Structure, } \\
\text { random and fixed } \\
\text { effect regression } \\
\text { models, Lagrange }\end{array}$ & $\begin{array}{l}\text { County-level total } \\
\text { number of } \\
\text { establishments per } \\
1000 \text { people, total } \\
\text { number of food } \\
\text { stores per } 1000 \\
\text { people, eating and } \\
\text { drinking places per } \\
1000 \text { people, } \\
\text { average travel time } \\
\text { to work }\end{array}$ \\
\hline $\begin{array}{l}\text { Dubowitz T, et } \\
\text { al. } 2015\end{array}$ & $2011 ; 2014$ & $\begin{array}{l}\text { Pittsburgh, } \\
\text { PA }\end{array}$ & $\begin{array}{l}\text { Two demographic } \\
\text { and geographic } \\
\text { matched } \\
\text { neighborhoods; } \\
\mathrm{N}=1,372 \text { baseline } \\
\text { participant's } \\
\text { Full-service } \\
\text { supermarket opened } \\
\text { in } 2013, \mathrm{~N}=831 \\
\text { follow-up: } 75 \% \\
\text { female, } 95.2 \% \\
\text { African American, } \\
82.3 \% \text { not married or } \\
\text { living with a partner, } \\
\text { low-income of } \\
\$ 13,608,53.3 \text { years } \\
\text { old, BMI of } \\
30.5 \mathrm{~kg} / \mathrm{m}^{2}, 77.4 \% \\
\text { met criteria for being } \\
\text { overwweight; }\end{array}$ & $\begin{array}{l}\text { Quasi-experimental } \\
\text { longitudinal; Two } \\
\text { neighborhoods where } \\
\text { a new full-service } \\
\text { supermarket was } \\
\text { opening in one; } \\
\text { surveys, ASA 24- } \\
\text { hour recalls }\end{array}$ & $\begin{array}{l}\text { Perceived access, } \\
\text { choice, quality, and } \\
\text { cost of healthy } \\
\text { foods }\end{array}$ \\
\hline
\end{tabular}

Results

\begin{tabular}{lll}
\hline \multicolumn{2}{c}{ Results } & \\
\hline Prevalence of access & Demographic factors & Obesity factors \\
& & \\
\hline Total establishments: & $1 \%$ increase in college & Total number of food stores per \\
$20.48+5.84 ;$ Total food & education completion & thousand population (one unit \\
stores: $0.88+0.27 ;$ Eating & significantly decreases & increase in number of food stores \\
and drinking places: & obesity rates by about & significantly decreases obesity by \\
$1.38+0.64 ;$ Travel time & $0.3 \% ;$ County annual per & $2.6 \%)$; business sestablishments $(1$ \\
$26.12+5.77$ min & capita wage positively and & unit increase significantly raises \\
& significantly contribute to & obesity by $0.2 \%$ ) and mean travel \\
& obesity; $\$ 1,000$ & time to work (one minute increase \\
& significantly increases & raise obesity by $0.2 \%)$ are \\
& obesity by $0.3 \%$ & significant built environment \\
& & contributors of county-level \\
& & obesity \\
& &
\end{tabular}

For nearly all variables regarding access, significant increases were new store in those residing in the natura intervention Those who frequently used the store users increased 8 of 10 perceived access variables

Intervention neighborhood saw kilocalories, added suga and percent of solid fats, (SoFAAS). These variables increased remained the same in the comparison comparison
neighborhood.
After new supermarket arrived consumption of fruits and eclined in both whe grains and overall diet quality. Weight and overall diet quality. Weight in both renained relatively stabe significant facross time. purches fors on for purchasing places and diet were in diet when shepent grocery store. 
Table 2: Reviewed articles examining food access and obesity among an Appalachian population

\begin{tabular}{|c|c|c|c|c|c|c|c|c|}
\hline \multirow[b]{2}{*}{ Authors } & \multirow[b]{2}{*}{$\begin{array}{l}\text { Data } \\
\text { collection } \\
\text { time } \\
\text { frame }\end{array}$} & \multirow[b]{2}{*}{ Setting } & \multirow[b]{2}{*}{$\begin{array}{l}\text { Sample } \\
\text { demographics }\end{array}$} & \multirow[b]{2}{*}{$\begin{array}{l}\text { Study design and } \\
\text { approach }\end{array}$} & \multirow[b]{2}{*}{$\begin{array}{l}\text { Food access } \\
\text { measures }\end{array}$} & \\
\hline & & & & & & Prevalence of access & Demographic factors & Obesity factors \\
\hline $\begin{array}{l}\text { Gustafson A, et } \\
\text { al. } 2017\end{array}$ & 2015 & $\begin{array}{l}\text { Rural } \\
\text { Kentucky }\end{array}$ & $\begin{array}{l}6 \text { rural Kentucky } \\
\text { counties. Random } \\
\text { dials to registered } \\
\text { telephone landline or } \\
\text { cellular numbers. } \\
\mathrm{N}=741 \text { completed } \\
\text { surveys. } 76 \% \text { female, } \\
59 \text { years, } 97 \% \text { white. }\end{array}$ & $\begin{array}{l}\text { Cross-sectional. } \\
\text { Multiple Logistic } \\
\text { Regression }\end{array}$ & $\begin{array}{l}\text { Qualitative data: } \\
\text { participants self- } \\
\text { report }\end{array}$ & $\begin{array}{l}\text { Participants self-reported } \\
\text { communities as 'food- } \\
\text { deserts' where their } \\
\text { accessible options are } \\
\text { fast-food chains, a limited } \\
\text { number of grocery stores } \\
\text { that struggle to keep fresh } \\
\text { items, and costs being } \\
\text { higher for those fresh } \\
\text { items. }\end{array}$ & $\begin{array}{l}6 \text { counties participating } \\
\text { have poverty rates of } 11- \\
19 \% \text { and educational } \\
\text { attainment of } 10-20 \% \text { for } \\
\text { associate's degree or } \\
\text { higher. }\end{array}$ & $\begin{array}{l}\text { All counties participating have } \\
\text { obesity rates }>40 \% \text {. } \\
40 \% \text { participants had serious concern } \\
\text { with obesity and } 59 \% \text { believed it was } \\
\text { easy to obtain information about } \\
\text { obesity; } \\
66 \% \text { were unaware of community } \\
\text { resources to address obesity. } 36 \% \\
\text { had a serious concern with healthy } \\
\text { eating and } 68 \% \text { believed it would be } \\
\text { easy to access information; } \\
54 \% \text { were unaware of any } \\
\text { community resources for healthy } \\
\text { eating; } \\
67 \% \text { and } 65 \% \text { of participants } \\
\text { consumed } 2 \text { or less servings of fruits } \\
\text { and vegetables per day, respectively. }\end{array}$ \\
\hline Li Y, et al. 2015 & 2013 & $\begin{array}{l}\text { Alabama } \\
\text { county }\end{array}$ & $\begin{array}{l}\mathrm{N}=613 \text { African } \\
\text { American children, } \\
\text { ages } 4-13.50 .9 \% \\
\text { male, } 42.1 \% \\
\text { overweight or obese }\end{array}$ & $\begin{array}{l}\text { Cross-sectional. } \\
\text { Multi-level } \\
\text { regression to } \\
\text { examine relation } \\
\text { between food } \\
\text { environments and } \\
\text { children weight } \\
\text { status. }\end{array}$ & $\begin{array}{l}\text { Food Environment } \\
\text { Score (FES): } \\
\text { summed score of } \\
\text { four composite z- } \\
\text { scores (probability } \\
\text { that student } \\
\text { patronizes type of } \\
\text { store): convenience } \\
\text { stores, fast food, } \\
\text { supermarket, and } \\
\text { restaurant. }\end{array}$ & $\begin{array}{l}\text { Census blocks with }>50 \% \\
\text { African Americans, (scale } \\
-5.35 \text { to } 5.3 \text {; higher } \\
\text { number as healthier food } \\
\text { environment) only } 7.28 \% \\
\text { had FES }>1 \\
\text { Blocks with }<50 \% \\
\text { African Americans, } 26 \% \\
\text { has FES over 1. } \\
\text { Total census blocks with } \\
>50 \% \text { African Americans } \\
\text { had } 11.37 \% \text { in FES <-1, } \\
\text { while the }<50 \% \text { African } \\
\text { American blocks had } 0 \% \\
\text { in FES }<-1\end{array}$ & $\begin{array}{l}\text { Blocks with median } \\
\text { household incomes of } \\
>\$ 30,000 \text { had } 11.16 \% \\
\text { with FES >1 } \\
\text { Blocks with }<\$ 30,000 \\
\text { median income had } 7.18 \% \\
\text { with FES }>1 \\
\text { Greater median income } \\
\text { also had } 16.73 \% \text { FES }<-1 \\
\text { and lower median income } \\
\text { had } 6.36 \% \text { in this } \\
\text { category. }\end{array}$ & $\begin{array}{l}\text { Regression model 1: convenience } \\
\text { store and restaurants had a } \\
\text { significant, positive effect on } \\
\text { weight status, supercenters had a } \\
\text { negative impact and fast food had } \\
\text { no significant impact. } \\
\text { Model } 2 \text { including } \% \text { of African } \\
\text { Americas, median household } \\
\text { income, and school distance: fast } \\
\text { food remained insignificant while } \\
\text { convenience, restaurant, } \\
\text { supercenter, and median household } \\
\text { income had a significant, negative } \\
\text { impact on weight and \% African } \\
\text { American and school distance had } \\
\text { a significant positive association } \\
\text { with weight }\end{array}$ \\
\hline
\end{tabular}


Table 2: Reviewed articles examining food access and obesity among an Appalachian population

\begin{tabular}{|c|c|c|c|c|c|c|c|c|}
\hline \multirow[b]{2}{*}{ Authors } & \multirow[b]{2}{*}{$\begin{array}{l}\text { Data } \\
\text { collection } \\
\text { time } \\
\text { frame }\end{array}$} & \multirow[b]{2}{*}{ Setting } & \multirow[b]{2}{*}{$\begin{array}{l}\text { Sample } \\
\text { demographics }\end{array}$} & \multirow[b]{2}{*}{$\begin{array}{l}\text { Study design and } \\
\text { approach }\end{array}$} & \multirow[b]{2}{*}{$\begin{array}{l}\text { Food access } \\
\text { measures }\end{array}$} & \\
\hline & & & & & & Prevalence of access & Demographic factors & Obesity factors \\
\hline $\begin{array}{l}\text { Slack T, et al. } \\
2014\end{array}$ & $2000-2009$ & $\begin{array}{l}\text { United } \\
\text { States }\end{array}$ & $\begin{array}{l}\mathrm{N}=3109 \text { U.S. } \\
\text { counties in } 48 \text { states; } \\
30.3 \% \text { adults with } \\
\text { obesity, } 17.1 \% \text { less } \\
\text { than high school } \\
\text { education, } 4.1 \% \\
\text { unemployed, } 15.4 \% \\
\text { poor, } 9.6 \% \text { families } \\
\text { headed by single } \\
\text { mother, } 59.8 \% \text { rural }\end{array}$ & $\begin{array}{l}\text { Cross-sectional; } \\
\text { spatial statistical } \\
\text { methods }\end{array}$ & $\begin{array}{l}\text { USDA defined } \\
\text { food-desert census } \\
\text { tracts and number } \\
\text { of fast food } \\
\text { restaurants per } \\
1000 \text { people ( } 2000 \\
\text { and } 2006 \text { data for } \\
\text { food-desert, } 2009 \\
\text { data for fast food } \\
\text { restaurants) }\end{array}$ & $\begin{array}{l}\text { 17.3\% living in a food } \\
\text { desert; } 0.6 \text { fast food } \\
\text { restaurants per } 1000 \\
\text { population } \\
\text { Neither showed a } \\
\text { significant association } \\
\text { with obesity prevalence }\end{array}$ & $\begin{array}{l}\text { Areas with higher African } \\
\text { Americans, } \\
\text { unemployment, female- } \\
\text { headed families, and less } \\
\text { than high school } \\
\text { education had significant } \\
\text { positive correlations with } \\
\text { county obesity while areas } \\
\text { with a larger number of } \\
\text { available physicians, } \\
\text { natural amenities, } \\
\text { Hispanic population, } \\
\text { population size, } \\
\text { population age of } 65 \text { and } \\
\text { older, and fitness centers } \\
\text { had negative correlations } \\
\text { with county obesity }\end{array}$ & $\begin{array}{l}15.8 \% \text { of counties }(\mathrm{n}=492) \text { were } \\
\text { shown to be in high-obesity } \\
\text { regions including central } \\
\text { Appalachia }\end{array}$ \\
\hline $\begin{array}{l}\text { Flynt A, et al., } \\
2015\end{array}$ & 2010-2013 & PA and NY & $\begin{array}{l}\mathrm{N}=67 \text { PA counties, } \\
62 \mathrm{NY} \text { counties; } \\
28.9 \% \text { obesity and } \\
10.13 \% \text { diabetes, } \\
8.68 \% \\
\text { unemployment, } \\
\text { median Household } \\
\text { income } \$ 49,367\end{array}$ & $\begin{array}{l}\text { Cross-sectional, } \\
\text { observational: } \\
\text { Model-based cluster } \\
\text { analyses }\end{array}$ & $\begin{array}{l}\text { USDA Food } \\
\text { Environment Atlas } \\
\text { percent of each } \\
\text { county's population } \\
\text { in } 2010 \text { living in a } \\
\text { 'food desert', } \\
\text { without } \\
\text { supermarkets or } \\
\text { large grocers }\end{array}$ & $\begin{array}{l}16.4 \% \text { defined as low- } \\
\text { access }\end{array}$ & $\begin{array}{l}\text { Large proportion lacking } \\
\text { access to supermarkets } \\
\text { were generally medium or } \\
\text { large fringe metropolitan } \\
\text { areas }\end{array}$ & $\begin{array}{l}\text { Large fringe and large central } \\
\text { metropolitan counties with } \\
\text { significantly lower rates of obesity } \\
\text { than those in more rural or } \\
\text { suburban clusters }\end{array}$ \\
\hline
\end{tabular}


Table 2: Reviewed articles examining food access and obesity among an Appalachian population

\begin{tabular}{|c|c|c|c|c|c|c|c|c|}
\hline \multirow[b]{2}{*}{ Authors } & \multirow[b]{2}{*}{$\begin{array}{l}\text { Data } \\
\text { collection } \\
\text { time } \\
\text { frame }\end{array}$} & \multirow[b]{2}{*}{ Setting } & \multirow[b]{2}{*}{$\begin{array}{l}\text { Sample } \\
\text { demographics }\end{array}$} & \multirow[b]{2}{*}{$\begin{array}{l}\text { Study design and } \\
\text { approach }\end{array}$} & \multirow[b]{2}{*}{$\begin{array}{l}\text { Food access } \\
\text { measures }\end{array}$} & \\
\hline & & & & & & Prevalence of access & Demographic factors & Obesity factors \\
\hline $\begin{array}{l}\text { Schafft, K. A., et } \\
\text { al., 2009 }\end{array}$ & $1999-2000$ & $\begin{array}{l}\text { Rural PA } \\
\text { school } \\
\text { districts }\end{array}$ & $\begin{array}{l}\mathrm{N}=243 \text { rural school } \\
\text { districts, } 34 \% \text { of } \\
\text { students within, data } \\
\text { including 2-20 year } \\
\text { olds }\end{array}$ & $\begin{array}{l}\text { Longitudinal; } \\
\text { Inclusion: rural } \\
\text { school districts with } \\
\text { BMI data; following } \\
\text { fifth graders in } 1999 \\
\text { to 7th grade in } 2001\end{array}$ & $\begin{array}{l}\text { GIS 10-mile buffer } \\
\text { zone around each } \\
\text { zip code with one } \\
\text { or more large } \\
\text { grocery store } \\
\text { Missouri Census } \\
\text { Data Center's } \\
\text { Geographic } \\
\text { Correspondence } \\
\text { Engine with Census } \\
2000 \text { Geography to } \\
\text { calculate food- } \\
\text { desert zip codes } \\
\text { inside school } \\
\text { districts. School } \\
\text { districts defined a } \\
\text { 'food desert' if } \\
>50 \% \text { of population } \\
\text { lived in food-desert } \\
\text { zip codes. }\end{array}$ & $\begin{array}{l}45(18.5 \%) \text { school } \\
\text { districts labeled as food- } \\
\text { desert. }\end{array}$ & $\begin{array}{l}\text { Food-desert school } \\
\text { districts had smaller } \\
\text { populations, lower per } \\
\text { capita income, median } \\
\text { family income, income- } \\
\text { to-poverty ratios, high } \\
\text { school or less education, } \\
\text { and more unemployed } \\
\text { individuals, students } \\
\text { receiving reduced or free } \\
\text { lunch, at risk or } \\
\text { overweight or overweight } \\
\text { students in 1999, and } \\
\text { students overweight in } \\
\text { 2001. } \\
\text { Regression model } \\
\text { identifies median family } \\
\text { income, percent mobile } \\
\text { home residence, and } \\
\text { percent incomplete } \\
\text { kitchen as significant } \\
\text { predictors of food-desert } \\
\text { residence. }\end{array}$ & $\begin{array}{l}\text { In } 1999 \text { data each 1-point increase } \\
\text { in \% of population residing in } \\
\text { food-desert is associated with .06\% } \\
\text { increase in student at risk or } \\
\text { overweight. } \\
\text { Median family income and percent } \\
\text { food-desert residence are strongest } \\
\text { predictors of student risk of } \\
\text { overweight. } \\
2001 \text { data, percent residence in } \\
\text { food-desert is the only predictor of } \\
\text { student risk of overweight, } \\
\text { although weaker than } 1999 \text {. }\end{array}$ \\
\hline
\end{tabular}


Locations of studies ranged across the Appalachian region and a United States general study referencing the Appalachian region (Table 1). Most studies did not represent ethnicity/racial breakdown however two were predominately black $[85,142]$ and one predominately white [84]. For locale of the studies, five were defined as rural [83-86, 143], one urban [142], and one a combination [87].

\section{Study Measures}

Four of the selected studies used a cross-sectional design $[84-86,142,143]$ while the remaining two used a longitudinal design [87] and data with two time points of county-level data [83]. Minimal articles clearly defined their sample as being within the Appalachian region. Utilizing 'rural' in search terms opened up to articles in the Appalachian region that weren't clearly defined in the article. Reviewers determined Appalachian status of the study through Appalachian Regional Commission list of Appalachian counties in comparison to study location [144]. Food access measures included two studies using USDA defined food-desert census tracts $[87,143]$ and others using participant self-reported perceived food-desert communities $[84,86$, 142], county-level number of business, grocery stores, convenience stores, food stores, average travel time to work [83], or an access score using probability of individuals using four types of restaurants [85]. Excess weight was determined by overweight and obesity or high BMI determined through county available, census, or self-reported data.

\section{Study Analyses}

The included studies were largely cross-sectional $[84,85,87,142,143]$ with one longitudinal study [142] and one county-level study at two time points $[83,86]$. Due to the crosssectional nature of the majority of studies included, descriptive and bivariate analyses were predominately used for demographic data, food access, and obesity measures. Regression models 
were used to identify confounding factors that may predict obesity in various studies [83-85].

This included percentage increases of obesity with changes such as a decrease in food access or increases with increasing number of food stores. One article utilized cluster analyses to cluster counties based on socioeconomic, demographic, and environmental variables to then use ANOVA to compare rates of obesity among their clusters [143]. Longitudinal studies used prepost changes in diet, access, behaviors via t test, correlations, and regression [83-87, 142, 143].

\section{Food Access}

Articles used in this review chose various routes of describing access prevalence due to studies utilizing county-wide data with a range of access. Slack et al, utilized USDA census-tract data and number of fast food restaurants per 1000 population to identify $17.3 \%$ of United States counties were defined as living in a food-desert [87]. Flynt et al. used USDA Food Environment Atlas to determine that $16.4 \%$ of counties within New York and Pennsylvania were low access [143]. For Schafft et al., authors used zip-code business patterns and GIS buffer zone of ten miles to determine that 45 school districts (18.5\%) were food-deserts [86]. All participants, in the study by Gufstafson et al., were stated to have labelled themselves as living in a food-desert, where their most accessible foods are from fast food chains [84]. Li et al. describes access in terms of a score including probabilities of students visiting a certain type (convenience, fast food, restaurant, supermarket) and those with a higher score are deemed healthier environments and thus, greater food access [85]. The average scores were found within the -1 to +1 range (total range -5.35 to 5.35), however authors recognized that areas with lower income and higher percentage of African Americans had a larger proportion in the -1 and lower scores [85]. Amarasinghe et al. utilized averages of county data to deem low access, built environments by showing the average total establishments ( $20.48 \pm 5.84$ per 1000 population), food stores 
(0.88 \pm 0.27 per 1000 population), eating and drinking places ( $1.38 \pm 0.64$ per 1000 population), and travel time to work $(26.12 \pm 5.77$ minutes) as access variables [83]. Lastly, in the only longitudinal intervention type of study, Dubotiwz et al. identified that from baseline to one-year post supermarket addition in a neighborhood, variables included in 'perceived access to health foods \%' (easy accessibility, choice, quality and cost to fruits and vegetables, whole grain products, and low fat products), all significantly improved in the intervention group [142]. Within a group of store 'users' most perceptions of access improved as compared to those nonusers. Improvements in dietary quality weren't improved in 'users' compared to 'non-users' [142].

Obesity and Food Access

As criteria for the review, each study included obesity measurements among their population with food access issues. Two similar studies showed that their population resided in a food-desert and/or rural area that also had high rates of obesity [84, 85]. Flynt et al. identified that large fringe or large central metropolitan counties had significantly lower rates of obesity as compared to suburban or rural clusters [143]. Likewise, Li et al. acknowledged that in a county with $>40 \%$ rates of obesity, there was a positive effect of using convenience stores and restaurants with weight status [85]. These results shifted when percentage of African American residents, median household income, and school distance to stores were included. Percent of African Americans and school distance were the only variables with a positive effect on weight status.

Two similar studies identified that with decreasing levels of food access among a population, obesity levels would increase [83, 85]. Amarasinghe et al. identified a one-unit increase in total number of food stores per thousand populations would decrease obesity by $2.6 \%$ 
[83]. Similarly, Schafft et al. found in both 1999 and 2001 data, residing a food-desert was a strong predictor of risk for overweight [86]. In the 1999 data each 1-point increase in percentage of population residing in a food-desert, there was an associated $.06 \%$ increase in student's risk of overweight [86]. Among Alabama students, Li et al. found convenience stores and restaurants had a significant positive association with weight status while supermarkets had a negative effect [85]. However, when controlling for demographic variables, these food places all had a negative association with weight status. In Dubowitz et al., with the introduction of a new supermarket, no significant change was seen with overall diet quality or weight status [142]. However, Gustafson et al. studied a county with obesity rates $>40 \%$ where although they were concerned with healthy eating, $67 \%$ and $65 \%$ of participants consumed 2 or less servings of fruits and vegetables per day, respectively [84]. Similarly, to Dubowitz et al. findings, although $15.8 \%$ of counties in the United States were found to be high-obesity regions, Slack et al. found that the food environment had no significant association with local obesity prevalence among all U.S. counties, which encompassed those regions with in Appalachia [87].

\section{DISCUSSION}

Food deserts, and thus food access, has been understudied in the health disparate region of Appalachia. With previous research identifying that this area has the highest prevalence of individuals overweight and obese, food access research plays a prominent role. This study aimed to understand the body of literature behind food access and obesity in the Appalachian region of the United States. Over 480 articles were reviewed and assessed for inclusion into this review. Ultimately, 6 peer-reviewed and 1 gray literature article met inclusion criteria, which demonstrates the minimal amount of research on food access/deserts and obesity across the Appalachian region. A large body of work focuses on urban sprawl and food deserts, food 
deserts across the United States, and the use of federal funding agencies within these communities (eg, SNAP-ed) [129, 145-148]. However, this is a disconnect in the research regarding rural, health disparate Appalachia. Within the current studies examined in this review, the majority conclude with statistical associations of increasing obesity levels among rural, fooddesert areas that have limited access. Those studies examining food access at a county or state wide level show increasing prevalence of obesity in these areas [83-86, 143] however in studies including all United States counties and urban Pennsylvania, those results were conflicting [87, 142]. Slack et al. found that within all United States counties, food access was not associated with obesity rates. Of the same background, in the urban Pennsylvania neighborhoods who received a new supermarket, BMI remained relatively stable and dietary quality didn't improve as one would expect [142]. However, this was the only intervention study that met the criteria for the review and results should be taken with caution.

The limited number of studies within this review highlights the need for further exploration of these disparities among this population. An updated study in 2010 from the USDA examining poverty and low access to foods identified that there had been very little change from 2006 to 2010 in distance to a supermarket [75]. Individuals with limited access to a vehicle improved over the years. Contrastingly, individuals in low-income areas with a distance more than 1-mile to a supermarket increased. Noteworthy that rural areas distance to supermarkets and income differ to urban areas: lower income individuals live closer to supermarkets than their moderate-to-high counterparts while this is found to be the opposite in rural locations. Authors follow this summary up by indicating that this study time frame was before policy makers began initiatives to improve food access in 2011 [75]. 


\section{Strengths and Limitations}

Due to variability amongst study measures for food access, conclusive comparisons between studies were unmanageable, and likewise impossible to complete a meta-analysis. A systematic review of food deserts and obesity across United States populations also saw a lack of connection in measurements of food access and obesity that rendered an incomplete conclusion to be drawn [149]. Minimal data and studies available on the topic renders it difficult to capture a full comprehensive look at food access and obesity among Appalachian residents. However, utilizing county and nationwide data allows for a broad picture of the issue in larger populations while smaller scale studies provided support to the understanding of personal an individual needs and perceptions of the populations being examined. Capturing more data in this capacity is important to the lifestyle and quality of life improvements in areas such as Appalachia. Further, the consideration of the populations beliefs and behaviors are vital when directing future interventions.

\section{CONCLUSION}

Our comprehensive systematic review provides support for the need of understanding and addressing the gap in food access literature and the impact on chronic disease such as obesity in the Appalachian region specifically. The reviewed articles here provide the support for delving into studying this specific rural population and move toward prospective interventions with a community-based participatory research approach. Future study recommendations to examine food access specifically in the heart of the Appalachian region of West Virginia along with access impacts within a population with obesity. 


\section{Declarations}

Ethics approval and consent to participate: Not applicable

Consent for publication: Not applicable

Availability of data and materials: Not applicable

Competing interests: The authors declare that they have no competing interests.

Funding: This work was supported by West Virginia University Experimental Station Hatch WVA00627 and WVA00641. The funding sponsors had no role in the design of the study; in the collection, analyses, or interpretation of the data; in the writing of the manuscript; or in the decision to publish the results.

Authors' contributions: Article search was completed by MLB. Inclusion review of articles completed by MLB and RLH. Final review of articles and tie breaking competed by MDO. Manuscript written by MLB, RLH, and MDO. All authors read and approved the final manuscript. 


\section{Chapter V: Bariatric Surgery Outcomes in Appalachia influenced by Surgery Type, Diabetes and Depression}




\title{
Abstract \\ Bariatric Surgery Outcomes in Appalachia influenced by Surgery Type, Diabetes and Depression
}

\author{
ML Barr ${ }^{1}$, RL Hagedorn ${ }^{1}$, LE Tabone ${ }^{2}$, SJ Cox ${ }^{3}$, C Brode $^{3}$, N Szoka $^{2}$, IM Olfert ${ }^{4}$, MD Olfert $^{1}$ \\ ${ }^{1}$ West Virginia University, Davis College of Agriculture, Natural Resources and Design, Division of Animal and Nutritional \\ Sciences in Department of Human Nutrition and Food; ${ }^{2}$ Department of Surgery, West Virginia University School of Medicine, \\ Morgantown, West Virginia; ${ }^{3}$ Department of Behavioral Medicine and Psychiatry, West Virginia University School of Medicine, \\ Morgantown, West Virginia; ${ }^{4}$ Department of Exercise Physiology, West Virginia University School of Medicine, Morgantown, \\ West Virginia
}

The most effective treatment for morbid obesity and its co-morbidities is bariatric surgery. However, in an area with the highest rates of these health disparities, there is no research examining a population of surgical patients and their weight loss success. Our objective was to examine demographics and surgical outcomes of the population including: weight, body mass index (BMI kg/m²), excess body weight (EBW), percent excess weight loss (\%EWL), Beck's Depression Inventory (BDI) and laboratory values (i.e., hemoglobin A1c (HbA1c), systolic and diastolic blood pressure). A retrospective electronic medical record (EMR) data extraction was performed on patients receiving bariatric surgery at a large tertiary academic medical center within Appalachia between 2013-2017. Descriptive statistics shown in means and standard deviations. Independent t-test, Wilcoxon Rank Sum and Spearman's Rho used for identifying significant relationships on \%EWL. Variables significantly related to \%EWL were used in ANOVA and ACOVA model building for examining relationship with \%EWL. Average patient population was $92.5 \%$ Caucasian, $79.3 \%$ female, $62.8 \%$ married, $45+11.1$ years old, and $75.8 \%$ receiving bypass surgery. Average $\%$ EWL from baseline to one year follow up was $68.5 \pm 18.4 \%$ $(n=224)$. In final descriptive models, surgery type, diagnosed diabetes, HbA1c and clinical depression were significant co-variates associated with \%EWL. Findings suggest patients completing surgery within an Appalachian region have successful surgical outcomes, as indicated by significant reductions of $>50 \%$ EWL regardless of other covariates. However, outcomes suggest consideration during bariatric programs for those with diagnosed diabetes and depression. Results will inform future prospective studies, along with specific interventions tailored to address unique needs of this population.

Keywords: obesity, bariatric surgery, Appalachia, outcomes

Abstract Word Count: 237

Manuscript Word Count: 2,144 


\section{INTRODUCTION}

The Appalachian region has had a well-established reputation of health disparities [133, 134]. The area has been among the highest rates of diabetes, obesity, mental health issues along with economic and infrastructure disparities $[23,133,150]$. Among the highest of these disparities, overweight and obesity rates have remained elevated among Appalachian residents. When combating obesity, behavior, dietary, or lifestyle, interventions are employed on a community-based level. However, for those suffering from morbid obesity $\left(\mathrm{BMI} \geq 40 \mathrm{~kg} / \mathrm{m}^{2}\right)$, which is over $6 \%$ of the United States population, behavioral interventions tend to fall short in combating the issue long-term or with only marginal weight improvements [6, 151-153]. Furthermore, in a region such as Appalachia, access to participants to implement interventions can be difficult due to their rural locality. Distances to health care facilities [68], lack of access to a vehicle, lack of support from family and providers, low educational attainment, perceptions of health [115] and specific cultural and family ties that can all impact lifestyle habits and impede health improvements. Solutions to contest these issues may be alleviated with a clinical intervention such as metabolic surgery.

Metabolic, or bariatric surgery, although poorly utilized by individuals meeting the criteria in the United States, has been deemed the most effective treatment for morbid obesity [3, 90, 113, 154, 155]. Primary bariatric procedures performed in the United States include laparoscopic gastric bypass and sleeve gastrectomy [3, 14, 15, 154, 156]. Between 2014 and 2016, total amount of surgeries in the United States increased from 193,000 to 216,000 with gastric bypass currently making up $18.7 \%$ and sleeve gastrectomy making up $58.1 \%[14,15]$. Noteworthy, across the same years, gastric bypass surgeries have declined $(-8.1 \%)$ while sleeve gastrectomy’s increased $(+6.4 \%)[14,15]$. Influential outcomes of bariatric surgeries such as 
significant reductions in excess body weight and declines or remission of co-morbidities (type 2 diabetes, improved quality of life, hypertension, gastrointestinal reflux disease, depression, and others), make bariatric surgery the most effective treatment for individuals with morbid obesity. However, in Appalachia, a region with peak obesity rates and related health disparities, there is a gap in the research regarding bariatric surgery patient populations, their surgical and related outcomes. An article by Bergmann et al. examined how rurality of surgery patients impacted their access to and outcomes of surgery [26]. Authors found that rural status, based on RuralUrban Commuting Areas, did not have a relationship with surgical weight outcomes or compliance with follow-up appointments [26]. A similar study by Mock et al. examined limited food budgets among bariatric patients to find a significant reduction in weight loss outcomes when on a limited budget at 3-months post-bariatric surgery, however that significance was not found at 12-months post-bariatric surgery [157]. These minimal studies bring about the question of other underlying correlations with baseline patient health, demographics, and behaviors that may be influencing outcomes. Understanding the impact health disparities make on the outcomes of metabolic surgery are poorly understood but vital to recognize.

The objective of the current study was to expand the research and knowledge base supporting bariatric surgery patients located in a health disparate region of Appalachia, and their surgical outcomes of bariatric surgery. To our knowledge, this is the first study to comprehensively describe a large Appalachian bariatric surgery patient population and their surgical outcomes.

\section{METHODS}

Approval to conduct research was obtained via West Virginia University Institutional Review Board (\#1611355277) in March 2017. Data capturing through a retrospective chart 
review of bariatric surgery patients was conducted. A patient query was completed on all patients ( $\mathrm{n}=672), 18$ years and older, who had completed all required clearance and received gastric bypass or sleeve gastrectomy surgery between 2013-2017. Researchers completed required HIPAA training for clearance into patient electronic medical records (EMR). Upon EMR clearance, researchers were trained on patient chart navigation and reliability of data capturing. Data collection took place between March-September 2017. Retrieval of information was found in forms of both electronically entered data as well as scanned and uploaded PDF files. All data were entered into a HIPAA compliant RedCap survey and downloaded onto secure hard drive for further data analyses. A second data pass was completed on $2 \%$ of charts to ensure data reliability of $85 \%$.

\section{Study Measures}

Patient EMR data were captured at patient's initial visit to the bariatric clinic. Baseline demographics, anthropometrics, labs, health history, family history, nutrition habits, and psychological testing scores were recorded. Changes in anthropometrics obtained through follow-up visits logged in patient EMR. Main outcome measure was percent excess weight loss (\%EWL) from baseline to one-year follow up. \%EWL was calculated as (initial weight - 1-year follow-up weight) / (initial weight - weight at BMI of 25) x 100. Within previous bariatric literature, and a criteria utilized in this study, a $\% \mathrm{EWL}$ of $50 \%$ is loosely considered successful loss after one-year post bariatric surgery. Predictor variables used include surgery type, age, gender, ethnicity, education, marital status, type 2 diabetes, percent follow-up attendance (number of follow-ups attended/determined by amount of follow-ups possible multiplied by 100), diagnosed high blood pressure, diagnosed depression, and cooking responsibilities. In addition, co-morbidities included in analyses were EMR reported diabetes, hypertension and 
depression included as they typically are found simultaneously with obesity. Additionally, to the subjective chart declared diabetes, hypertension, and depression, HbA1c lab values, blood pressure values, and BDI scores taken from patient EMR data were used for objective measures of the co-morbidities.

\section{Statistical Analyses}

All analyses were performed using SAS (SAS®, Version 9.3) [158] and JMP (JMP®, Version Pro 13) [159]. Data were examined for variable specific outliers greater than 3 standard deviations above the mean, which were removed prior to analyses ( $\mathrm{n}=10$ outliers). Differences were tested between baseline measures of surgery groups (gastric bypass vs. sleeve gastrectomy). Independent t-test was used for assessing association between \%EWL and variables with two groups (Surgery type, Gender, Ethnicity, Education level, State, Marital Status, Diabetic, Diagnosed Hypertension, Diagnosed Depression). ANOVA was used testing for testing hypothesis of equality among more than two groups of categorical variables (education and marital status), and Spearman's Rho was used for examining correlation of \%EWL with continuous variables (age, \% Attended follow-up, Systolic Blood Pressure, Diastolic Blood Pressure, HbA1c and BDI). Fisher's Exact test was used for cell sizes < five. Significant correlations of $\mathrm{p}<.05$ were included in next step of building ANOVA and ANCOVA models to test relationship between \%EWL and categorical and continuous predictor variables. Model assumptions of homoscedasticity, normality, and lack of multicolinnearity were assessed. Cook's D influence was set at 0.0227 (4/n). Data with an influence greater than Cook's D were removed from analysis $(n=7)$. Effect size in models were assessed by change in adjusted $\mathrm{R}^{2}$ values to calculate variance of each variable when placed in the model. ANOVA models computed using PROC MIXED procedure Type III Sum of Squares (SS) in SAS (partial) and ANCOVA models 
computed using PROC GLM procedure Type I SS (sequential). In partial SS, the hypothesis to be tested are invariant to the ordering of effects in the model. In sequential SS, order of effects matters and latter effects are being adjusted to previous variable effects in the model. For examples, effect of surgery type on \%EWL is adjusted to HbA1c on \%EWL. Effect size in final models were assessed by change in adjusted $\mathrm{R}^{2}$ values to calculate variance of each variable when placed in the model.

\section{RESULTS}

A total of 582 patient charts were reviewed for data extraction. Thirty-five charts and corresponding data were removed due to type of surgery being a gastric band or revision of previous surgery leaving a sample of $n=547$. Bariatric surgery patients receiving surgery between 2013-2017, in an Appalachian centered clinic, were predominately 92.5\% Caucasian, 79.3\% female, $62.8 \%$ married, $45 \pm 11.1$ years old, and $75.8 \%$ receiving bypass surgery. When stratifying the population by surgery type, similar demographic breakdowns were seen. No significant demographic differences were found among between two surgery type groups (Table 1). Bypass patients had average baseline weight of $299.9 \pm 64.0$ pounds, BMI of $48.5 \pm 8.1 \mathrm{~kg} / \mathrm{m}^{2}$, and EBW of $146.3 \pm 55.5$ pounds. Sleeve patients had average baseline weight of $305.0 \pm 59.1$ pounds, BMI of $49.2 \pm 8.0 \mathrm{~kg} / \mathrm{m}^{2}$, and EBW of $150.1 \pm 52.7$ pounds. Among population EMR reported baseline co-morbidities, diagnosed diabetic $(n=174)$, diagnosed depressed $(n=259)$, and diagnosed hypertensive patients $(n=304)$ were examined. Among these co-morbidities, no significant differences were found among groups at baseline (Table 1; all p>.05). Likewise, no significant differences between surgery groups were found among objective measures of HbA1c, blood pressure, and BDI scores (all p-values >.05). Percent follow up at 1-year appointment was $47 \%$ for bypass $(n=196)$ and $30 \%$ for sleeve patients $(n=40)(\mathrm{p}<.001)$. Average \%EWL among 
whole sample was $68.80 \pm 18.92 \%$ and percent body weight loss was $33 \pm 8.68 \%(n=224)$ with

bypass patients achieving higher \%EWL than their sleeve counterparts $(\mathrm{p}<.0001)$.

Table 1: Descriptive Statistics, by Surgery Type, of Appalachian Bariatric Surgery Patients between 2013-2017 Receiving Surgery in West Virginia

\begin{tabular}{|c|c|c|c|c|c|c|}
\hline \multicolumn{7}{|c|}{ Demographics $(n=547)$} \\
\hline \multirow[t]{2}{*}{ Sex } & Male & 407 & $81(20)$ & 128 & $29(22.7)$ & 0.5012 \\
\hline & Female & & $326(80)$ & & $99(77.3)$ & \\
\hline \multirow[t]{2}{*}{ State } & West Virginia & 406 & $326(80.3)$ & 128 & $104(81.3)$ & 0.8121 \\
\hline & Other & & $80(19.7)$ & & $24(18.7)$ & \\
\hline \multirow[t]{2}{*}{ Race } & Caucasian only & 407 & $376(92.4)$ & 127 & $118(92.9)$ & 1.0000 \\
\hline & Other & & $31(7.6)$ & & $9(7.1)$ & \\
\hline \multirow[t]{4}{*}{ Education } & High School or Less & 386 & $149(38.6)$ & 125 & $40(32.0)$ & 0.4079 \\
\hline & Some College or Associates & & $131(33.9)$ & & $44(35.2)$ & \\
\hline & Bachelors & & $67(17.4)$ & & $29(23.2)$ & \\
\hline & Post Grad, Masters, PhD, Law & & $39(10.1)$ & & $12(9.6)$ & \\
\hline \multirow[t]{4}{*}{ Marital } & Single & 377 & $65(17.2)$ & 117 & $22(18.8)$ & 0.8468 \\
\hline & Married & & $235(62.3)$ & & $74(63.2)$ & \\
\hline & Divorced & & $53(14.1)$ & & $16(13.7)$ & \\
\hline & Other & & $24(6.4)$ & & $5(4.3)$ & \\
\hline \multicolumn{2}{|c|}{ Baseline Comorbidities } & $\mathrm{n}$ & $\%$ & $\mathrm{n}$ & $\%$ & \\
\hline & Diabetes & 138 & 62.6 & 36 & 30.0 & 0.1414 \\
\hline & Hypertension & 227 & 64.9 & 77 & 68.1 & 0.5226 \\
\hline & Depression & 184 & 53.0 & 67 & 59.8 & 0.2091 \\
\hline \multicolumn{7}{|c|}{ Baseline Measures } \\
\hline & Height (in) & 407 & $65.7(3.7)$ & 127 & $66.0(3.7)$ & 0.2308 \\
\hline & Weight (pounds) & 407 & $300.3(64.2)$ & 127 & $306.8(58.3)$ & 0.1312 \\
\hline & $\operatorname{BMI}\left(\mathrm{kg} / \mathrm{m}^{2}\right)$ & 407 & $48.5(8.1)$ & 127 & $49.4(7.9)$ & 0.2443 \\
\hline & EBW (pounds) & 407 & $146.7(55.6)$ & 127 & $151.7(52.3)$ & 0.2344 \\
\hline & HbA1c & 195 & $6.1(1.1)$ & 64 & $6.1(1.1)$ & 0.6093 \\
\hline & Systolic Blood Pressure & 407 & $126.7(13.7)$ & 123 & $128.7(13.7)$ & 0.1053 \\
\hline & Diastolic Blood Pressure & 407 & $78.0(8.3)$ & 123 & $77.5(7.8)$ & 0.4733 \\
\hline & Beck's Depression Inventory & 303 & $10.4(9.0)$ & 105 & $9.4(105)$ & 0.5659 \\
\hline \multicolumn{7}{|c|}{ Year-One Measures } \\
\hline & Weight (pounds) & 188 & $199.2(45.3)$ & 36 & $227.0(51.0)$ & $0.0006^{*}$ \\
\hline & BMI $\left(\mathrm{kg} / \mathrm{m}^{2}\right)$ & 188 & $32.8(5.9)$ & 36 & $37.4(7.6)$ & $0.0004 *$ \\
\hline & EBW (pounds) & 188 & $47.1(37.5)$ & 36 & $74.2(46.3)$ & $0.0003^{*}$ \\
\hline & $\%$ EWL & 188 & $71.8(16.8)$ & 36 & $51.1(16.6)$ & $<.0001 *$ \\
\hline \multicolumn{7}{|c|}{$\begin{array}{l}\text { Independent t-test was used for assessing association between \%EWL and variables with two groups (Surgery type, Gender, } \\
\text { Ethnicity, Education level, State, Marital Status, Diabetic, Diagnosed Hypertension, Diagnosed Depression). ANOVA was used } \\
\text { testing for testing hypothesis of equality among more than two groups of categorical variables (education and marital status), and } \\
\text { Spearman's Rho was used for examining correlation of \%EWL with continuous variables (age, \% Attended follow-up, Systolic } \\
\text { Blood Pressure, Diastolic Blood Pressure, HbA1c and BDI). Fisher's Exact test used for cell sizes }<5 \\
\text { *Significant at }<0.05 \text { level }\end{array}$} \\
\hline
\end{tabular}


Bivariate analyses identified 6 of 15 dependent variables of interest had significant associations ( $\mathrm{p}<.05)$ with \%EWL (Table 2). Surgery type, age, diagnosed diabetes, diagnosed depression, and HbA1c values all found to have a significant association with \%EWL (Table 2; all $\mathrm{p}<.05)$. As HbA1c and EMR declared diabetes were both significantly related to \%EWL, separate models were used to display their effect as they both describe abnormal glucose control. Variables were utilized in further model building to test the influence of each significant identified variable on predicting \%EWL at one-year post-bariatric surgery. In a preliminary full screening model, surgery type, EMR reported diagnosed diabetes, depression, and hypertension, and $\mathrm{HbA} 1 \mathrm{c}$ value remained significant (Table 2). To further analyze variance of \%EWL caused by remaining significant variables. To show variance via changes in adjusted $\mathrm{R}^{2}$ across significantly correlated variables, five models listed below were developed (Table 3). Both HbA1c and Diagnosed Diabetes measured blood glucose control status and thus, separate models were designed for both:

Model 1: \%EWL = surgery type

Model 2: $\% \mathrm{EWL}=$ surgery type + Diagnosed Diabetes

Model 3: $\% \mathrm{EWL}=$ surgery type $+\mathrm{HbA1c}$

Model 4: $\% E W L=$ surgery type + Diagnosed Diabetes + Diagnosed Depression

Model 5: \%EWL $=$ surgery type $+\mathrm{HbA} 1 \mathrm{c}+$ Diagnosed Depression

Model 1 examines the main effect of surgery alone on \%EWL $(F(1,222)=45.72$, $\mathrm{p}<.0001)$. Figure 1 shows significantly higher \%EWL in bypass patients $(72.16 \pm 17.44 \%$ EWL $)$ compared to sleeve $(51.15 \pm 16.62 \% \mathrm{EWL})$ at one-year follow-up ( $\mathrm{p}<.001)$. Effect of EMR diagnosed diabetes, surgery and interaction between diabetes and surgery on \%EWL is depicted in Model 2. Type 3 fixed effects for both surgery $(F(1,199)=44.95, \mathrm{p}<.0001)$ and EMR diagnosed diabetes were significant $(\mathrm{F}(1,199)=15.49, \mathrm{p}=.0001)$. Figure 2 represents the main effect of surgery type although interaction between the two were not significant $(F(1,199)=$ 0.38, $\mathrm{p}=0.5368$ ). Model 3 examines surgery type, EMR diagnosed diabetes, and EMR diagnosed 
depression and their interactions. Type 3 fixed effects identify significance among surgery type $(\mathrm{F}(1,170)=15.88, \mathrm{p}<.0001)$, diagnosed diabetes $(\mathrm{F}(1,170)=5.59, \mathrm{p}=.0192)$, as well as diagnosed depression $(\mathrm{F}(1,170)=8.37, \mathrm{p}=.0043)$. All interaction terms between each combination of surgery, diabetes, and depression were found as non-significant ( $\mathrm{p}>.05)$.

Table 2: Values between percent excess weight loss and other possible associated variables for entry into ANOVA and ANCOVA models

\begin{tabular}{llrr}
\hline Success Variable & Covariates & Test Effect & p-value \\
\hline \%EWL & & & \\
\hline \multirow{2}{*}{ Categorical } & Surgery type & -6.900 & $<.0001^{* *}$ \\
& Gender & 1.274 & 0.2070 \\
& Ethnicity & 0.397 & 0.6973 \\
& Education level & 0.455 & 0.7141 \\
& State & -0.106 & 0.9160 \\
& Marital Status & 1.966 & 0.1202 \\
& Diabetic & -4.015 & $<.0001^{* *}$ \\
& Diagnosed Hypertension & -2.235 & $0.0274^{*}$ \\
& Diagnosed Depression & -2.913 & $0.0040^{* *}$ \\
Continuous & Age & -0.258 & $<.0001^{* *}$ \\
& \% Attended follow-up & -0.520 & 0.4375 \\
& Systolic Blood Pressure & -0.752 & 0.2625 \\
& Diastolic Blood Pressure & -0.012 & 0.8545 \\
& HbA1c & -0.313 & $0.0002^{* *}$ \\
& BDI & -0.005 & 0.9469 \\
\hline
\end{tabular}

Independent t-test was used for assessing association between \%EWL and variables with two groups (Surgery type, Gender, Ethnicity, Education level, State, Marital Status, Diabetic, Diagnosed Hypertension, Diagnosed Depression). ANOVA was used testing for testing hypothesis of equality among more than two groups of categorical variables (education and marital status), and Spearman's Rho was used for examining correlation of \%EWL with continuous variables (age, \% Attended follow-up, Systolic Blood Pressure, Diastolic Blood Pressure, HbA1c and BDI).*Significant at $<0.05$ level $* *$ Significant at $<0.01$ level

Among models 4 and 5 (Table 4), EMR diagnosed diabetes was replaced with objective measure of HbA1c blood glucose control. Model $4(\mathrm{~F}(3,133)=9.46, \mathrm{p}<.0001)$, examined main effect of surgery on \%EWL while controlling for HbA1c. Model 4 had an R-squared value of 0.31 and found both surgery type and HbA1c had significant relationship with \%EWL (p's<.0001), however, interaction term between surgery and HbA1c was not significant ( $p=.07)$. Model $5(\mathrm{~F}(7,110)=9.46, \mathrm{p}<.0001)$ with an R-squared value of 0.39 , examined main effect of surgery type on \%EWL while controlling for HbA1c and EMR diagnosed depression. Variables 
of surgery type $(\mathrm{p}<.0001), \mathrm{HbA1c}(\mathrm{p}<.0001)$, and diagnosed depression $(\mathrm{p}=.0229)$ were all significant, however all interaction combinations were not statistically significant ( $\mathrm{p}>.05)$.

\section{DISCUSSION}

In our study population of Appalachian bypass and sleeve bariatric surgery patients, when examining excess weight loss one-year post-surgery, outcomes were impressive by reaching and exceeding those of current literature. Within each ANOVA and ANCOVA model, figures depicted sleeve patients typically having less \%EWL than bypass patients. However, when looking at both diabetes and depression, depiction of \%EWL were lower when having a diagnosed of these co-morbidities. However, as we didn't find significant interactions between our variables in models, which limits the ability to specify that those with co-morbidities had lower amount of \%EWL. However, we were able to identify that each variable separately (surgery type, diagnosed diabetes, HbA1c, and diagnosed depression) impact \%EWL. Generally, those receiving sleeve surgery, or being diagnosed with diabetes or depression, or having a higher HbA1c test at baseline had lower \%EWL. Contrastingly, those receiving bypass, or nondiagnosed with diabetes or depression, or having a lower HbA1c value at baseline had greater $\%$ EWL at one-year follow-up. Our data seems to be both similar and contrasting to those of nationwide numbers. Various studies and reviews identify bariatric surgery as aiding in the success of $40-71 \%$ EWL post-surgery [156]. Specifically, with diabetic patient receiving sleeve gastrectomy, patients had a 47\% EWL which is similar to our findings [160]. The well-known Swedish Obese Subject (SOS) study examined longitudinal weight loss at 20-30\% in 2 years $[161,162]$. This population had a larger cohort of bypass patients while similarly to a 2003-2015 registry report by the International Federation for Surgery for Obesity and Metabolic Disorders, $49.4 \%$ received gastric bypass followed by $40.7 \%$ receiving sleeve gastrectomy. Weight loss at 
one-year follow-up in this population was 30\%. A similar study by Shah et al. examined retrospective data of bypass and sleeve patients. Outcomes of $>50 \%$ EWL was seen more frequently in those patients who had lower initial BMI, absence of type 2 diabetes, and underwent bypass surgery [163]. Our population data shows similar and exceeding results as compared to these listed studies and national averages for percent excess body weight loss one year after surgery. With this study being the first to our knowledge to examine an Appalachian centered population, more work is warranted on solidifying these results.

\section{Limitations}

Due to the retrospective nature of data retrieval, some data could not be captured through patient EMR. A significant amount of data was in forms of hand written copies of PDF documents scanned into patient charts. Consequently, illegibility of writing led to areas of incomplete data. Further, our patient population was largely Caucasian females who received bypass surgery. Of these patients a significantly higher amount of bypass patients returned for one-year follow up as compared to sleeve patients. However, this population demographic is largely representative and similar to that of the nation's bariatric surgery demographic breakdown.

\section{CONCLUSION}

In summary, this study found that although patients may reside in a health disparate location such as Appalachia, metabolic surgeries are still successful for achieving significant weight loss after one-year follow-up. Although, consideration needs to be taken when supporting individuals with obesity related co-morbidities such as diabetes and depression. Therefore, it is recommended that health practitioners/public health experts endorse metabolic surgery for populations who are morbidly obese, specifically in Appalachian regions, as well as support 
individuals with co-morbidities with additional resources for success. However, due to limited longitudinal data regarding this population, future research examining success of behavioral and dietary patterns changes as well as co-morbidity resolution are warranted. 
Table 3: Models and Figures 1-3: ANOVA model building and figures of surgery, diabetes, and depression relationship with $\%$ EWL outcome

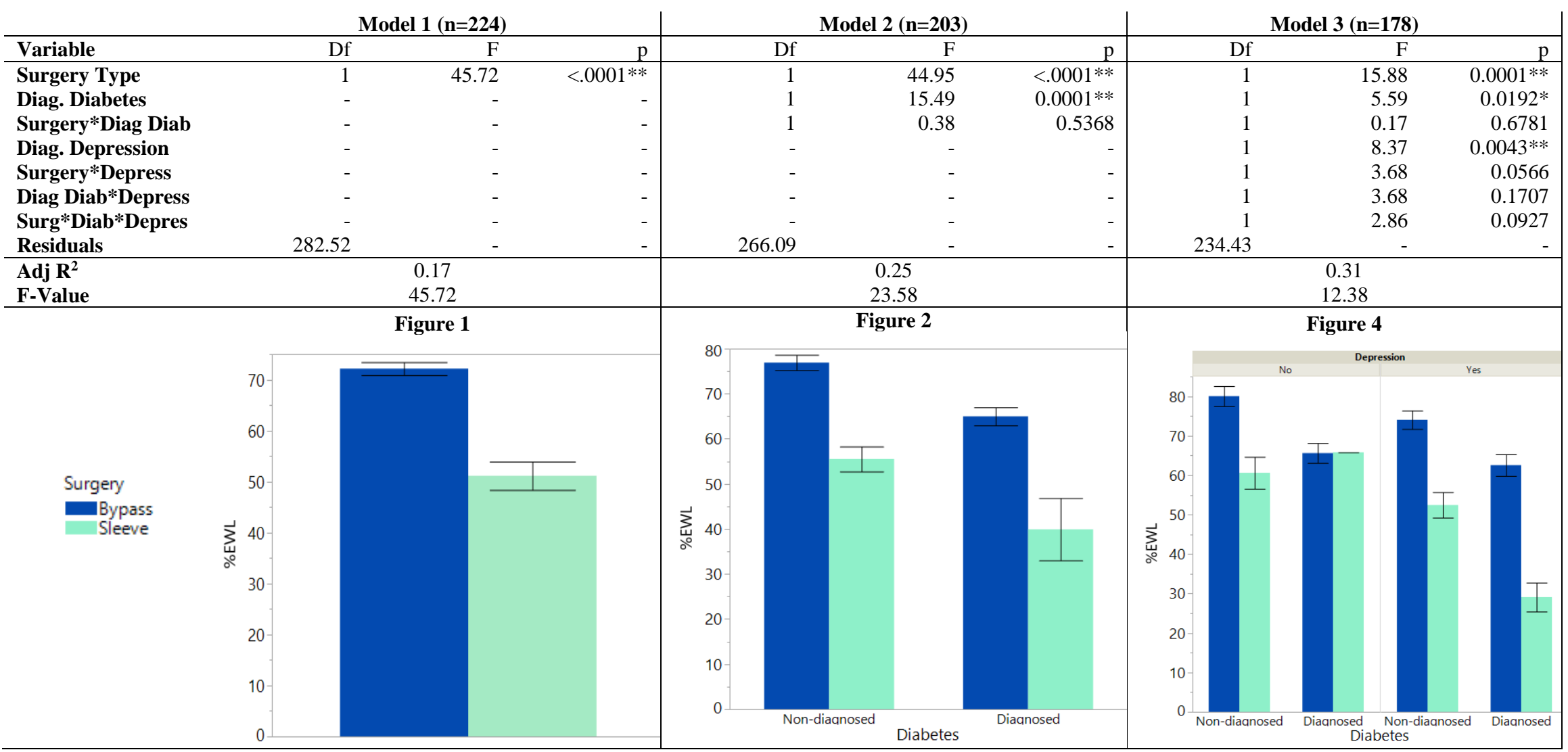

Model building through ANOVA analyses examining main effect of surgery type (Model 1; Figure 1). Model 2 and Figure 2 depict main effect of surgery type with diagnosed diabetes as well as the interaction term. Model 3 and Figure 3 includes variables of Model 2 with the additional effect of diagnosed depression and interaction terms between surgery type, diabetes, and depression.

* Significance level of $<.05$

$* *$ Significance level of $<.01$ 
Table 4: Models and Figures 4 and 5: ANCOVA model building and figures of surgery, HbA1c, and depression relationship with \%EWL outcome

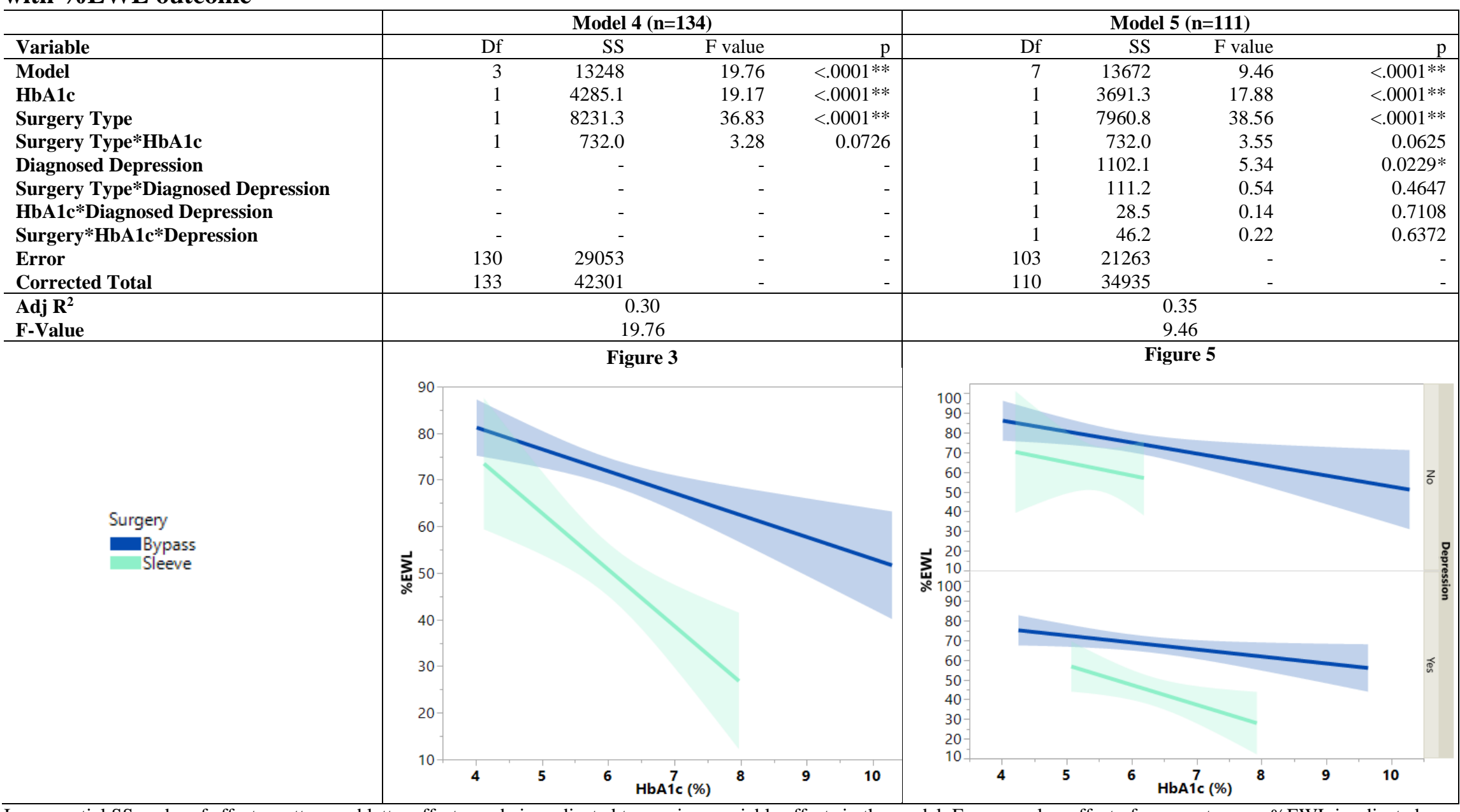

In sequential SS, order of effects matters and latter effects are being adjusted to previous variable effects in the model. For examples, effect of surgery type on \%EWL is adjusted to HbA1c on \%EWL. Model 4 and Figure 4 depict main effect of surgery type with covariate HbA1c (Hemoglobin A1c) values as well as their interaction. Model 5 and Figure 5 includes co-variates of Model 4 with the additional co-variate effect of diagnosed depression and interaction terms between surgery type, HbA1c, and depression.

*Significance level of $<.05$

$* *$ Significance level of $<.01$ 


\section{Chapter VI: Food Access Ranking Score among West Virginia Bariatric Surgery \\ Patients}




\title{
Abstract \\ Successful Weight Loss after Bariatric Surgery Regardless of Food Access Ranking Score in West Virginia
}

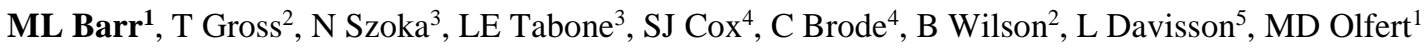 \\ ${ }^{1}$ West Virginia University, Davis College of Agriculture, Natural Resources and Design, Division of Animal and Nutritional Sciences in Department of Human \\ Nutrition and Food; ${ }^{2}$ Department of Geology and Geography, Eberly College of Arts and Science ; ${ }^{3}$ Department of Surgery, West Virginia University School of \\ Medicine, Morgantown, West Virginia; ${ }^{4}$ Department of Behavioral Medicine and Psychiatry, West Virginia University School of Medicine, Morgantown, West \\ Virginia; ${ }^{5}$ Department of Internal Medicine, West Virginia University School of Medicine, Morgantown, West Virginia
}

In addition to having highest rates of obesity, diabetes, and hypertension, West Virginia Appalachian population has limited food access that may contribute to the prevalence of obesity and potentially mitigate treatments of obesity. This research aimed to identify food access within a cohort of metabolic surgery patients in an Appalachian area, specifically West Virginia. A retrospective data extraction of patients receiving bariatric surgery between 2013-2017 was performed. Variables collected included preoperative weight, demographics, lifestyle and dietary behaviors, and geographical location information. Patient geographical location was identified for West Virginia residing patients through Geographic Information Systems (GIS) to calculate food accessibility. Patients were given a food access ranking score (FARS) between 0 (low food access) and 4 (high food access) based on four criteria of quantity, quality, income, and vehicle access. We examined significant relationships of FARS with patient anthropometrics, demographics, and dietary and lifestyle factors. Patients were predominately 45-year-old, married (60.5\%), Caucasian (92.4\%), females (77.8\%), who received bypass surgery (75.9\%). Average FARS for subjects was $1.67 \pm 0.73$. The highest proportion of patients were located within FARS between low and moderate-low (72.6\%). Significant correlations were found among those that were in the minority ethnicity, had a family history of obesity, and were clinically depressed. Due to the homogenous nature of our population, levels of FARS saw similar initial weight before surgery and weight loss after surgery. Those that were nonCaucasian, had diagnosed depression, and those without a family history of obesity were found to be in the lower FARS categories. Future studies examining mixed-method approaches to identify patient perceptions of food access in this population are warranted to understanding the impact that food access is making bariatric surgery outcomes in this health disparate population.

Keywords: food access, obesity, Appalachia, bariatric surgery, health disparate, rural

Abstract Word Count: 284

Manuscript Word Count: 3,224 


\section{INTRODUCTION}

West Virginia has the highest prevalence of obesity (37.7\%) and weight related comorbidities, including diabetes (14.5\%), and hypertension (42.7\%) in the United States [6-8, 23, 46, 69, 164, 165]. In addition, the locality of the state, within central Appalachian, has unique influences on the food environment and thus, access [23, 46, 83, 117, 166]. The United States Department of Agriculture's (USDA) definition of a food desert is areas of the country void of fresh fruit, vegetables, and other healthful whole foods [12, 13]. Lack of grocery stores, farmers' markets, and healthy food providers are evidence of these food deserts [12, 13]. In addition, the USDA employs the criteria of (1) low income and (2) low access to determine United States areas of food deserts. Collaborative work nationwide has shown a significant association between increased rates of obesity with low food access [83-87, 142, 143]. These results are prevalent largely in rural areas and those with a larger amount of minority populations [85]. Specifically, within rural areas such as Appalachia, obesity and food access have been minimally investigated. One study of West Virginia census data found that total number of food stores, business establishments, and mean travel time to work increased rates of obesity among the population [83]. The limited food access in these areas are in part due to rural locality, lower income in the state and lack of vehicle access [74, 83, 145, 167-169]. As dietary change is a common recommendation for weight loss, for those in a health disparate population with limited access to food, following a prescribed or suggested dietary pattern for health purposes may be difficult to achieve and near impossible to sustain [170]. These factors may contribute to the prevalence of obesity and potentially mitigate the treatments for obesity.

A target population needing to follow a specific dietary regimen are post-bariatric surgery patients residing in these food-desert areas. As bariatric surgery is the most effective treatment 
for morbid obesity (Body Mass Index of $>40 \mathrm{~kg} / \mathrm{m}^{2}$ or $>35 \mathrm{~kg} / \mathrm{m}^{2}$ with comorbidities) $[3,90,113$, $154,155]$, those receiving the surgery in the top ranking state of obesity, West Virginia, are underrepresented within the literature [27]. Lifestyle adjustments after bariatric surgery should change to following a lifelong, healthful, nutritious diet. Therefore, to sustain lifestyle change, access to fresh, healthy, nutritious foods at affordable prices is vital.

The USDA defines a food desert as "areas of the country void of fresh fruit, vegetables, and other healthful whole foods" $[75,76]$. This definition specifically uses lack of grocery stores, farmers' markets, and healthy food providers as evidence of these food deserts $[75,76]$. These data are combined with US Census data to create a food desert map in the United States. Criteria for these measured areas of food deserts include low income areas (median household income $<80 \%$ of state median income or poverty rate of $\geq 20 \%$ ) and low access areas (proximity to a grocery store such as $>1$ mile in urban areas and $>10$ miles in rural) [75-79]. The USDA defines a grocery store with the minimal criteria as one that sells a wide variety of products [75-79]. Further, low access communities are areas also defined by at least 500 persons or $33 \%$ of a census tract's population live more than one mile from a supermarket (10 miles if nonmetropolitan tract) [75-79]. All of these criteria are used to create binary sets for each census tract. However, the USDA definition is void of an important component of understanding the ‘quality' of food retailers.

The objective of the current study was to examine food access among West Virginia bariatric surgery patients and its correlation with demographic, health history, dietary behaviors, and excess body weight loss percentage one-year after surgery. To our knowledge, this is the first published work looking at this novel approach to capturing a more comprehensive look at food access by incorporating quantity, quality, income, and vehicle transportation access. 


\section{METHODS}

Approval to conduct research was obtained via West Virginia University Institutional Review Board (\#1611355277) in March 2017. Data collection was achieved through a retrospective chart review of bariatric surgery patients. A comprehensive inclusion patient identification was done by a patient query of all bariatric surgery patients $(n=672), 18$ years and older, who had completed all required clearance and received gastric bypass or sleeve gastrectomy surgery between 2013-2017. All researchers completed required HIPAA training for clearance into patient electronic medical records (EMR). Upon EMR clearance, researchers were trained on patient chart navigation and reliability of data capturing. Data collection took place between March-September 2017. Retrieval of information was in found in forms of both electronically entered data as well as scanned and uploaded PDF files. All data was entered into a HIPAA compliant RedCap survey and downloaded onto secure hard drive for further data analyses. A second data pass was completed on $2 \%$ of charts to ensure data reliability of $85 \%$ or higher. Demographics and baseline anthropometrics and labs, health history, family history, nutrition habits, and psychological testing scores were captured via EMR. Main outcome measure was percent excess body weight loss (\%EWL) from baseline to one-year follow up. Food Access determined through Geographic Information Systems (GIS) was used as main predictor.

\section{Food Access Measures}

The current study utilizes a novel Food Access Ranking Score (FARS) developed by WV FOODLINK GIS experts $[117,118]$. Due to the exclusiveness of the map to the state of West Virginia, only patients residing in the state were included in further analyses $(\mathrm{n}=369)$. FARS is based on four weighted variables to illustrate the complexity of food access. This map utilizes census block group scales to calculate food access as compared to the USDA census tract usage. 
The four variables included in the Food Access Ranking Score (FARS) are (1) quality of retailers, (2) quantity of retailers, (3) income of resident, and (4) vehicle access for transportation.

\section{Table 1: Food Access Ranking Score (FARS) Description}

\begin{tabular}{ll} 
Variable & Description \\
\hline Quantity of Retailers & $\begin{array}{l}\text { Calculated a score for each census block group based upon the presence of } \\
\text { absence of a type of retailer and was normalized to create a weighted variable } \\
\text { between } 0 \text { and } 1\end{array}$ \\
Quality of Retailers & $\begin{array}{l}\text { Calculated by multiplying the number of retailers in each category (SNAP and } \\
\text { WIC) times the quality of the retailer and then divided by the highest score to } \\
\text { create a normalized weighted variable between } 0 \text { and } 1\end{array}$ \\
Income of Resident & $\begin{array}{l}\text { Census block groups were given a score of } 0 \text { or } 1 \text { based upon the median } \\
\text { household income being above or below } 80 \% \text { of the } \text { national household median } \\
\text { income as it more accurately reflects purchasing power }\end{array}$ \\
Vehicle Access & $\begin{array}{l}\text { USDA data and disaggregated from the census tract scale to the census block } \\
\text { group scale. Tracts that had high vehicle access were given a } 1 \text { and tracts with } \\
\text { low vehicle access were given a 0 }\end{array}$ \\
\hline
\end{tabular}

The state of WV requires stores to meet criteria to be able to participate in federally funded programs such as Supplemental Nutrition Assistance Program (SNAP-P = SNAP plus Produce) and Women, Infants and Children (WIC) which plays a role in our quality and quantity variables. The quantity variable (1) calculated a score for each census block group based upon the presence of absence of a type of retailer and was normalized to create a weighted variable between 0 and 1 $\left(\right.$ Quantity Score Calculation $\left.=\left(\mathrm{WIC}^{*} 1\right)+\left(\mathrm{SNAP}^{*} 0.2\right)+(\mathrm{SNAPP} * 0.5) / 1.7\right)$. The quality variable (2) was calculated by multiplying the number of retailers in each category (SNAP and WIC) times the quality of the retailer and then divided by the highest score to create a normalized weighted variable between 0 and $1($ Quality Ranking $($ highest score possible $=7.2)=$ $\left(\left(\# \mathrm{WIC}^{*} 1\right)+(\# \mathrm{SNAP} * 0.2)+(\# \mathrm{SNAP}-\mathrm{P} * 0.5)\right) /$ 7.2). The income variable (3) was calculated differently from the USDA calculations as well. Rather than using the state median household income, census block groups were given a score of 0 or 1 based upon the median household income being above or below $80 \%$ of the national household median income as it more 
accurately reflects purchasing

power ${ }^{1}$. Finally, the vehicle access

variable (4) was taken from USDA

data and disaggregated from the

census tract scale to the census

block group scale. Tracts that had

high vehicle access were given a 1

and tracts with low vehicle access

were given a 0 . The FARS was

then calculated by summing the

weighted variables into a final
Figure 1: WV FOODLINK map of food access among West Virginia

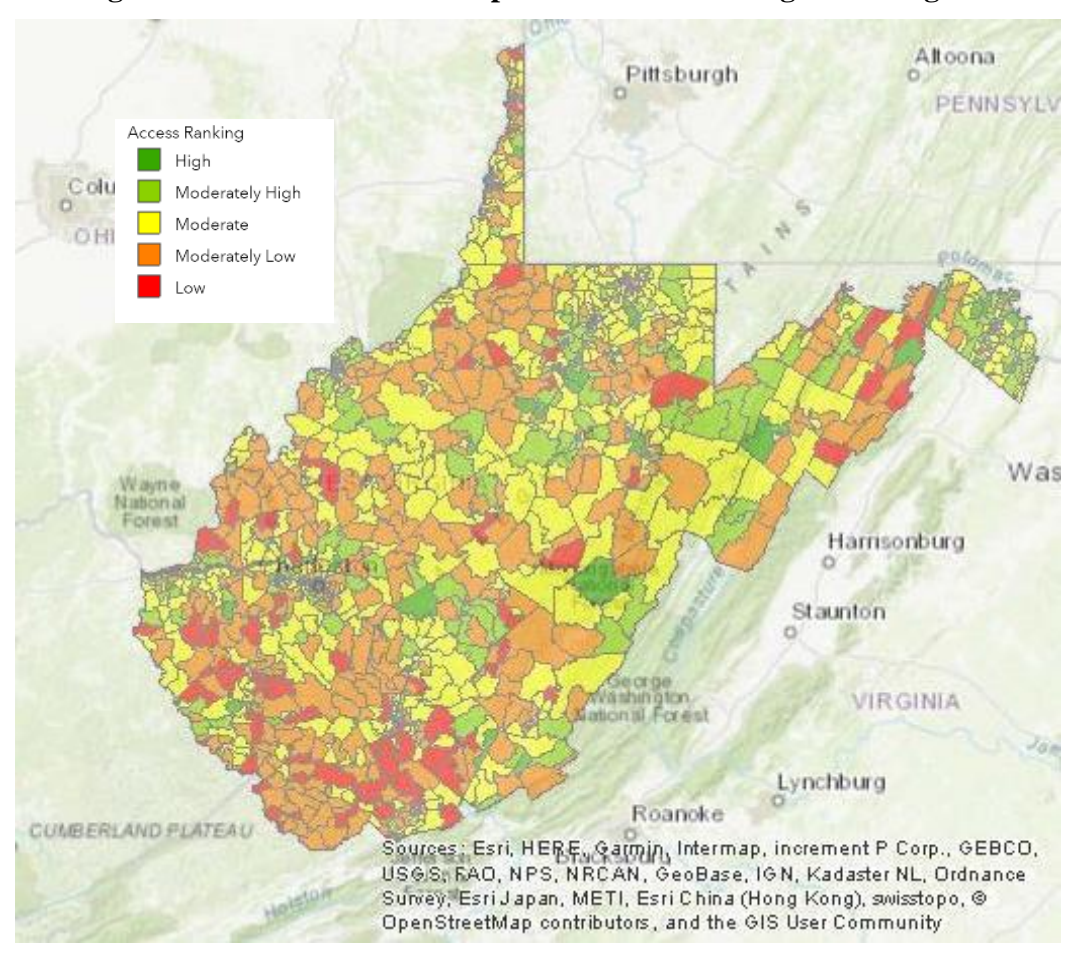

access score between 0 and 4 . Figure 1 represents FARS by heat map color coding. Block groups that scored a zero are shown in red and have little to no food access (do not have access to a quality store of any kind, they have low incomes and low vehicle access), areas in yellow fall in the moderate range of 1 to 2 , and groups that scored between a 3 and 4 are shown in green (have each type of quality store, more than one of some of them have household incomes above the national median, and have access to a vehicle).

\section{Health History and Behavior Measures}

Variables of interest for correlational analyses with FARS were demographics (gender, age, race, education, marital status), family history of obesity and diabetes, patient's baseline comorbidities (diabetes, hypertension, high cholesterol), baseline anthropometrics (weight, EBW, 
BMI), and follow-up measures (\%EWL and \% follow-up appointment attendance determined individually by duration since surgery date).

\section{Statistical Analyses}

Baseline descriptive statistics in forms of frequency, percent, mean and standard deviation were used. FARS scores initially utilized on a continuous scale were later adapted into quartiles for further analyses to compare differences in the extreme low and high food access areas. Wilcoxon Rank Sum test was used to examine relationship between continuous FARS scores and binary variables; Kruskal-Wallis test was used for comparing FARS scores among multiple categories of categorical variables. Fisher's Exact test was used for categorical variables when cell sizes were less than 5. Pearson's Chi-Square test was used for analyses of contingency tables of FARS quartiles (1 and 4) and categorical variables, while Wilcoxon Rank Sum test was used to test differences in continuous variables between the two FARS quartiles.

\section{RESULTS}

Other than marital status $(\mathrm{p}=.026)$, no significant differences were found among sociodemographic or baseline anthropometrics by surgery type (Table 2). Patients were predominately 45-year-old, married (60.5\%), Caucasian (92.4\%), females $(77.8 \%)$, who received bypass surgery $(75.9 \%)$. Average patient baseline weight was $301.9 \pm 62.8$ pounds, they had a BMI of $48.5 \pm 8.2 \mathrm{~kg} / \mathrm{m}^{2}$, and an EBW of $147.2 \pm 54.8$ pounds (total population average data not shown). No significant differences were found between surgery types for baseline co-morbidities or behaviors (Tables 2 and 3). From the total population $24.4 \%$ had a family history of obesity, $62.6 \%$ had a family history of diabetes, $38.1 \%$ had diagnosed diabetes, $65.2 \%$ had diagnosed hypertension, $56.2 \%$ had diagnosed high cholesterol, and 56.2\% were clinically depressed. Among personal dietary and lifestyle behaviors, 57.5\% took vitamin and/or mineral supplements, 
$51 \%$ cooked for themselves, $24.7 \%$ had a limited food budget, and $54.7 \%$ were moderately

stressed. No significant differences were seen among behaviors by surgery group (Table 3).

Percent EWL was significantly higher in the bypass patients, however when analyzing

relationship of food access to surgery groups, there was lack of evidence of significant

relationship. Further analyses combined surgery types due to similarity of populations in food

access.

Table 2: Descriptive characteristics of bariatric patients residing in West Virginia between 2013-2017

\begin{tabular}{|c|c|c|c|c|c|c|}
\hline \multicolumn{2}{|c|}{$\begin{array}{l}\text { Variable } \\
\text { Demographics }\end{array}$} & \multirow{2}{*}{$\begin{array}{c}\mathbf{n} \\
280\end{array}$} & \multirow{2}{*}{$\begin{array}{c}\text { Bypass } \\
\mathrm{n}(\%) \\
61(21.8) \\
219(78.2)\end{array}$} & \multirow{2}{*}{$\begin{array}{c}\mathbf{n} \\
89\end{array}$} & \multirow{2}{*}{$\begin{array}{c}\text { Sleeve } \\
\mathrm{n}(\%) \\
21(23.6) \\
68(76.4)\end{array}$} & \multirow{2}{*}{$\begin{array}{r}\text { P-value } \\
0.7700\end{array}$} \\
\hline Sex & $\begin{array}{l}\text { Male } \\
\text { Female }\end{array}$ & & & & & \\
\hline Race & $\begin{array}{l}\text { Caucasian only } \\
\text { Other }\end{array}$ & 280 & $\begin{array}{c}259(92.5) \\
21(7.5)\end{array}$ & 89 & $\begin{array}{c}82(92.1) \\
9(7.9)\end{array}$ & 1.0000 \\
\hline Education & $\begin{array}{l}\text { High School or Less } \\
\text { Some College or Associates } \\
\text { Bachelors } \\
\text { Post Grad, Masters, PhD, Law }\end{array}$ & 267 & $\begin{array}{l}95(35.6) \\
89(33.3) \\
55(20.6) \\
28(10.5)\end{array}$ & 86 & $\begin{array}{l}25(29.1) \\
27(31.4) \\
25(29.1) \\
9(10.5)\end{array}$ & 0.4002 \\
\hline Marital & $\begin{array}{l}\text { Single } \\
\text { Married } \\
\text { Divorced } \\
\text { Other }\end{array}$ & 258 & $\begin{array}{l}42(16.3) \\
154(59.7) \\
40(15.5) \\
22(8.5)\end{array}$ & 79 & $\begin{array}{l}16(20.3) \\
50(63.3) \\
13(16.5) \\
0(0)\end{array}$ & $0.0226 *$ \\
\hline \multicolumn{2}{|c|}{ Baseline Comorbidities } & $n$ & $\%$ & $n$ & $\%$ & p-value \\
\hline & $\begin{array}{l}\text { Family Hx of Obesity } \\
\text { Family Hx of Diabetes } \\
\text { Diagnosed Diabetes } \\
\text { Diagnosed High blood pressure } \\
\text { Diagnosed High Cholesterol } \\
\text { Diagnosed Depression }\end{array}$ & $\begin{array}{r}66 \\
181 \\
103 \\
158 \\
121 \\
129 \\
\end{array}$ & $\begin{array}{r}23.6 \\
64.6 \\
40.7 \\
65.3 \\
56.8 \\
54.0 \\
\end{array}$ & $\begin{array}{l}24 \\
50 \\
25 \\
52 \\
38 \\
48 \\
\end{array}$ & $\begin{array}{r}27.0 \\
56.2 \\
30.1 \\
65.0 \\
54.3 \\
63.2 \\
\end{array}$ & $\begin{array}{l}0.5159 \\
0.1672 \\
0.0916 \\
1.0000 \\
0.7816 \\
0.1850 \\
\end{array}$ \\
\hline \multicolumn{2}{|c|}{ Anthropometrics } & $n$ & Mean (SD) & $n$ & Mean $(S D)$ & p-value \\
\hline & $\begin{array}{l}\text { Height (in) } \\
\text { Weight (pounds) } \\
\text { BMI }\left(\mathrm{kg} / \mathrm{m}^{2}\right) \\
\text { EBW (pounds) } \\
\text { FARS } \\
\% \text { Attended Follow-up } \\
\text { \%EWL (baseline to one-year) }\end{array}$ & $\begin{array}{l}280 \\
280 \\
280 \\
280 \\
280 \\
280 \\
189\end{array}$ & $\begin{array}{c}65.8(3.7) \\
299.7(62.7) \\
48.3(8.1) \\
145.6(54.2) \\
1.6(0.7) \\
45.9(34.1) \\
72.2(17.4)\end{array}$ & $\begin{array}{l}89 \\
89 \\
89 \\
89 \\
89 \\
89 \\
27\end{array}$ & $\begin{array}{c}66.3(3.7) \\
308.9(63.3) \\
49.2(8.3) \\
152.4(56.7) \\
1.8(0.7) \\
42.3(30.7) \\
49.4(18.4)\end{array}$ & $\begin{array}{r}0.2642 \\
0.2330 \\
0.3925 \\
0.3560 \\
0.1153 \\
0.3078 \\
<.0001^{*}\end{array}$ \\
\hline
\end{tabular}

Independent t-test was used for parametric data tests (\%EWL). Wilcoxon Rank Sum test was used for examining demographics, height, weight, BMI, EBW, and Food Access Ranking Score (FARS) by surgery type for nonparametric data. Pearson's Chisquare analysis was used to test associations among categorical variables. Fisher's Exact test was used for cell sizes $<5$.

*Significance level <.05 
Table 3: Nutrition and lifestyle behaviors among surgery patient groups at baseline

\begin{tabular}{llrrrrr}
\hline Behavior Variable & & \multicolumn{3}{c}{ Bypass } & \multicolumn{3}{c}{ Sleeve } \\
\cline { 2 - 7 } Cooking responsibilities & Self & $n$ & $\%$ & $n$ & $\%$ & $p$-value \\
& Shared & 93 & 52.2 & 30 & 47.6 & \\
& Other & 56 & 31.5 & 19 & 30.2 & \\
& & 29 & 16.3 & 14 & 22.2 & 0.5662 \\
Limited Food Budget & Yes & & & & & \\
& No & 41 & 24.7 & 14 & 23.3 & \\
& & 125 & 75.3 & 46 & 76.7 & 0.8327 \\
Daily Stress & Not at all/ somewhat stressed & 55 & 28.8 & 24 & 35.8 & \\
& Moderately stressed & 110 & 57.6 & 31 & 46.3 & \\
& Very stressed & 26 & 13.6 & 12 & 17.9 & 0.2746 \\
& & & & & & \\
Taking Vitamin/Mined & Yes & 88 & 59.5 & 28 & 47.5 & \\
& No & 60 & 40.5 & 31 & 52.5 & 0.4364 \\
\hline
\end{tabular}

Pearson Chi-Square contingency tables were used to find differences among categorical variables

*significance level of $<.05$

Table 4: Categorical FARS by Surgery Type

\begin{tabular}{lrrrr} 
Food Access & Total & Bypass & Sleeve & p-value \\
\hline & $\mathrm{n}(\%)$ & $\mathrm{n}(\%)$ & $\mathrm{n}(\%)$ & By surgery type \\
\hline 1 (Low) & $97(26.3)$ & $76(27.1)$ & $21(23.6)$ & 0.2123 \\
2 (Moderate-Low) & $171(46.3)$ & $135(48.2)$ & $36(40.4)$ & \\
3 (Moderate-High) & $80(21.7)$ & $54(19.3)$ & $26(29.2)$ & \\
4 (High) & $21(5.7)$ & $15(5.4)$ & $6(6.7)$ & \\
\hline
\end{tabular}

Pearson's Chi-square analysis was used to test food access by surgery type.

*Significance level <.05

Food access was given whole categorical scoring of 1, 2, 3, or 4 with 1 being low access and 4 being high access (Table 4). Within the current population, $72.6 \%$ fell in the lesser two categories of low (26.3\%) and moderate-low (46.3\%) (Table 4).

Significant associations with food access were found among patient ethnicity $(Z=-2.16$, $\mathrm{p}<.01)$, family history of obesity $(\mathrm{Z}=2.06, \mathrm{p}<.05)$. and diagnosed depression $(\mathrm{Z}=-2.11, \mathrm{p}<.05)$ (Table 5). Interestingly, although income is playing a role as a variable within the calculation of FARS, a significant correlation with self-reported limited food budget and FARS was not found $(\mathrm{Z}=-1.05, \mathrm{p}=0.29)$ 


\section{Table 5: Correlation Table of Continuous FARS}

\begin{tabular}{|c|c|c|c|}
\hline & & Test Effect & p-value \\
\hline \multicolumn{4}{|l|}{ Food Access } \\
\hline \multirow[t]{12}{*}{ Categorical } & Gender & -0.047 & 0.9624 \\
\hline & Ethnicity & -2.614 & $0.0090 * *$ \\
\hline & Education level & 0.325 & 0.9553 \\
\hline & Marital Status & 4.109 & 0.2499 \\
\hline & Family Hx of Obesity & 2.065 & $0.0389 *$ \\
\hline & Family Hx of Diabetes & -1.585 & 0.1129 \\
\hline & Diabetic & 0.444 & 0.6564 \\
\hline & Diagnosed High blood pressure & 0.332 & 0.7299 \\
\hline & Diagnosed High Cholesterol & -1.851 & 0.0642 \\
\hline & Diagnosed Depression & 2.109 & $0.0350 *$ \\
\hline & Limited Food Budget & -1.047 & 0.2949 \\
\hline & Taking Vitamin/Minerals & -1.330 & 0.1834 \\
\hline \multirow[t]{8}{*}{ Continuous } & Age & -0.016 & 0.7553 \\
\hline & Initial Weight & -0.038 & 0.4696 \\
\hline & Initial EBW & -0.061 & 0.2458 \\
\hline & BMI & -0.085 & 0.1029 \\
\hline & Cooking responsibilities & -0.002 & 0.9809 \\
\hline & Daily Stress & -0.052 & 0.4039 \\
\hline & $\%$ Attended follow-up & -0.009 & 0.8664 \\
\hline & $\%$ EWL & -0.009 & 0.9096 \\
\hline
\end{tabular}

Wilcoxon Rank Sum test was used for binary variables and Kruskal-Wallis test was used for categorical variables with $>2$ groups. Spearman rho correlations of food access and continuous variables.

*Significance level $<.05$

**Significance level $<.01$

FARS was placed into quartiles to examine differences among lowest and highest quartiles (Table 5). Similarly, to total FARS, significant associations were found among ethnicity Chi-square $(1, \mathrm{~N}=189)=4.73, \mathrm{p}=.03$; family history of obesity Chi-square $(1, \mathrm{~N}=189)=6.52$, $\mathrm{p}=.01$; and diagnosed depression Chi-square $(1, \mathrm{~N}=161)=5.84, \mathrm{p}=.02$.

Table 6: Categorical FARS by Quartiles

\begin{tabular}{lr}
\hline FARS & Total \\
\hline & $\mathrm{n}(\%)$ \\
\hline Quartile 1: Low Access & $97(26.3)$ \\
Quartile 4: High Access & $92(24.9)$ \\
\hline
\end{tabular}

Figures 2a-c depict relationships of lowest and highest food access with ethnicity/race, history of obesity and depression. Specifically, percentage of patients in the 'other' category (African American, Asian, Hispanic, bi-racial) of ethnicity/race was higher in the lower food access as compared to higher food access having higher percentage of White/Caucasian 
individuals (Figure 1a; $\mathrm{p}<.05$ ). Those with a higher family history of obesity were found in larger frequency in highest food access (Figure $2 b ; \mathrm{p}<.05$ ). Those in low food access had higher rates of diagnosed depression as compared to high food access (Figure 2c; $p<.05$ ).

Table 7: Correlation Table of low vs high FARS

\begin{tabular}{|c|c|c|c|}
\hline FARS & Variables & Test Effect & p-value \\
\hline \multirow{14}{*}{ Categorical } & Gender & 0.001 & 0.9810 \\
\hline & Ethnicity & 4.729 & $0.0297 *$ \\
\hline & Education level & 0.837 & 0.8406 \\
\hline & Marital Status & 2.117 & 0.5485 \\
\hline & Family Hx of Obesity & 6.516 & $0.0107 *$ \\
\hline & Family Hx of Diabetes & 1.471 & 0.2251 \\
\hline & Diabetic & 0.080 & 0.7777 \\
\hline & Diagnosed Hypertension & 0.070 & 0.7910 \\
\hline & Diagnosed High Cholesterol & 3.617 & 0.0572 \\
\hline & Diagnosed Depression & 5.839 & $0.0157 *$ \\
\hline & Limited Food Budget & 0.054 & 0.8168 \\
\hline & Taking Vitamin/Minerals & 0.910 & 0.3400 \\
\hline & Cooking responsibilities & 0.724 & 0.6962 \\
\hline & Daily Stress & 2.339 & 0.3106 \\
\hline \multirow[t]{6}{*}{ Continuous } & Age & -1.009 & 0.3142 \\
\hline & Initial Weight & 0.155 & 0.8773 \\
\hline & Initial EBW & -0.691 & 0.9450 \\
\hline & BMI & -0.567 & 0.5715 \\
\hline & $\%$ Attended follow-up & -0.374 & 0.7090 \\
\hline & $\%$ EWL & -0.151 & 0.8803 \\
\hline
\end{tabular}

Associations (Chi-square test) and correlations (Spearman's rho) of food access (FARS) with demographics, dietary behaviors, and health history variables of categorical and continuous classification, respectively.

*Significance level <.05

\section{DISCUSSION}

Within literature among food access and obesity among Appalachian residents, low food access is correlated with increased obesity rates although some results conflicting [83-87, 142, 143]. The vast majority of studies in this area take place across the United States, with minimal studies in the Appalachian region specifically.

When examining food access among bariatric patients who need access to adequate and nutritious food we utilized a novel approach within the state of West Virginia. Low access ranking score among our population was over $26 \%$ while USDA labeled low-income, low-access tracts in West Virginia were a total of 13.2\% [77-79]. The difference among our results and 
others could be attributed to the WV FOODLINK including quality of stores into scoring food access, not just quantity as USDA defines $[117,118]$. This warranted examination of further cohorts to identify the extent of this quality variable among general populations of West Virginians.

Our population was largely homogeneous. All individuals considered in this study had met criteria to have bariatric surgery which requires a similar weight and/or BMI. These criteria also influence similar EBW, health history, and health behaviors. Due to this, levels of FARS saw similar initial weight before surgery and weight loss after surgery. Associations with food access were only present among ethnicity/race, family history of obesity, and diagnosed depression. Those that were non-Caucasian, had diagnosed depression, and those without a family history of obesity were found to be in the lower FARS categories. Similar results seen in a study by Li et al. found that census blocks with $>50 \%$ African American populations had lower food environment scores as compared to their counterparts [85]. These predominately African American locations also showed higher weight status [85]. Further, large bodies of work have examined the relationship among poor physical health, depression or poor mental health with food insecurity [171-174]. These correlations, although largely represented in the literature, warrant attention when treating patients who have multiple morbidities and are seeking a metabolic intervention that requires access to adequate food and resources afterwards.

\section{Limitations}

Because this is a non-traditional approach to addressing food access in West Virginia, the cohort in this study is limited to those in residing in the state who are receiving bariatric surgery. This collaboration is within its infancy and is the beginning of further exploration. This limits the generalizability of the results to the entire WV population. This is also true to the body of work 
surrounding food access and obesity specifically in Appalachia. Researchers tend to use various tools to define a low access or food-desert area which limits the comparability of the results. However, further expanding our approach to other samples and cohorts may bring to light a variety of findings outside of these as well. This will allow us to begin understanding the expanse of food accessibility in West Virginia and ultimately, other states.

\section{CONCLUSION}

Access to healthy nutritious food, defined predominately in a central Appalachian population, was found to be influential in ethnicity, family history of obesity, and diagnosed depression among post bariatric surgery patients. Specifically, due to their homogeneous nature, limited associations were seen outside of these. This initial utilization of our novel food access ranking score is promising for beginning formative work on West Virginia's food-desert areas. Within bariatric surgery, implementing educational and resource toolkits during pre-operative programs could enhance their comfortability with major dietary changes needed after surgery. These resources can incorporate how and where to access these foods within their area. Future experimental studies investigating how food access resources or counseling could impact minority races or depressed individuals during their pre-operative journey. 


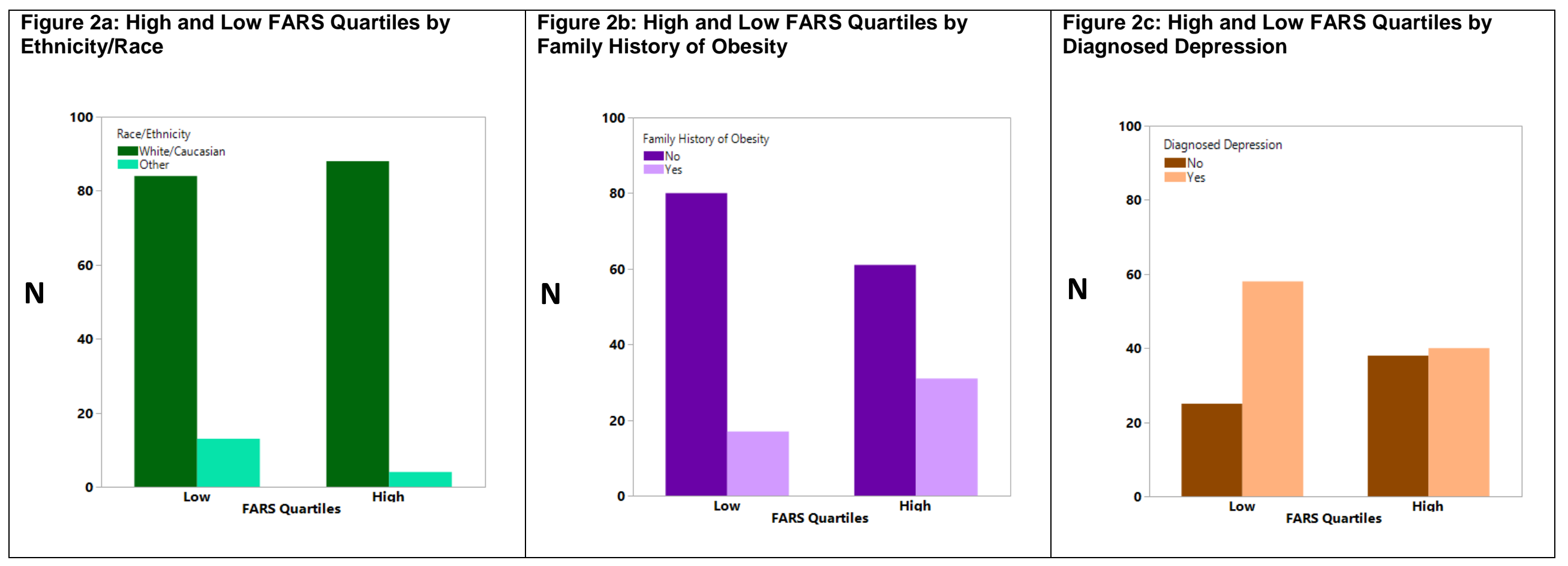




\section{Chapter VII: Discussion and Conclusion}




\section{Discussion}

The purpose of the research in this dissertation was to provide formative research and insight into the underrepresented population of Appalachian based individuals who sought bariatric surgery as a weight loss intervention. The research examined in this dissertation had interesting findings regarding the impact of food access on outcomes of bariatric surgery. Several studies regarding food access and obesity or rural locations indicate that there is a correlation between lower food access and higher rates of obesity $[175,176]$. In Chapter 5, it was hypothesized that those patients with lower food access would have poorer outcomes (i.e $\%$ EWL). However, findings suggest that regardless of food access, outcomes were still deemed successful (\%EWL of $>50 \%$ ). These findings, albeit surprising, indicate that even in food desert regions bariatric surgery is still successful. Nonetheless, these results do not mean that food access is irrelevant in dietary interventions. Because bariatric surgery is a metabolic tool to significantly reduce weight, and patients were a largely homogenous group at baseline, weight changes at one-year may have been too significant and similar to identify any other changes that may have been seen in a general food desert population.

Equally, reiterating these same results when aiming to identify differences among the population regarding food access saw limited associations. This population began at similar weight, BMI, EBW, and health conditions at baseline which may influence those lesser correlations. However, some variables were found to be associated with food access: ethnicity, diagnosed depression, and a family history of obesity. It is well known in the literature that racial minorities are found to have lower food access. Although the population was largely Caucasian, those non-Caucasian individuals were found to have lower access than their Caucasian counterparts. Similarly, with diagnosed depression, individuals who were non-depressed had 
higher food access ranking. Among current literature it is expressed that poor access is associated with areas of lower income, higher disparities, and poorer mental health. This falls in line with the disparities among the Appalachian regions, or those of rural locale. In contrast, those with a family history of obesity had higher food access. This is contrary to literature supporting associations between the paradoxical relationship of obesity and food deserts [176]. A body of work examines that those residing in an area with lower access, there is a larger frequency of convenience, dollar, or small box store that rarely sell fresh foods and have a surplus of energy dense snack and meal items $[80,118]$. This influences higher calorie food consumption in these individuals, and thus increases weight. These aspects are also compounded by limited health care resources, vehicle access, or even opportunities to be physically active. All of these aspects in conjunction can lead to greater health disparities and morbidity or mortality. Ironically, in our population, those with a lower family history of obesity fell in the higher food access category. This opposes that paradoxical relationship of low food access and obesity. However, this does not define this relationship as truth. Our population was similar in baseline weight, BMI, EBW, and health histories so finding associations with food access among initial descriptions were scarce.

Interesting findings from Chapter 4 indicate that surgery type, diabetes and depression were the only indicators of \%EWL in our population. Those receiving gastric bypass surgery had larger \%EWL than those receiving sleeve gastrectomy surgery (nearly $20 \%$ more). A study comparing bypass to sleeve results, Peterli et al. identifies very similar results in \%EWL between surgeries [98]. However, important to take into consideration the proportion of patients within our bariatric population returning for their one-year follow-up appointments, there were 188 bypass patients ( $83.9 \%$ of patients at one-year) compared to 36 sleeve which is similar to the 
overall breakdown of bypass to sleeve patients in the entire sample ( $75.8 \%$ receiving bypass surgery).

Education, health literacy, rural status, and co-morbidities impact the health among the region and, on average, our population fell into these criteria. Although being a largely homogeneous group of individuals meeting a certain criterion to receive bariatric surgery, they also display these similar Appalachian characteristics. When using demographic variables to predict \%EWL or association with FARS, no significant relationships were seen. This does not discredit the importance of socioeconomic factors in this region and that they should be considered when preparing future interventions. These aspects may play a role in the accessibility of patients in a rural setting as well as the importance of tailoring interventions to the need of the population.

When examining co-morbidities among the cohort and their \%EWL outcomes at oneyear follow-up (Chapter 4) we found significant relationships. Those patients who were diagnosed in their EMR as a Type 2 Diabetic had lesser \%EWL than those non-diagnosed. Similarly, with diagnosed depression in EMR, patients with a diagnoses had lesser outcomes than those non-diagnosed. When we examined both HbA1c and Beck's Depression Inventory as objective measures of blood glucose control and depression severity, we found that higher HbA1c values was negatively related to $\%$ EWL while BDI scores were found to be unrelated to \%EWL. However, when examining interactions between variables and their effect on \%EWL, no significant interactions were detected. These results, taken together, identify that separately, these variables are impacting patient \%EWL at one-year follow-up, although not having a significant relationship together. 


\section{Future Research}

Future prospective studies based on this preliminary descriptive examination is warranted for Appalachian patients. Consideration of individuals who present with co-morbid conditions before bariatric surgery, such as diabetes and depression, should receive additional resources, counseling, or education throughout their program. Although bariatric surgery has been found to reduce or alleviate co-morbid conditions, our population with these conditions did see lesser weight loss outcomes than their non- co-morbid diagnosed counterparts.

When examining food access, future research that employs both qualitative and quantitative methods, or a mixed-methods approach, along with the perceptions, descriptions, and factors influencing patient food choices needs to be explored. Within the literature regarding Appalachia, food access and obesity, minimal conclusions can be drawn. The vast majority of the work focuses on defining and locating food deserts within each population. Gufstufson et al. was the one of two studies that examined perception work regarding food access where the population self-reported living in a food desert and how they described their surroundings [84]. Individuals expressed living in a food desert and the barriers they feel when trying to find healthful foods [84]. Another study by Dubowitz et al. examined a natural experiment of a new supermarket in one neighborhood compared to a control [142, 177]. Although specific dietary quality didn't change, individuals perceived their access to healthier foods greater after the new market came [142]. All remaining studies of food access and obesity in the Appalachian region utilized large-scale data (i.e. county-level census data, GIS data) to examine food environments with no qualitative data included. This provides an avenue for future research in the area along with the novelty of including bariatric surgery patients whose food accessibility and dietary quality are important to understand post-operatively. 


\section{Limitations}

These studies are not without limitations. The non-experimental retrospecctive design of this study urges results to be taken with caution. Correlational analyses only identify association among outcomes and patient characteristic, and thus, any cause-and-effect relationship cannot be determined. Among demographics, Caucasian, female patients made up the majority of the population as males and other race and ethnicities were underrepresented. Due to the retrospective nature of the studies, limited clarification on data retrival could be retrieved. A large quanitity of data were entered into patient charts in the form of PDF documents that were hand written by the patient at their intial clinic visit. Further, changes in surgerons came with changes in documentation and thus, missing data point. This reduced some of the sample size however, still gave adequate numbers for analyses. Also, this study aimed to be an overview of the population and their outcomes as a starting point for future examination and analyses which makes this formative research limited in specific conclusions.

Outcome data (\%EWL), which a large portion of analyses were based upon, were data from those individuals who attended their one-year follow-up appointments. This could impose an extent of bias in the results due to the fact that these individuals may have taken their success more seriously and believed attending follow-up appointments were important to their attainment of significant weight loss.

Lastly, the novelty of our food access scoring limits comparibility to other food access scoring of its type. Our scoring is exclusive to West Virginia residents and could not be compared across the entire sample size. However, utilizing this scoring to use a qualitative approach capturing perceptions of residents food access will be useful when approaching interventions targeting food access among Appalachian West Virginia residents. 


\section{Conclusion}

This dissertation aimed to provide a systematic review into the literature on food access and obesity within the Appalachian region, examine the overall population and any specific characteristics of individuals with more successful \%EWL, and investigate relationships among patient characteristics and outcomes with their food accessibility score. Findings suggest that those with diagnosed diabetes or depression have lower \%EWL after bariatric surgery, while LRYBG overall provided higher \%EWL. Among food access ranking scores, those of nonCaucasian race and with diagnosed depression had lower food access ranking while those with a family history of obesity had a higher food access ranking. Generally, minimal correlations in this data set may have been observed due to bariatric surgery being successful among those individuals who our data represented. In out Appalachian population, \%EWL met and exceeded some weight loss representations in the literature. A follow-up repeated measures survey on behavioral patterns and patient remission of co-morbid conditions can be worthy moving forward. This will inform longer follow-up duration outcomes and inform a prospective study reaching these Appalachian populations seeking bariatric surgery. 


\section{References}




\section{References:}

1. Surgery, A.S.f.M.a.B., Bariatric Surgery FAQs - American Society for Metabolic and Bariatric Surgery. 2017.

2. ASMBS, Bariatric Surgery Procedures - ASMBS |American Society for Metabolic and Bariatric Surgery. 2017.

3. $\quad$ Nguyen, N.T., et al., The ASMBS Textbook of: Bariatric Surgery. 2015: Springer.

4. Appalachian Regional, C., Appalachian Region Endures Dramatic Health Challenges Compared with Nation, New Research Shows - Appalachian Regional Commission. 2017.

5. CDC, Defining Adult Overweight and Obesity | Overweight \& Obesity | CDC. 2018.

6. Centers for Disease Control \& Prevention, Adult Obesity Facts $\mid$ Overweight \& Obesity | CDC. 2017.

7. West Virginia State, O., West Virginia State Obesity Data, Rates and Trends - The State of Obesity. 2017.

8. Trust for America's Health, The State of Obesity 2017 - Trust for America's Health. 2017.

9. WVDHHR, West Virginia Behavioral Risk Factor Surveillance System Report 2016. 3/14/2018, HSC Publications: Health Statistics Center.

10. Cawley, J. and C. Meyerhoefer, The medical care costs of obesity: an instrumental variables approach. Journal of health economics, 2012. 31(1): p. 219-230.

11. Dee, A., et al., The direct and indirect costs of both overweight and obesity: a systematic review. BMC Research Notes, 2014. 7(1): p. 242.

12. Padula, W.V., R.R. Allen, and K. Nair, Determining the cost of obesity and its common comorbidities from a commercial claims database. Clinical obesity, 2014. 4(1): p. 53-58.

13. Burguera, B., et al., An Intensive Lifestyle Intervention Is an Effective Treatment of Morbid Obesity: The TRAMOMTANA Study-A Two-Year Randomized Controlled Clinical Trial. International Journal of Endocrinology, 2015. 2015: p. 194696.

14. Ponce, J., et al., American Society for Metabolic and Bariatric Surgery estimation of bariatric surgery procedures in 2015 and surgeon workforce in the United States. Surgery for obesity and related diseases : official journal of the American Society for Bariatric Surgery, 2016. 12(9): p. 1637-1639.

15. Ponce, J., et al., American Society for Metabolic and Bariatric Surgery estimation of bariatric surgery procedures in the United States, 2011-2014. Surgery for Obesity and Related Diseases, 2015. 11(6): p. 1199-1200.

16. English, W.J., et al., American Society for Metabolic and Bariatric Surgery estimation of metabolic and bariatric procedures performed in the United States in 2016. Surgery for Obesity and Related Diseases, 2018.

17. Luppino, F.S., et al., Overweight, obesity, and depression: a systematic review and metaanalysis of longitudinal studies. Arch Gen Psychiatry, 2010. 67(3): p. 220-9.

18. Jumbe, S., C. Hamlet, and J. Meyrick, Psychological Aspects of Bariatric Surgery as a Treatment for Obesity. Current Obesity Reports, 2017. 6(1): p. 71-78.

19. Marks, D.F., Homeostatic theory of obesity. Health Psychology Open, 2015. 2(1): p. 2055102915590692.

20. Litz, M., et al., The impact of mental health disorders on 30-day readmission after bariatric surgery. Surgery for Obesity and Related Diseases. 14(3): p. 325-331.

21. Mitchell, J.E., et al., Course of depressive symptoms and treatment in the longitudinal assessment of bariatric surgery (LABS-2) study. Obesity, 2014. 22(8): p. 1799-1806. 
22. Appalachian Regional Commission, Economic assessment of Appalachia: an Appalachian regional development initiative report. 2010: Washington, DC.

23. Behringer, B. and G.H. Friedell, Appalachia: Where Place Matters in Health. Preventing Chronic Disease, 2006. 3(4): p. A113.

24. Herath, J. and C. Brown, An analysis of adult obesity and hypertension in appalachia. Global journal of health science, 2013. 5(3): p. 127.

25. McGarvey, E.L., et al., Health disparities between Appalachian and non-Appalachian counties in Virginia USA. Journal of Community Health, 2011. 36(3): p. 348-356.

26. Bergmann, K.L., S.J. Cox, and L.E. Tabone, Influence of a rural environment on patient access and outcomes for bariatric surgery. Surgery for Obesity and Related Diseases, 2017. 13(4): p. 632-636.

27. Bergmann, K.L., S.J. Cox, and L.E. Tabone, Influence of a rural environment on patient access and outcomes for bariatric surgery. Surgery for obesity and related diseases : official journal of the American Society for Bariatric Surgery, 2017. 13(4): p. 632-636.

28. Bandura, A., Social cognitive theory of mass communication. Media psychology, 2001. 3(3): p. 265-299.

29. Bandura, A., Health promotion by social cognitive means. Health education \& behavior, 2004. 31(2): p. 143-164.

30. Glanz, K., B.K. Rimer, and K. Viswanath, Health behavior and health education: theory, research, and practice. 2008: John Wiley \& Sons.

31. Bandura, A., Social foundations of thought and action: A social cognitive theory. 1986: Englewood Cliffs, NJ, US: Prentice-Hall, Inc.

32. Control, C.f.D. and Prevention, The social-ecological model: A framework for prevention. Injury center: Violence prevention, 2009.

33. Rundle, A., et al., Neighborhood food environment and walkability predict obesity in New York City. Environmental health perspectives, 2009. 117(3): p. 442.

34. Drewnowski, A., et al., Food environment and socioeconomic status influence obesity rates in Seattle and in Paris. International journal of obesity, 2014. 38(2): p. 306.

35. National Center for Health Statistics. Health, United States, 2016: With Chartbook on Long-term Trends in Health. 2017; Available from:

https://www.google.com/search?q=Health\%2C+United+States\%2C+2016\%3A+At+a+Gl ance \&rlz=1C1CHBF_enUS726US726\&oq $=$ Health $\% 2 \mathrm{C}+$ United+States $\% 2 \mathrm{C}+2016 \% 3 \mathrm{~A}+$ At+a+Glance\&aqs=chrome..69i57j69i60.1221j0j4\&sourceid=chrome\&ie=UTF-8.

36. Miller, J.D., et al., Obesity, Exercise, Obstructive Sleep Apnea, and Modifiable Atherosclerotic Cardiovascular Disease Risk Factors in Atrial Fibrillation. Journal of the American College of Cardiology, 2015. 66(25): p. 2899-2906.

37. $\mathrm{Xu}, \mathrm{W}$., et al., Meta-analysis of modifiable risk factors for Alzheimer's disease. Journal of Neurology, Neurosurgery \&amp; Psychiatry, 2015.

38. Corbin, L.J., et al., Body mass index as a modifiable risk factor for type 2 diabetes: Refining and understanding causal estimates using Mendelian randomisation. Diabetes, 2016.

39. Williams, E.P., et al., Overweight and Obesity: Prevalence, Consequences, and Causes of a Growing Public Health Problem. Current Obesity Reports, 2015. 4(3): p. 363-370.

40. Prevention, C.f.D.C.a. National Center for Chronc Disease Prevention and Health Promotion, Division of Nutrition, Physical Activity, and Obesity. Data, Trend and Maps. 2017; Available from: 
https://nccd.cdc.gov/dnpao_dtm/rdPage.aspx?rdReport=DNPAO_DTM.ExploreByTopic \&islClass $=\mathrm{PA} \& \mathrm{isl}$ Topic $=\mathrm{PA} 1 \& \mathrm{go}=\mathrm{GO}$.

41. Ogden, C.L., et al., Prevalence of childhood and adult obesity in the United States, 2011 2012. Jama, 2014. 311(8): p. 806-814.

42. Trust for America's Health. The State of Obesity 2017 - Adult Obesity in the United States. 2017; Available from: http://healthyamericans.org/reports/stateofobesity2017/.

43. Flegal, K.M., et al., Trends in obesity among adults in the United States, 2005 to 2014. Jama, 2016. 315(21): p. 2284-2291.

44. Fryar, C.D., M.D. Carroll, and C.L. Ogden, Prevalence of overweight, obesity, and extreme obesity among adults aged 20 and over: United States, 1960-1962 through 2013-2014. National Center for Health Statistics, 2016.

45. The State of Obesity. The Healthcare Costs of Obesity. 2017; Available from: http://stateofobesity.org/healthcare-costs-obesity/.

46. ARC. The Appalachian Region - Appalachian Regional Commission. 2018; Available from: https://www.arc.gov/appalachian_region/TheAppalachianRegion.asp.

47. Appalachian Regional Commission. The Appalachian Region. 2018; Available from: https://www.arc.gov/appalachian_region/TheAppalachianRegion.asp.

48. Appalachian Regional Commission. About Appalachian Regional Commission. 2018; Available from: https://www.arc.gov/about/index.asp.

49. Barker, L., et al., Residence in a Distressed County in Appalachia as a Risk Factor for Diabetes, Behavioral Risk Factor Surveillance System, 2006-2007. Preventing Chronic Disease, 2010. 7(5): p. A104.

50. Meit, M., et al., Appalachian diseases of despair. 2017.

51. Kruger, T.M., et al., Formative research conducted in rural Appalachia to inform a community physical activity intervention. American Journal of Health Promotion, 2012. 26(3): p. 143-151.

52. Cradock, K.A., et al., Behaviour change techniques targeting both diet and physical activity in type 2 diabetes: A systematic review and meta-analysis. International Journal of Behavioral Nutrition and Physical Activity, 2017. 14(1): p. 18.

53. Ross, R., et al., Effects of exercise amount and intensity on abdominal obesity and glucose tolerance in obese adults: A randomized trial. Annals of Internal Medicine, 2015. 162(5): p. 325-334.

54. CDC, CDC - Current Physical Activity Guidelines. 2017.

55. CDC, Facts about Physical Activity | Physical Activity | CDC. 2017.

56. PDA, I., Cecil G. Sheps Center, Appalachian Regional Commission. Health Disparities in Appalachia. 2017; Available from:

https://www.arc.gov/research/researchreportdetails.asp?REPORT_ID=138.

57. Commission, A.R., Health care costs and access disparities in Appalachia. 2012.

58. Michael Meit, M.H., Erin Tanenbaum, Topher Hoffmann. Appalachian Diseases of Despair. 2018; Available from: https://www.arc.gov/research/researchreportdetails.asp?REPORT_ID=139.

59. Ward, Z.J., et al., Redrawing the US obesity landscape: bias-corrected estimates of statespecific adult obesity prevalence. PLoS One, 2016. 11(3): p. e0150735.

60. Khaodhiar, L., K.C. McCowen, and G.L. Blackburn, Obesity and its comorbid conditions. Clin Cornerstone, 1999. 2(3): p. 17-31. 
61. Richardson, A.S., W.H. Dietz, and P. Gordon-Larsen, The association between childhood sexual and physical abuse with incident adult severe obesity across 13 years of the National Longitudinal Study of Adolescent Health. Pediatric obesity, 2014. 9(5): p. 351361.

62. Mannan, M., et al., Is there a bi-directional relationship between depression and obesity among adult men and women? Systematic review and bias-adjusted meta analysis. Asian Journal of Psychiatry, 2016. 21: p. 51-66.

63. Marmorstein, N.R., W.G. Iacono, and L. Legrand, Obesity and depression in adolescence and beyond: reciprocal risks. International Journal Of Obesity, 2014. 38: p. 906.

64. Ribera, E., et al., Is there a relationship between morbid obesity and depression? European Psychiatry, 2017. 41: p. S324.

65. Luppino, F.S., et al., Overweight, obesity, and depression: a systematic review and metaanalysis of longitudinal studies. Archives of general psychiatry, 2010. 67(3): p. 220-229.

66. De Wit, L., et al., Depression and obesity: a meta-analysis of community-based studies. Psychiatry research, 2010. 178(2): p. 230-235.

67. Wallace, A.E., et al., Racial, socioeconomic, and rural-urban disparities in obesityrelated bariatric surgery. Obesity surgery, 2010. 20(10): p. 1354-1360.

68. Rural Health Information Hub, Healthcare Access in Rural Communities Introduction Rural Health Information Hub. 2018.

69. United States Census, B., U.S. Census Bureau QuickFacts: UNITED STATES. 2017.

70. Gutschall, M., K. Thompson, and E. Lawrence, Addressing Health Disparities in Rural Nutrition Practice: A Qualitative Model from Rural Appalachia. Journal of Hunger \& Environmental Nutrition, 2017: p. 1-16.

71. Schoenberg, N.E., et al., Appalachian residents' experiences with and management of multiple morbidity. Qualitative health research, 2011. 21(5): p. 601-611.

72. Gundersen, C. and J.P. Ziliak, Food Insecurity And Health Outcomes. Health Affairs, 2015. 34(11): p. 1830-1839.

73. WIC, W.V. Quick WIC Facts. 2018; Available from: http://ons.wvdhhr.org/AboutWIC/QuickWICFacts/tabid/1184/Default.aspx.

74. Andress, L. and C. Fitch, Juggling the five dimensions of food access: Perceptions of rural low income residents. Appetite, 2016. 105: p. 151-155.

75. Ver Ploeg, M., Access to affordable and nutritious food: updated estimates of distance to supermarkets using 2010 data. 2012: United States Department of Agriculture, Economic Research Service.

76. Rhone, A., et al., Low-income and Low-supermarket-access Census Tracts, 2010-2015. 2017: United States Department of Agriculture, Economic Research Service.

77. USDA. USDA ERS - Food Access Research Atlas Data. 2018; Available from: https:/www.ers.usda.gov/data-products/food-access-research-atlas/download-the-data/.

78. USDA. USDA ERS - Food Access Research Atlas. 2018; Available from: https://www.ers.usda.gov/data-products/food-access-research-atlas/.

79. USDA. USDA ERS - Documentation. 2018; Available from: https://www.ers.usda.gov/data-products/rural-urban-commuting-areacodes/documentation.aspx.

80. WV FOODLINK, W., B et al.,, Nourishing Networks: West Virginia Community Food Security Assessment. 2016, West Virginia University: Morgantown, WV. 
81. Andress, L. and S.S. Hallie, Co-constructing food access issues: Older adults in a rural food environment in West Virginia develop a photonarrative. Cogent Medicine, 2017. 4(1): p. 1309804.

82. Berkowitz, S.A., et al., Food Insecurity, Food "Deserts," and Glycemic Control in Patients With Diabetes: A Longitudinal Analysis. Diabetes Care, 2018.

83. Amarasinghe, A., et al., The Impact of County Level Factors on Obesity in West Virginia. 2006.

84. Gustafson, A., et al., Examining Key Stakeholder and Community Residents' Understanding of Environmental Influences to Inform Place-Based Interventions to Reduce Obesity in Rural Communities, Kentucky 2015. The Journal of Rural Health, 2017.

85. Li, Y., et al., Childhood obesity and community food environments in Alabama's Black Belt region. Child: Care, Health \& Development, 2015. 41(5): p. 668-676.

86. Schafft, K.A., E.B. Jensen, and C.C. Hinrichs, Food Deserts and Overweight Schoolchildren: Evidence from Pennsylvania. Rural Sociology, 2009. 74(2): p. 153-177.

87. Slack, T., et al., The geographic concentration of US adult obesity prevalence and associated social, economic, and environmental factors. Obesity, 2014. 22(3): p. 868874.

88. Buchwald, H., et al., Bariatric surgery: A systematic review and meta-analysis. JAMA, 2004. 292(14): p. 1724-1737.

89. Martin, L.F., Obesity surgery. 2004: McGraw-Hill New York.

90. Salameh, J.R.M., Bariatric Surgery: Past and Present. 2006. 331(4): p. 194-200.

91. Johnson, E.E., et al., Trends in bariatric surgery, 2002-2012: do changes parallel the obesity trend? Surg Obes Relat Dis, 2016. 12(2): p. 398-404.

92. Yaghoubian, A., et al., Laparoscopic Roux-en-Y gastric bypass and sleeve gastrectomy achieve comparable weight loss at 1 year. Am Surg, 2012. 78(12): p. 1325-8.

93. Praveenraj, P., et al., Comparison of weight loss outcomes 1 year after sleeve gastrectomy and Roux-en-Y gastric bypass in patients aged above 50 years. J Minim Access Surg, 2016. 12(3): p. 220-5.

94. Garg, H., et al., Comparative study of outcomes following laparoscopic Roux-en-Y gastric bypass and sleeve gastrectomy in morbidly obese patients: A case control study. World J Gastrointest Endosc, 2017. 9(4): p. 162-170.

95. Peterli, R., et al., Laparoscopic Sleeve Gastrectomy Versus Roux-Y-Gastric Bypass for Morbid Obesity-3-Year Outcomes of the Prospective Randomized Swiss Multicenter Bypass Or Sleeve Study (SM-BOSS). Ann Surg, 2017. 265(3): p. 466-473.

96. Peterli, R., et al., Effect of Laparoscopic Sleeve Gastrectomy vs Laparoscopic Roux-en-Y Gastric Bypass on Weight Loss in Patients With Morbid Obesity: The SM-BOSS Randomized Clinical Trial. Jama, 2018. 319(3): p. 255-265.

97. Salminen, P., et al., Effect of Laparoscopic Sleeve Gastrectomy vs Laparoscopic Rouxen-Y Gastric Bypass on Weight Loss at 5 Years Among Patients With Morbid Obesity: The SLEEVEPASS Randomized Clinical Trial. Jama, 2018. 319(3): p. 241-254.

98. Peterli, R., et al., Early Results of the Swiss Multicentre Bypass or Sleeve Study (SMBOSS): A Prospective Randomized Trial Comparing Laparoscopic Sleeve Gastrectomy and Roux-en-Y Gastric Bypass. Annals of Surgery, 2013. 258(5): p. 690-695.

99. Burguera, B., Jess Tur, Juan Escudero, Antonio Jorge Alos, Mar Pagn, Alberto Corts, Baltasar Gonzlez, Xavier Francesc Soriano, Joan B., An Intensive Lifestyle Intervention Is 
an Effective Treatment of Morbid Obesity: The TRAMOMTANA Study\&\#x2014;A TwoYear Randomized Controlled Clinical Trial. International Journal of Endocrinology, 2015. 2015: p. 11.

100. Dhabuwala, A., R.J. Cannan, and R.S. Stubbs, Improvement in Co-Morbidities Following Weight Loss From Gastric Bypass Surgery. Obesity Surgery, 2000. 10(5): p. 428-435.

101. White, S., et al., Long-Term Outcomes after Gastric Bypass. Obesity Surgery, 2005. 15(2): p. 155-163.

102. Brethauer, S.A., et al., Can Diabetes Be Surgically Cured?: Long-Term Metabolic Effects of Bariatric Surgery in Obese Patients with Type 2 Diabetes Mellitus. Annals of surgery, 2013. 258(4): p. 628-637.

103. de Zwaan, M., et al., Anxiety and depression in bariatric surgery patients: A prospective, follow-up study using structured clinical interviews. Journal of Affective Disorders. 133(1): p. 61-68.

104. Zeller, M.H., et al., Health-Related Quality of Life and Depressive Symptoms in Adolescents With Extreme Obesity Presenting for Bariatric Surgery. Pediatrics, 2006. 117(4): p. 1155-1161.

105. Melissa A. Kalarchian , P.D., et al., Psychiatric Disorders Among Bariatric Surgery Candidates: Relationship to Obesity and Functional Health Status. American Journal of Psychiatry, 2007. 164(2): p. 328-334.

106. Abilés, V., et al., Psychological Characteristics of Morbidly Obese Candidates for Bariatric Surgery. Obesity Surgery, 2010. 20(2): p. 161-167.

107. Averbukh, Y., et al., Depression Score Predicts Weight Loss following Roux-en-Y Gastric Bypass. Obesity Surgery, 2003. 13(6): p. 833-836.

108. Dawes, A.J., et al., Mental health conditions among patients seeking and undergoing bariatric surgery: A meta-analysis. JAMA, 2016. 315(2): p. 150-163.

109. Dawes, A.J., et al., Mental Health Conditions Among Patients Seeking and Undergoing Bariatric Surgery: A Meta-analysis. Jama, 2016. 315(2): p. 150-63.

110. Switzer, N.J., et al., The Impact of Bariatric Surgery on Depression: a Review. Current Cardiovascular Risk Reports, 2016. 10(3): p. 12.

111. Yusufov, M., et al., Body mass index, depression, and suicidality: The role of self-esteem in bariatric surgery candidates. Journal of Affective Disorders. 208: p. 238-247.

112. Booth, H., et al., Impact of bariatric surgery on clinical depression. Interrupted time series study with matched controls. Journal of Affective Disorders, 2015. 174: p. 644649.

113. Imbus, J.R., C.I. Voils, and L.M. Funk, Bariatric surgery barriers: A review using andersen's model of health services use. Surgery for Obesity and Related Diseases, 2017.

114. Johnson, E.E., et al., Trends in bariatric surgery, 2002-2012: do changes parallel the obesity trend? Surgery for Obesity and Related Diseases, 2016. 12(2): p. 398-404.

115. Griffith, B.N., et al., Self-rated health in rural Appalachia: health perceptions are incongruent with health status and health behaviors. BMC Public Health, 2011. 11(1): p. 229.

116. WVDHSEM, WVGISTC: GIS Data Clearinghouse. 2017.

117. Barr ML, O.M., Tabone L, Szoka N, Brode C, Cox S, Gross T, Wilson B, Davisson L. Low Food Access Ranking among West Virginia Appalachian Metabolic Surgery Patients. in International Federation for the Surgery of Obesity and Metabolic Disorders Conference Absract Book. 2018. 
118. WV FOODLINK, Story Map Journal. 2017.

119. Adler, N.E. and J. Stewart, Health disparities across the lifespan: meaning, methods, and mechanisms. Annals of the New York Academy of Sciences, 2010. 1186(1): p. 5-23.

120. Adler, N.E. and D.H. Rehkopf, US disparities in health: descriptions, causes, and mechanisms. Annu. Rev. Public Health, 2008. 29: p. 235-252.

121. Braveman, P., Health disparities and health equity: concepts and measurement. Annu. Rev. Public Health, 2006. 27: p. 167-194.

122. Hartley, D., Rural health disparities, population health, and rural culture. American Journal of Public Health, 2004. 94(10): p. 1675-1678.

123. Carter-Pokras, O. and C. Baquet, What is a" health disparity"? Public health reports, 2002. 117(5): p. 426.

124. Walsh, M., K. Tanoue, and J. Daws, UNPACKING RURALITY. 2015.

125. Barker, L., et al., Peer Reviewed: Residence in a Distressed County in Appalachia as a Risk Factor for Diabetes, Behavioral Risk Factor Surveillance System, 2006-2007. Preventing chronic disease, 2010. 7(5).

126. Beverly, E.A., et al., Understanding the Meaning of Food in People With Type 2 Diabetes Living in Northern Appalachia. Diabetes Spectrum, 2017: p. ds 160059.

127. O'Brien, T., et al., Obesity Among Women Living in Appalachia: A Dimensional Analysis. Online Journal of Cultural Competence in Nursing \& Healthcare, 2015. 5(1): p. 118-140.

128. Miller, W.C., et al., Misconceptions about health and disease prevention behaviors of rural Appalachian Americans. Int J Med (Dubai), 2014. 2(2): p. 71-5.

129. Wang, L., et al., Home food environment, dietary intake, and weight among overweight and obese children in Southern Appalachia. Southern Medical Journal, 2013. 106(10): p. 550-557.

130. Berlin, K.S., J. Hamel-Lambert, and C. DeLamatre, Obesity and Overweight Status Health Disparities Among Low-Income Rural Appalachian Preschool Children. Children's Health Care, 2013. 42(1): p. 15-26.

131. Mamudu, H.M., et al., Association Between Multiple Modifiable Risk Factors of Cardiovascular Disease and Hypertension among Asymptomatic Patients in Central Appalachia. Southern Medical Journal, 2017. 110(2): p. 90-96.

132. Amarasinghe, A., et al., The influence of socioeconomic and environmental determinants on health and obesity: $a$ West Virginia case study. International Journal of Environmental Research and Public Health, 2009. 6(8): p. 2271-2287.

133. Amarasinghe, A., et al., The Influence of Socioeconomic and Environmental Determinants on Health and Obesity: A West Virginia Case Study, in Int J Environ Res Public Health. 2009. p. 2271-87.

134. Hartley, D., Rural Health Disparities, Population Health, and Rural Culture. http://dx.doi.org/10.2105/AJPH.94.10.1675, 2011.

135. Sparks, P.J., Rural health disparities, in International handbook of rural demography. 2012, Springer. p. 255-271.

136. Gamm, L., et al., Rural healthy people 2010: Identifying rural health priorities and models for practice. The Journal of rural health, 2002. 18(1): p. 9-14.

137. Walker, R.E., C.R. Keane, and J.G. Burke, Disparities and access to healthy food in the United States: A review of food deserts literature. Health \& Place, 2010. 16(5): p. 876884. 
138. Larson, N.I., M.T. Story, and M.C. Nelson, Neighborhood Environments: Disparities in Access to Healthy Foods in the U.S. American Journal of Preventive Medicine, 2009. 36(1): p. 74-81.e10.

139. McEntee, J. and J. Agyeman, Towards the development of a GIS method for identifying rural food deserts: Geographic access in Vermont, USA. Applied Geography, 2010. 30(1): p. 165-176.

140. Raja, S., C. Ma, and P. Yadav, Beyond food deserts: measuring and mapping racial disparities in neighborhood food environments. Journal of Planning Education and Research, 2008. 27(4): p. 469-482.

141. Moher, D., et al., Preferred reporting items for systematic reviews and meta-analyses: the PRISMA statement. PLoS medicine, 2009. 6(7): p. e1000097.

142. Dubowitz, T., et al., Diet And Perceptions Change With Supermarket Introduction In A Food Desert, But Not Because Of Supermarket Use. Health Aff (Millwood), 2015. 34(11): p. 1858-68.

143. Flynt, A. and M.I. Daepp, Diet-related chronic disease in the northeastern United States: a model-based clustering approach. International journal of health geographics, 2015. 14(1): p. 25.

144. Appalachian Regional Commission. Counties in Appalachia - Appalachian Regional Commission. 2018; Available from: https://www.arc.gov/appalachian_region/CountiesinAppalachia.asp.

145. Ghosh-Dastidar, B., et al., Distance to Store, Food Prices, and Obesity in Urban Food Deserts. American Journal of Preventive Medicine, 2014. 47(5): p. 587-595.

146. Smith, L.H. and C.H. Holloman, Health status and access to health care services: a comparison between Ohio's rural non-Appalachian and Appalachian families. Family \& Community Health, 2011. 34(2): p. 102-110.

147. Muamba, F., J.K. Clark, and N. Betz, Food access gaps in rural Ohio. Center for farmland policy innovation department of agricultural, environmental and development economics.[Accessed August 2, 2012], 2010: p. 2010-1.

148. Mayle, A.W., The Relationship Between Food Insecurity, Produce Intake and Behaviors, Hemoglobin Levels, BMI, and Health Status Among Women Participating in the West Virginia WIC and WIC FMNP Programs. 2015, Ohio University.

149. Gamba, R.J., et al., Measuring the food environment and its effects on obesity in the United States: a systematic review of methods and results. Journal of community health, 2015. 40(3): p. 464-475.

150. Rimando, M., J. Warren, and K. Smalley, Heart disease in rural areas. Rural public health: best practices and preventive models, 2014: p. 115.

151. Wallace, D., et al., Evaluation of the 'Live Life Better Service', a community-based weight management service, for morbidly obese patients. J Public Health (Oxf), 2016. 38(2): p. e138-49.

152. Nield, L. and S. Kelly, Outcomes of a community-based weight management programme for morbidly obese populations. J Hum Nutr Diet, 2016. 29(6): p. 669-676.

153. Karlsen, T.I., M. Sohagen, and J. Hjelmesaeth, Predictors of weight loss after an intensive lifestyle intervention program in obese patients: a 1-year prospective cohort study. Health Qual Life Outcomes, 2013. 11: p. 165.

154. Azim, S. and S.R. Kashyap, Bariatric surgery: pathophysiology and outcomes. Endocrinology and Metabolism Clinics, 2016. 45(4): p. 905-921. 
155. Nguyen N, V.S., Kim E, Bodunova N, Phelan M, Trends in utilization of bariatric surgery, 2009-2012. 2017.

156. Ionut, V. and R.N. Bergman, Mechanisms Responsible for Excess Weight Loss after Bariatric Surgery. http://dx.doi.org/10.1177/193229681100500536, 2011.

157. Mock, K., et al., Limited Food Budget Affects Weight Loss Outcomes After Bariatric Surgery in an Appalachian Population. Surgery for Obesity and Related Diseases, 2016. 12(7): p. S170.

158. Inc, S.I., Base SAS® 9.3 Procedures Guide [computer program]. 2011, SAS Institute Inc; Cary, NC.

159. Pro, J., v13. Cary, NC: SAS, 2012.

160. Gill, R.S., et al., Sleeve gastrectomy and type 2 diabetes mellitus: a systematic review. Surgery for Obesity and Related Diseases. 6(6): p. 707-713.

161. Torgerson, J.S., et al., Gallstones, gallbladder disease, and pancreatitis: Cross-Sectional and 2-year data from the Swedish obese subjects (SOS) and SOS reference studies. The American Journal of Gastroenterology, 2003. 98(5): p. 1032.

162. Sjöström, L., et al., Bariatric Surgery and Long-term Cardiovascular Events. JAMA, 2018. 307(1): p. 56-65.

163. Shah, N., et al., Weight loss after bariatric surgery: a propensity score analysis. Journal of Surgical Research, 2016. 202(2): p. 449-454.

164. United States Census, B., U.S. Census Bureau QuickFacts: West Virginia. 2017.

165. Skinner, A.C., et al., Prevalence and Trends in Obesity and Severe Obesity Among Children in the United States, 1999-2012. JAMA Pediatrics, 2017. 168(6): p. 561-566.

166. Thatcher, E., et al., Retail Food Store Access in Rural Appalachia: A Mixed Methods Study. Public Health Nursing, 2017. 34(3): p. 245-255.

167. Gibson, D.M., The neighborhood food environment and adult weight status: estimates from longitudinal data. American Journal of Public Health, 2011. 101(1): p. 71-78.

168. Hardin-Fanning, F. and A.T. Wiggins, Food Costs Are Higher in Counties With Poor Health Rankings. Journal of Cardiovascular Nursing, 2017. 32(2): p. 93-98.

169. Hardin-Fanning, F. and M.K. Rayens, Food cost disparities in rural communities. Health promotion practice, 2015. 16(3): p. 383-391.

170. Hardin-Fanning, F., Adherence to a Mediterranean diet in a rural Appalachian food desert. Rural and remote health, 2013. 13(2): p. 2293.

171. Melchior, M., et al., Food insecurity and children's mental health: a prospective birth cohort study. PloS one, 2012. 7(12): p. e52615.

172. Leung, C.W., et al., Household Food Insecurity Is Positively Associated with Depression among Low-Income Supplemental Nutrition Assistance Program Participants and Income-Eligible Nonparticipants. The Journal of Nutrition, 2015. 145(3): p. 622-627.

173. McIntyre, L., et al., Depression and suicide ideation in late adolescence and early adulthood are an outcome of child hunger. Journal of Affective Disorders. 150(1): p. 123-129.

174. Muldoon, K.A., et al., Food insufficiency is associated with psychiatric morbidity in a nationally representative study of mental illness among food insecure Canadians. Social psychiatry and psychiatric epidemiology, 2013. 48(5): p. 795-803.

175. Trivedi, T., et al., Obesity and obesity-related behaviors among rural and urban adults in the USA. Rural Remote Health, 2015. 15(4): p. 3267. 
176. Lenardson, J.D., A.Y. Hansen, and D. Hartley, Rural and Remote Food Environments and Obesity. Current Obesity Reports, 2015. 4(1): p. 46-53.

177. Dubowitz, T., et al., A natural experiment opportunity in two low-income urban food desert communities: research design, community engagement methods, and baseline results. Health Educ Behav, 2015. 42(1 Suppl): p. 87s-96s. 
Appendix 


\title{
Institutional Review Board Approval
}

\section{W. WestVirginiaUniversity. \\ Office of Research Integrity and Compliance \\ 886 CHESNUT RIDGE ROAD MORGANTOWN, WV 26506}

\section{Approval Letter Expedited}

\author{
Action Date \\ 03/09/2017 \\ To \\ Melissa Olfert \\ From \\ WVU Office of Research Integrity and Compliance \\ Approval Date \\ 03/09/2017 \\ Expiration Date \\ $03 / 08 / 2018$ \\ Subject \\ Protocol Approval Letter \\ ProtocolNumber \\ 1611355277 \\ Title \\ Bariatric Surgery Patient Lifestyle Behav ior and Clinical Outcomes
}

The above-referenced research study was rev iewed by the West Virginia University Institutional Review Board

IRB and was approved in accordance with 46 CFR $46.101 \mathrm{~b}$.

It has been determined that this study is of minimal risk and meets the criteria as defined by the expedited categories listed below:

- Category 5. Research inv olving materials (data, documents, records, or specimens) that have been collected, or will be collected solely for nonresearch purposes (such as medical treatment or diagnosis).

- Category 7. Research on individual or group characteristics or behavior (including, but not limited to, research on perception, cognition, motiv ation, identity, language, communication, cultural beliefs or practices, and social behavior) or research employing survey, interview, oral history, focus group, program evaluation, human factors evaluation, or quality assurance methodologies. [NOTE: Some research in this category may be exempt from the DHHS regulations for the protection of human subjects. See Exempt Categories and $45 \mathrm{CFR} 46.101(\mathrm{~b})(2)$ and (b)(3). This listing refers only to research that is not exempt ]

Documents reviewed and/or approved as part of this submission:

Overall HIPAA Waiver_3.8.17.docx: 2017-03-08-05:00

Bariatric consent_3.8.17.pdf: 2017-03-08-05:00

FollowUp_BariatricDataEntry (3).p df: 2017-03-08-05:00

Bariatric Revisions 3.8.17.docx: 2017-03-08-05:00 
Specific Minor Revisions_investigator notes 22217.docx: 2017-02-24-05:00

Szola_emailfollowup.docx 2017-03-02-05:00

Bariatric Revisions_3.1.17.docx: 2017-03-03-05:00

Retrospective_BariatricDataE nt (1).pdf: 201 7-03-03-05:00

Documents for use in this study are available in the WUVc system in the Hotes and Attachmerts section of your protocol.

The Office of Research Irtegrity and Complianoe is here to provide as sistance to you from the iritial sub ris sion of an IRB protoool and all subsequent activity. Flease feel free to contact us by phore at 304.293 .7073 with any question you may have. Thank you.

WVU Office of Research Integrity and Compliance

Date:0309/2017

Sizned:

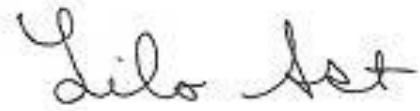

Lilo Ast

Senior Program Coordinator

Once you begin your human subject research, the following regulations apply.

1. Unarticipated or serious adverse eventsiside effects encourtered in this research study rnust be reported to the IRB within five (S) days via the Hotify IRB action

2. Any modifications to the study protocol or informed consent form roust be reviewed and approved by the $\mathbb{R} B$ prior to inqlementation via sub rrission of an amendmert.

3. You may notuse a modified infomed consent fom until it has been approved and validated by the IRB. 


\section{Retrospective Data Collection Survey}

\begin{tabular}{|c|c|}
\hline Variable / Field Name & Section Header Field Label \\
\hline record_id & Record ID \\
\hline ptname & Patient Name \\
\hline digit_id_number & 4-digit ID number \\
\hline gender & Gender \\
\hline dob & Date of Birth (MM/DD/YYYY) \\
\hline enter_patient_phone_number & Enter patient phone number \\
\hline address & Patient home address (include zip code) \\
\hline primary_insurance & Provide name of primary Insurance Provider Easiest way to find $\mathrm{i}$ \\
\hline second_insur & Please provide name of secondary Insurance Provider \\
\hline initalvisit & When was initial clinic visit? (MM/DD/MY) \\
\hline hadsurg & Has the patient had surgery yet? Easily found under operative (lo \\
\hline surgdate & When did the patient have surgery? $(\mathrm{MM} / \mathrm{DD} / \mathrm{VY})$ \\
\hline surgtype & Which surgery did the patient have? \\
\hline ebw & What was the patients calculated Excess Body Weight (EBW)? \\
\hline nutritioned & How many months of preoperative nutritional eduation was reqı \\
\hline preopwtls & How much preoperative weight loss was/is required? \\
\hline what_was_weight_at_surgery & What was weight AT SURGERY? Fou can find this in the note from \\
\hline preoploss & How much pre-operative weight loss was achieved? \\
\hline if_you_can_t_find_previous & If you can't find previous questions -- Did dietitian reduce calorie \\
\hline liquiddiet & How many days was the patients pre-operative liquid diet? \\
\hline goodmeasures & Did the patient receive a referral to use Good Measures? (this w \\
\hline surgeon_rating_of_patient & Surgeon rating of patient candidacy for surgery?\$subjective meas \\
\hline psychrate & Psychologist rating of patients candidacy for surgery?(\$subjective \\
\hline rdrate & Dietitian rating of patients candidacy for surgery? Dietitians usua \\
\hline age & The following in Age at initial visit \\
\hline height & Height \\
\hline initalwt & Weight at initial visit \\
\hline bmi_at_inital_visit & BMI at initial visit \\
\hline agehighestwt & The following in What age was their highest weight? \\
\hline wtat18 & Weight at age 18 \\
\hline ethnicity & Ethnicity, choose all that apply \\
\hline years_of_education & Years of education? \\
\hline occupation & Occupation \\
\hline typeoccupation & Nature of occupation \\
\hline maritalstat & Marital status \\
\hline chidren & Do you have children? \\
\hline noofchild & How many children do you have? \\
\hline illegal_drugs & Have you ever used illegal or street drugs? \\
\hline illegal_frequency & If you've used illegal drugs was it \\
\hline have_you_stopped_using_str & Have you stopped using street drugs? \\
\hline do_you_drink_alcohol & Do you drink alcohol? \\
\hline did_you_have_a_previous_al & Did you have a previous alcohol problem? \\
\hline how_often_do_you_drink_alc & How often do you drink alcohol? \\
\hline addiction_rehab_or_treat & Have you ever had an addiction problem that required treatmen \\
\hline which_addiction & If yes to an addiction problem, please check all that apply: \\
\hline family_history & Family History \\
\hline
\end{tabular}


father_s_present_age

father_age_death

mother_present_age

mother_age_death

siblings

family_history_disease

prediabetes_hbs

diabetes_current

diabetes_insulin

diabetes_meds

diabetes_diet

short_breath_steps

short_breath_block

do_you_have_asthma

inhaler_daily

inhaler_need

nebulizer

useoxygen

asthma_hospital

sleepapnea

oral_appli

cpap_bipap

nightoxygen

sleep_apnea_surgery

snore

night_catch

chair

copd

emphysema

cardiologist

highbp

highbp_med

irreg_hb

irreg_hb_meds

heartattack

abnormalekg

heart_cath

stresstest

chf

heartfail_hospital

angio_stent

bloodthinner

swelling

dvt

dvt_bloodthin

pulm_embolus

pe_bloodthin
Father's present age

If father is not living, what was age at death?

Mother's present age

If mother is not living, what was age at death?

How many brothers and sisters of you have in your family?

Please check all that apply if there is a family history of the follo

Endocrine

Have you been told that you are pre-diabetic or have high blood

Do you currently have diabetes?

Do you take insulin?

Do you take oral diabetic medication?

Do you use diet to treat your diabetes?

Pulmonary

Do you get short of breath when walking up a flight of steps?

Do you ever get short of breath walking a city block?

Do you have asthma?

(If yes to asthma) Do you use an inhaler daily?

(If yes to asthma) Do you use inhalers only when needed?

(If yes to asthma) Do you use nebulizer treatments?

(If yes to asthma) Do you use oxygen?

(If yes to asthma) Have you ever been hospitalized for asthma w Have you ever been diagnosed with sleep apnea?

(If yes to sleep apnea) Do you use oral appliance

(If yes to sleep apnea) Do you use a CPAP or Bipap machine?

(If yes to sleep apnea) Do you use nighttime oxygen?

(If yes to sleep apnea) Have you had surgery for the treatment o

Do you snore when you sleep?

Do you wake up at night trying to catch your breath?

Do you routinely sleep in a chair at night?

Have you ever been diagnosed with COPD?

Have you ever been diagnosed with emphysema?

Cardiac Have you been under the care of a heart specialist (cardiologist)

Do you have high blood pressure?

Do you take medication for high blood pressure?

Have you seen a doctor for irregular heartbeats?

Do you take medication for irregular heartbeats?

Have you ever had a heart attack?

Have you ever had an abnormal EKG (heart tracing?)

Have you ever had a cardiac (heart) catheterization?

Have you ever had a heart treadmill or chemical stress test?

Have you ever been told that you have congestive heart failure?

Have you ever been hospitalized for heart failure?

Have you ever had an angioplasty or cardiac stents placed for yo Are you on blood thinner for the treatment of your heart disease Do you have leg, ankle, or feet swelling?

Have you ever had blood clots in your legs (DVT)?

If yes to the previous question, were you treated with blood thir Have you ever had blood clots in your lungs (pulmonary embolu: If yes to the previous question, were you treated with blood thir 


varicose
ivcfilter
stroke
highchol
highchol_med
hightri
hightri_med
gastroenterologist
difficulty_chewing
constipation
diarrhea
acid_reflux
medications_for_heartburn
gerd
hiatal_hernia
stomach_or_duodenal_ulcer
ibs
lactose_intolerant
crohn_s_disease
ulcerative_colitis
cirrhosis
fatty_liver
hepatitis
celiac_sprue
pancreatitis
previouswtloss_surg
seizure
seizure_meds
ms
ps
ps_surgery
arthritis
hippain
kneepain
anklepain
shoulder_pain
backpain
cane_or_walker
scooter_wheelchair
fibromyalgia
cancer
type_cancer
proteinuria
kidney_stone
urine_leak
stool_leak
uti

Have you been treated for varicose veins? Have you ever had an IVC filter placed for blood clots? Have you ever had a stroke? Have you ever been told that your cholesterol levels are high? Do you have medication for high cholesterol levels? Have you ever been told that you have high triglyceride levels? Do you take medication for high triglyceride levels?

GI (Stomach/In1 Have you seen a GI specialist (gastroenterologist) in the past 2 y Do you have frequent difficulty chewing or swallowing? Do you suffer from difficulty having bowel movements (constipa Do you have frequent loose stools (diarrhea)? Do you suffer from heartburn (acid reflux)?

Do you routinely take over the counter medications for heartbur Do you take prescription medications for heartburn (GERD)? Have you ever been told that you have a hiatal hernia (hernia in Have you ever had a stomach or duodenal ulcer?

Have you ever been diagnosed with irritable bowel syndrome? Are you lactose intolerant?

Have you ever been diagnosed with Crohn's disease?

Have you ever been diagnosed with ulcerative colitis?

Have you ever been diagnosed with cirrhosis?

Have you ever been diagnosed with fatty liver?

Have you ever been diagnosed with hepatitis?

Have you ever been diagnosed with celiac sprue?

Have you ever been treated for pancreatitis?

Have you ever had a previous weight-loss surgery?

HEENT/Neuro Have you ever had a seizure?

Are you currently taking any medications to prevent seizures? Have you ever been diagnosed with multiple sclerosis (MS)?

Have you ever been diagnosed with pseudotumor cerebri? If yes to pseudotumor cerebri, have you received surgical treatm Have you ever been diagnosed with arthritis? If yes, indicate typ Do you have hip pain that limits your activity level? If yes, indica Do you have knee pain that limits your activity level? If yes, indic Do you have ankle pain that limits your activity? If yes, indicate $\bar{c}$ Do you have shoulder pain that limits your activity? If yes, indica Do you have frequent back pain which limits your activity level? Do you use a cane or walker to help you walk? Do you use a motorized scooter or wheelchair? Have you ever been diagnosed with fibromyalgia? If YES, how is Have you ever been diagnosed with a cancer other than skin can If YES to being diagnosed with cancer, indicate type

Bladder/kidney Have you ever been told that you have protein in your urine? Have you ever had a kidney stone? Do you have leakage of urine with laughing/coughing/sneezing? Do you have leaking of stool (feces) with laughing/coughing/sne Have you ever had a bladder infection (UTI)? 


\begin{tabular}{|c|c|c|}
\hline diagnoseddepression & Depression & Have you ever been diagnosed with depression? \\
\hline depress_meds & & Do you require medications for your depression? \\
\hline depress_ocass_episod & & Is your depression occasional or episodic? \\
\hline depress_lackcare & & Does your depression prevent you from caring for yourself? \\
\hline depress_lackjob & & Does your depression prevent you from keeping a job? \\
\hline depress_hospital & & Have you ever required hospitalization for depression? \\
\hline depress_psychcare & & Are you currently receiving care by a psychologist, psychiatrist, $\mathrm{c}$ \\
\hline depress_familydoc & & Is your depression being treated by your family doctor? \\
\hline anxiety_panic & & Have you ever been diagnosed with anxiety/panic attacks? \\
\hline anxiety_meds & Panic/Anxiety & Do you require medications for anxiety? \\
\hline anxiety_occas_episod & & Is your depression only occasional or episodic? \\
\hline anxiety_lackjob & & Does your anxiety prevent you from maintaining employment? \\
\hline anxiety_psychcare & & Have you ever required care by a psychologist, psychiatrist, or th \\
\hline anxiety_famdoc & & Is your anxiety being treated by your family doctor? \\
\hline bipolar & & Have you ever been diagnosed with having a bipolar disorder? \\
\hline bd_med & Bipolar Disorde & Do you require medications for your bipolar disorder? \\
\hline bd_preventcare & & Does your bipolar disorder prevent you from caring for yourself? \\
\hline bd_preventjob & & Does your bipolar disorder prevent you from keeping a job? \\
\hline bd_hospital & & Have you ever required hospitalization for bipolar disorder? \\
\hline bd_psychcare & & Are you currently receiving care by a psychologist, psychiatrist, $\mathrm{c}$ \\
\hline bd_famdoc & & Is your bipolar disorder being treated by your family doctor? \\
\hline bd_othermentalill & & Have you ever been diagnosed with schizophrenia or any other $f$ \\
\hline othermentalill_hosp & & Have you been hospitalized for any form of mental illness or bre \\
\hline fertilityworkup & Fertility & Have you ever had a fertility workup? \\
\hline current_pregnant & & Are you currently pregnant? \\
\hline irregular_period & & Are your periods irregular? \\
\hline heavy_prolong_period & & Do you have abnormally heavy or prolonged menstrual periods? \\
\hline ever_been_pregnant & & Have you ever been pregnant? \\
\hline preg_diabetes & During pregnan & Diabetes \\
\hline preg_low_iron_levels & & Low iron levels \\
\hline preg_high_blood_pressure & & High blood pressure \\
\hline preg_pre_eclampsia & & Pre-eclampsia \\
\hline menopause_2 & & Are you currently going through or in menopause? \\
\hline oral_contra & & Are you currently oral contraceptives? \\
\hline other_contra & & Are you currently using any other form of contraception? \\
\hline pcos ${ }^{-}$ & & Have you ever been diagnosed with polycystic ovarian disease ( $\mathrm{F}$ \\
\hline pcos_oralcontra & For your PCOS.. & Are you being treated with oral contraceptives? \\
\hline pcos_metformin & & Are you being treated with metformin? \\
\hline pcos_meds & & Are you being treated with any other medication(s)? \\
\hline pcos_infertile & & Have you been told that you are infertile? \\
\hline other_surgeries & & Have you ever had any of the following types of surgery: \\
\hline medications & & Type medications patient is taking from surgeons note \\
\hline allergies & & Type in any allergies patient has from EPIC \\
\hline sleepap_1 & Using the scale & Sitting and reading \\
\hline sleepap_2 & & Watching TV \\
\hline sleepap_3 & & Sitting inactive in a public place (theater, meeting) \\
\hline sleepap_4 & & As a passenger in a car for an hour without a break \\
\hline
\end{tabular}




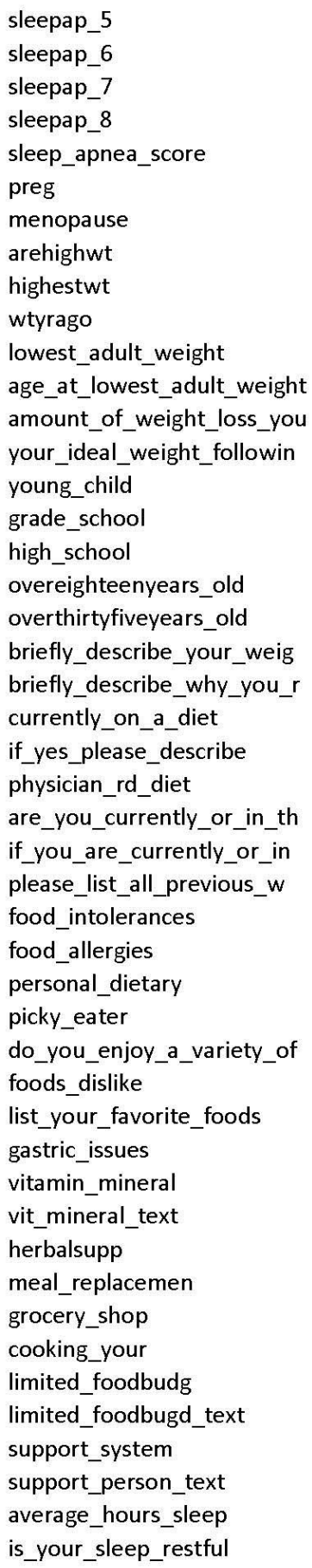

Lying down to rest in the afternoon when circumstances permit Sitting and talking to someone

Sitting quietly after a lunch without alcohol

In a car, while stopped for a few minutes in traffic

Sleep apnea score

Nutrition Quest For women: Do you have plans for future pregnancy?

For women: Are you...

Are you currently at your highest weight?

If you're not at your highest weight now, what has been your hic Weight one year ago

Lowest adult weight?

Age at lowest adult weight

Amount of weight loss you hope to see with surgery?

Your ideal weight following surgery?

Young child

Grade School

High School

18-35 years old

$35+$ years old

Briefly describe your weight history; has weight gain/loss been $\mathrm{g}$ Briefly describe why you're seeking bariatric surgery at this time, Are you currently on a diet for a medical reason?

If yes, please describe

Are you currently or have you in the past worked with a Dietitiar Are you currently or in the past used prescription or over the col If you are currently or in the past used prescription or over the $\mathrm{c}$ Please list all previous weight loss attempts not already listed (nc Any food intolerances? Please identify

Do you have any food allergies? Please identify

Please list any personal, cultural, religious, ethnic practices, or re Are you a picky eater?

Do you enjoy a variety of foods/trying new things?

What foods do you especially dislike?

List your favorite foods (rank is not important

Any problems with the following (check all that apply)?

Do you currently take any vitamin or mineral supplements?

Please list the name and amount of any vitamin or mineral suppl Do you use any other Dietary or Herbal Supplements on a regula Do you use Meal Replacement Products (liquids, bars, etc)? Eist b Who does your grocery shopping? (yourself, or please indicate o Who does your cooking (yourself or other, please indicate who) Are you on a limited food budget or rely on food stamps, food $p_{i}$ If you do have a limited budget or rely on food stamps, food pan Do you feel you have a support system in place as you go throug If you believe you have a support system in place as you go thro What is your average hours of sleep per night?

Is your sleep restful? 
rate_daily_stress techniques_stress eat_stress_response stress_typeof_food regular_exercise typeof_activity activity_limitations activity_typicalday activity_after_surgery times_eat_per_day meal_routine_change times_skip_meal often_snack_day type_of_snack meal_duration uncomfortable_full_meal where_do_you_typically_eat whom_do_you_typically_eat meals_prepared_away convenience_foods

fv_servingsday

common_fruits_veg

sweets

juice

regular_soda

diet_soda

unsweet_sweet_tea

sweet_tea

sweet_unsweet_not_specifie coffee

decaf_coffee

milk

water

alcohol

number_alcohol

tobacco

did_you_use_tobacco_produc which_tobacco_products

amount_tobacco

quit_tobacco

challenging_habits

easiest_habits

past_months_change

health_plans

hour_food_recall

gormally_binge_eating_scor md_health_locus_internal
How would you rate your daily stress level

What things/techniques do you use to manage or reduce stress? How often do you find yourself eating in response to stress, emc List any specific foods you have during those times of stress

Do you participate in regular exercise (walking, biking, swimming What types of activity do you do? List type, frequency/duration I If you have any activity limitations, please describe:

How would you describe your activity during a typical day at wor What plans do you have to increase physical activity after surger How many times do you eat a day (on average)?

Does your meal routine change greatly from weekdays to weeke How often do you skip meals?

Do you often snack, nibble or graze throughout the day? If you often snack, nibble or graze, please describe snack How long do your meals typically last?

How often do you feel uncomfortably full after eating?

Where do you typically eat?

With whom do you typically eat?

Meals consumed or prepared away from home (including fast for How often do you consume convenient foods such as: ready-mac How many servings of fruits or vegetables combined per day are List common fruits/vegetable choices

How often do you consume sweets (candy, cookies, cake, etc.)?E

How much of th Juice

Regular Soda

Diet soda

Unsweet tea

Sweet Tea

Sweet/unsweet, not specified

Coffee

Decaf coffee

Milk

Water

How often do you have a drink containing alcohol?

How many drinks containing alcohol do you have on a typical da Do you currently use tobacco products

Did you use tobacco products in the past?

Which tobacco products do you currently use. Check all that app Of your preferred use of tobacco, indicate the amount you use Have you previously quit using tobacco? (if yes, when?)

List which of your current eating and lifestyle habits will be the $t$ List which of your current eating and lifestyle habits are going wi List any changes you have made in the past 3-6 months to be he List something you are planning to start working on this month $f$ Type 24-hour food recall from dietitian note

The following ir Gromally Binge Eating Score

IF USED Multidimensional health locus of control scale: 
mdl_health_locus_chance md_health_locus_powerful threefactor_cogrestraint threefactor_disinhibition threefactor_hunger barratt_impulsiveness_scal brief_cope_score_most brief_cope_score_least becks_depression_inventory becks_anxiety_inventory audit_c_score date_of_baseline_labs systolic_blood_pressure diastolic_blood_pressure blood_o2_saturation pulse

baseline blood glucose mea

hemoglobin_a1c

calcium

albumin

total_protein

sodium

potassium

co2

chloride

bun

creatinine

alp

alt

ast

bilirubin

total_cholesterol

triglycerides

hdl

Idl

vldl

rbc

hemoglobin

hematocrit

wbc

platelet

ferritin

total_iron_binding_capacit

iron

folate

thyroid_stimulating_hormon vitamin_b12
IF USED Rultidimensional health locus of control scale: [ehance IF USED Multidimensional health locus of control scale:Bowerful Three Factor Eating Questionnaire Subscale:Cognitive Restraint o Three Factor Eating Questionnaire Subscale:Bisinhibition (0-16)] Three Factor Eating Questionnaire Subscale: : Eunger (0-14)? Barratt Impulsiveness Scale Brief COPE Score (MOST USED technique)

Brief COPE Score (LEAST USED technique)

Becks Depression Inventory Score

Becks Anxiety Inventory Score

AUDIT-C Score

The following q Date of baseline (initial visit lab)?

Systolic Blood Pressure - baseline

Diastolic Blood Pressure - baseline

Blood $\mathrm{O} 2$ saturation - baseline

Pulse - baseline

Baseline Blood Glucose Measure - baseline

Hemoglobin A1C (\%) - baseline

Calcium - baseline

Albumin - baseline

Total Protein - baseline

Sodium - baseline

Potassium - baseline

$\mathrm{CO} 2$ - baseline

Chloride - baseline

BUN - baseline

Creatinine - baseline

ALP - baseline

ALT - baseline

AST - baseline

Bilirubin - baseline

Total Cholesterol - baseline

Triglycerides- baseline

HDL - baseline

LDL - baseline

VLDL - baseline

RBC - baseline

Hemoglobin - baseline

Hematocrit - baseline

WBC - baseline

Platelet - baseline

Ferritin - baseline

Total Iron Binding Capacity - baseline

Iron - baseline

Folate - baseline

Thyroid Stimulating Hormone (TSH) - baseline

Vitamin B12 - baseline 
vitamin_d

date_of_3_month_labs

weight_at_3_months_post

bmi_3_month

systolic_blood_pressu2_ca3

diastolic_blood_press2_502

blood_o2_saturation2_aeb

pulse2_a37

baseline_blood_glucos2_a 61

hemoglobin_a1c2_dd3

calcium2_ec7

albumin2_f5b

total_protein2_8f4

sodium2_4d8

potassium2_a04

co22_fob

chloride2_6c1

bun2_48d

creatinine2_e37

alp2_01c

alt2_e57

bilirubin2_77b

ast2_e76

total_cholesterol2_5d8

triglycerides2_ffo

hdl2_aa0

IdI2_102

vld12_558

rbc2_c03

hemoglobin2_Obf

hematocrit2_b0a

wbc2_ac7

platelet2_ad6

ferritin2_b37

total_iron_binding_ca2_e9b

iron2_11b

folate2_1bc

thyroid_stimulating_h2_700

vitamin_b122_98d

vitamin_d2_93d

date_of_6_month_labs

bmi_6_month

weight_at_6_months

systolic_blood_pressu2_503

diastolic_blood_press2_3de

blood_o2_saturation2_599

pulse2_3fd
Vitamin D3, total - baseline

3 Month Meası Date of 3 month assessment/note/labs?

Weight at 3 months post

BMI - 3 month

Systolic Blood Pressure - 3 month

Diastolic Blood Pressure - 3 month

Blood $\mathrm{O} 2$ saturation - 3 month

Pulse - 3 month

Blood Glucose Measure - 3 month

Hemoglobin A1C (\%) - 3 month

Calcium - 3 month

Albumin - 3 month

Total Protein - 3 month

Sodium - 3 month

Potassium - 3 month

$\mathrm{CO} 2$ - 3 month

Chloride - 3 month

BUN - 3 month

Creatinine - 3 month

ALP - 3 month

ALT - 3 month

Bilirubin - 3 month

AST - 3 month

Total Cholesterol - 3 month

Triglycerides - 3 month

HDL - 3 month

LDL - 3 month

VLDL - 3 month

RBC - 3 month

Hemoglobin - 3 month

Hematocrit - 3 month

WBC - 3 month

Platelet - 3 month

Ferritin - 3 month

Total Iron Binding Capacity - 3 month

Iron - 3 month

Folate - 3 month

Thyroid Stimulating Hormone (TSH) - 3 month

Vitamin B12 - 3 month

Vitamin D3, total - 3 month

6 month measu Date of 6 month assessment/note/labs?

$\mathrm{BMI}-6$ month

Weight at 6 months post

Systolic Blood Pressure - 6 month

Diastolic Blood Pressure - 6 month

Blood $\mathrm{O} 2$ saturation - 6 month

Pulse - 6 month 
baseline_blood_glucos2_a73

hemoglobin_a1c2_06c

calcium2_4b9

albumin2_bf6

total_protein2_569

sodium2_956

potassium2_6f8

co22_3be

chloride2_808

bun2_257

creatinine2_c39

alp2_e11

alt2_66c

ast2 $\mathrm{d} 47$

bilirubin2_98a

total_cholesterol2_ca2

triglycerides2_a01

hdl2_dc7

Idl2_60f

vld12_99a

rbc2_364

hemoglobin2_4a6

hematocrit2_d4b

wbc2_c81

platelet2_dcc

ferritin2_3d4

total_iron_binding_ca2_58c

iron2_eca

folate2_556

thyroid_stimulating_h2_de8

vitamin_b122_2ab

vitamin_d2_4c4

date_of_9mo_labs_2

weight_at_9_month_post_2

bmi_9_month_2

systolic_blood_pressu2_79e_2

diastolic_blood_press2_2fa_2

pulse2_f4a_2

baseline_blood_glucos2_126

hemoglobin_a1c2_c85

calcium2_b2f_2

albumin2_913

total_protein2_a3f_2

sodium2_ade_2

potassium2_11e_2

co22_ca7

chloride2_8dd_2
Blood Glucose Measure - 6 month

Hemoglobin A1C (\%) - 6 month

Calcium - 6 month

Albumin - 6 month

Total Protein - 6 month

Sodium - 6 month

Potassium - 6 month

$\mathrm{CO} 2$ - 6 month

Chloride - 6 month

BUN - 6 month

Creatinine - 6 month

ALP - 6 month

ALT - 6 month

AST - 6 month

Bilirubin - 6 month

Total Cholesterol - 6 month

Triglycerides - 6 month

HDL - 6 month

LDL -6 month

VLDL -6 month

RBC - 6 month

Hemoglobin - 6 month

Hematocrit - 6 month

WBC - 6 month

Platelet -6 month

Ferritin - 6 month

Total Iron Binding Capacity - 6 month

Iron -6 month

Folate - 6 month

Thyroid Stimulating Hormone (TSH) - 6 month

Vitamin B12 - 6 month

Vitamin D3, total - 6 month

9 month measu Date of 9 month assessment/note/labs?

Weight at 9 month post

BMI- 9 month

Systolic Blood Pressure - 9 month

Diastolic Blood Pressure - 9 month

Pulse - 9 month

Blood Glucose Measure - 9 month

Hemoglobin A1C (\%) - 9 month

Calcium -9 month

Albumin - 9 month

Total Protein - 9 month

Sodium - 9 month

Potassium - 9 month

$\mathrm{CO} 2-9$ month

Chloride - 9 month 
bun2_b34

creatinine2_78f_2

alp2_b35

alt2_302

ast2 $7 \mathfrak{f 3}$

bilirubin2_146

total_cholesterol2_e62

triglycerides2_739

hdl2_c01

Idl2_d6f_2

vld12_278

rbc2_e4f_2

hemoglobin2_cd2

hematocrit2 $4 \mathrm{ff} 6$

wbc2_d0c_2

platelet2_753

ferritin2_715

total_iron_binding_ca2_bf6

iron2_71d_2

folate2_c6c_2

thyroid_stimulating_h2_177

vitamin_b122_e8d_2

vitamin_d2_305

date_of_1_year_labs

weight_at_1_year_post

bmi_1_year

systolic_blood_pressu2_79e

diastolic_blood_press2_2fa

blood_o2_saturation2_7f9

pulse2_f4a

baseline_blood_glucos2_125

hemoglobin_a1c2_c84

calcium2_b2f

albumin2_912

total_protein2_a3f

sodium2_ade

potassium2_11e

co22_ca6

chloride2_8dd

bun2_b33

creatinine2_78f

alp2_b34

alt2_301

ast2_7f2

bilirubin2 145

total_cholesterol2_e61

triglycerides2_738
BUN - 9 month

Creatinine - 9 month

ALP - 9 month

ALT - 9 month

AST - 9 month

Bilirubin - 9 month

Total Cholesterol - 9 month

Triglycerides - 9 month

HDL - 9 month

LDL - 9 month

VLDL - 9 month

RBC - 9 month

Hemoglobin - 9 month

Hematocrit - 9 month

WBC - 9 month

Platelet - 9 month

Ferritin - 9 month

Total Iron Binding Capacity - 9 month

Iron - 9 month

Folate - 9 month

Thyroid Stimulating Hormone (TSH) - 9 month

Vitamin B12 - 9 month

Vitamin D3, total - 9 month

1 year measure Date of 1 year assessment/note/labs?

Weight at 1 year post

BMI- 1 year

Systolic Blood Pressure - 1 year

Diastolic Blood Pressure - 1 year

Blood $\mathrm{O} 2$ saturation - 1 year

Pulse - 1 year

Blood Glucose Measure - 1 year

Hemoglobin A1C (\%) - 1 year

Calcium - 1 year

Albumin - 1 year

Total Protein - 1 year

Sodium - 1 year

Potassium - 1 year

$\mathrm{CO} 2$ - 1 year

Chloride - 1 year

BUN - 1 year

Creatinine - 1 year

ALP - 1 year

ALT - 1 year

AST - 1 year

Bilirubin - 1 year

Total Cholesterol - 1 year

Triglycerides - 1 year 


\begin{tabular}{|c|c|}
\hline hdl2_c00 & HDL - 1 year \\
\hline IdI2_d6f & LDL - 1 year \\
\hline vldl2_277 & VLDL - 1 year \\
\hline rbc2_e4f & RBC - 1 year \\
\hline hemoglobin2_cd1 & Hemoglobin - 1 year \\
\hline hematocrit2_4f5 & Hematocrit - 1 year \\
\hline wbc2_d0c & WBC -1 year \\
\hline platelet2_752 & Platelet - 1 year \\
\hline ferritin2_-714 & Ferritin - 1 year \\
\hline total_iron_binding_ca2_bf5 & Total Iron Binding Capacity - 1 year \\
\hline iron2_71d & Iron - 1 year \\
\hline folate2_c6c & Folate - 1 year \\
\hline thyroid_stimulating_h2_176 & Thyroid Stimulating Hormone (TSH) - 1 year \\
\hline vitamin_b122_e8d & Vitamin B12 - 1 year \\
\hline vitamin_d2_304 & Vitamin D3, total - 1 year \\
\hline date_of_18_month_labs_2 & Date of 18 month assessment/note/labs? \\
\hline weight_at_18_month_post_2 & Weight at 18 month post \\
\hline bmi_18_month_2 & BMI -18 month \\
\hline systolic_blood_pressu2_9fa_2 & Systolic Blood Pressure - 18 month \\
\hline diastolic_blood_press2_c100 & Diastolic Blood Pressure - 18 month \\
\hline blood_o2_saturation2_9f7 & Blood O2 saturation - 18 month \\
\hline pulse2_fof_2 & Pulse - 18 month \\
\hline baseline_blood_glucos2_1d 6 & Blood Glucose Measure - 18 month \\
\hline hemoglobin_a1c2_5a10 & Hemoglobin A1C (\%) - 18 month \\
\hline calcium2_b2b_2 & Calcium - 18 month \\
\hline albumin2_aeb_2 & Albumin - 18 month \\
\hline total_protein2_278 & Total Protein - 18 month \\
\hline sodium18_month & Sodium - 18 month \\
\hline potassium18_month & Potassium - 18 month \\
\hline co218_month & $\mathrm{CO} 2$ - 18 month \\
\hline chloride18_month & Chloride - 18 month \\
\hline bun18_month & BUN - 18 month \\
\hline creatinine18_month & Creatinine - 18 month \\
\hline alp18_month & ALP - 18 month \\
\hline alt18_month & ALT - 18 month \\
\hline ast18_month & AST - 18 month \\
\hline bilirubin18_month & Bilirubin - 18 month \\
\hline total_cholesterol18_month & Total Cholesterol - 18 month \\
\hline triglycerides18_month & Triglycerides - 18 month \\
\hline hdl18_month & HDL - 18 month \\
\hline Idl18_month & LDL - 18 month \\
\hline vldl18_month & VLDL - 18 month \\
\hline rbc18_month & RBC - 18 month \\
\hline hemoglobin18_month & Hemoglobin - 18 month \\
\hline hematocrit18_month & Hematocrit - 18 month \\
\hline wbc18_month & WBC -18 month \\
\hline platelet2_18_month & Platelet - 18 month \\
\hline
\end{tabular}


ferritin2_18_month

total_iron_binding_18_month

iron2_18_month

folate18_month

thyroid_stimulating18_month

vitamin_b1218_month

vitamin_d2_18_month

date_of_2_year_labs

weight_at_2_year_post

bmi_2_year

systolic_blood_pressu2_9fa

diastolic_blood_press2_c98

blood_o2_saturation2_9f6

pulse2_fof

baseline_blood_glucos2_1d 5

hemoglobin_a1c2_5a9

calcium2_b2b

albumin2_aeb

total_protein2_277

sodium2_Ocf

potassium2_4c8

co22_60b

chloride2_3d8

bun2_5c9

creatinine2_568

alp2_869

alt2_c53

ast2_7e5

bilirubin2_0b7

total_cholesterol2_346

triglycerides2_59a

hdl2_ecc

IdI2_8cb

vldl2_2b1

rbc2_499

hemoglobin2_d34

hematocrit2_3cc

wbc2_de9

platelet2_42d

ferritin2_d01

total_iron_binding_ca2_2c0

iron2_067

folate2_8ce

thyroid_stimulating_h2_af8

vitamin_b122_ed1

vitamin_d2_5f5

date_of_3_year_labs
Ferritin - 18 month

Total Iron Binding Capacity - 18 month

Iron - 18 month

Folate -18 month

Thyroid Stimulating Hormone (TSH) - 18 month

Vitamin B12 - 18 month

Vitamin D3, total - 18 month

2 year measure Date of 2 year assessment/note/labs?

Weight at 2 year post

BMI -2 year

Systolic Blood Pressure - 2 year

Diastolic Blood Pressure - 2 year

Blood $\mathrm{O} 2$ saturation -2 year

Pulse - 2 year

Blood Glucose Measure - 2 year

Hemoglobin A1C (\%) - 2 year

Calcium - 2 year

Albumin - 2 year

Total Protein - 2 year

Sodium - 2 year

Potassium - 2 year

$\mathrm{CO} 2$ - 2 year

Chloride - 2 year

BUN - 2 year

Creatinine - 2 year

ALP - 2 year

ALT - 2 year

AST - 2 year

Bilirubin - 2 year

Total Cholesterol - 2 year

Triglycerides - 2 year

HDL - 2 year

LDL - 2 year

VLDL - 2 year

RBC - 2 year

Hemoglobin - 2 year

Hematocrit - 2 year

WBC -2 year

Platelet - 2 year

Ferritin - 2 year

Total Iron Binding Capacity - 2 year

Iron - 2 year

Folate - 2 year

Thyroid Stimulating Hormone (TSH) - 2 year

Vitamin B12 - 2 year

Vitamin D3, total - 2 year

3 year measure Date of 3 year assessment/note/labs? 
weight_at_3_year_posts

bmi_3_year

systolic_blood_pressu2_beb

diastolic_blood_press2_abd

blood_o2_saturation2_f6a

pulse2_248

baseline_blood_glucos2_1df

hemoglobin_a1c2_add

calcium 2_67a

albumin2_a4c

total_protein2_9a7

sodium2_a21

potassium2_c2a

co22 251

chloride2_710

bun2_7e9

creatinine2_f9a

alp2_704

alt2_b89

ast2_889

bilirubin2_160

total_cholesterol2_e51

triglycerides2_5ef

hdl2_9ab

IdI2_3ab

vldl2_01d

rbc2_e1d

hemoglobin2_fbe

hematocrit2_5d7

wbc2_913

platelet2_363

ferritin2_fe1

total_iron_binding_ca2_bbc

iron2_5bd

folate2_333

thyroid_stimulating_h2_e49

vitamin_b122_0a4

vitamin_d2_519

key_previous_diagnoses

clinical_events_procedures

add_any_additional_notes_a
Weight at 3 year post

$\mathrm{BMI}-3$ year

Systolic Blood Pressure - 3 year

Diastolic Blood Pressure - 3 year

Blood $\mathrm{O} 2$ saturation - 3 year

Pulse - 3 year

Blood Glucose Measure - 3 year

Hemoglobin A1C (\%) - 3 year

Calcium - 3 year

Albumin - 3 year

Total Protein - 3 year

Sodium - 3 year

Potassium - 3 year

$\mathrm{CO} 2$ - 3 year

Chloride - 3 year

BUN - 3 year

Creatinine - 3 year

ALP - 3 year

ALT - 3 year

AST - 3 year

Bilirubin - 3 year

Total Cholesterol - 3 year

Triglycerides -3 year

HDL - 3 year

LDL -3 year

VLDL - 3 year

RBC - 3 year

Hemoglobin - 3 year

Hematocrit -3 year

WBC - 3 year

Platelet - 3 year

Ferritin - 3 year

Total Iron Binding Capacity - 3 year

Iron - 3 year

Folate - 3 year

Thyroid Stimulating Hormone (TSH) - 3 year

Vitamin B12 - 3 year

Vitamin D3, total - 3 year

Key Previous Diagnoses

Clinical events/procedures relevant to cardiovascular disease an

Add any additional notes about the patient 


\section{Makenzie L. Barr, BS, RDN, LD}

mbarr6@mix.wvu.edu

Updated 3/24/2018

\section{Education}

Ph.D. Student in Animal and Nutritional Sciences

Current

Faculty Advisor: Dr. Melissa D. Olfert

West Virginia University, Morgantown, WV

Registered Dietitian

Individual Supervised Practice Pathway

University of Arizona, Tucson, $A Z$

B.S. Degree in Human Nutrition and Foods

Minor: Food Science and Technology

West Virginia University, Morgantown, WV

\section{Honors \& Awards}

E.J. Van Liere Oral Presentation

Graduate Student Enhancement Grant

Davis College $\mathrm{PhD}$ Travel Grant

Rural Health Conference Scholarship

Graduate Student Enhancement Grant

WVCTSI/ATRN Annual Conference Travel Award

Dean's List

2011-2014

Undergraduate Research Day Presenter

2013

President's List

2013

\section{Memberships and Affiliations}

Healthy Campus Research Consortium

2017-current

- Information, Data, and Outputs Committee

Society for Nutrition Education and Behavior (SNEB)

2014-current

- Student Committee Member - Social Media Committee

- Student volunteer

American Society for Nutrition (ASN)

2015-current

Academy of Nutrition and Dietetics (AND)

2014-current

Phi Sigma Pi National Honors Fraternity

2012-current

- Social Committee Co-chair

Student Academy of Nutrition and Dietetics (SAND)

2012-2013

- Volunteered and attended local nutrition related activities 


\section{Work Experience}

Graduate Research Assistant

2014-current

- Self-driven student with capabilities to learn new skills and concepts quickly

- Thrives under pressure, balancing Ph.D. course work and research endeavors

- Work under Assistant Professor on multiple nutrition related research projects

- Constantly working in group settings

- Campus Coordinator on large USDA funded multi-state grant: Get Fruved

- Skills in various computer programs. Analyze and present data

\section{Graduate Teaching Assistant}

- Worked, interacted, and led nutrition courses with undergraduate students of all ages and ethnicities

- Graded and kept track of student's grades and assignments

- Formed professional and working relationships with students

- Lectured and mentored graduate students in Maternal and Child Nutrition

\section{Dietetic Internship}

- Completed 1200 hours of supervised practice within the realms of community, foodservice, and clinical nutrition

- Personalized all rotations individually 


\section{Presentations and Publications}

1. Barr ML*, Olfert MD, Tabone L, Szoka N, Brode C, Cox S, Davisson L. Describing a United States Appalachian Bariatric Surgery Patient Population. International Federation for the Surgery of Obesity and Metabolic Disorders Conference. Athens, Greece 2018. Poster Presentation

2. Barr ML*, Olfert MD, Tabone L, Szoka N, Brode C, Cox S, Olfert IM, Davisson L. Metabolic Surgical Outcomes in a United States Appalachian Population. International Federation for the Surgery of Obesity and Metabolic Disorders Conference. Athens, Greece 2018. Oral Presentation

3. Barr ML*, Olfert MD, Tabone L, Szoka N, Brode C, Cox S, Gross T, Wilson B, Davisson L. Low Food Access Ranking among West Virginia Appalachian Metabolic Surgery Patients. International Federation for the Surgery of Obesity and Metabolic Disorders Conference. Athens, Greece 2018. Oral Presentation

4. Sriram K*, Barr ML*, Colby SE, Mathews A, Riggsbee K, Zhou W, Horacek TM, Mosby T, Olfert MD. (In Review) Health, Lifestyle, And Environmental Characteristics Of College Vegetarians. American Society for Nutrition. Boston, MA. June 2018.

5. Olfert MD, Barr ML*, Hagedorn R*, Horacek TM, Colby SE, Shelnutt K, Mathews A, Franzen-Castle L, White A, Greene GW, Kattelmann KK, Byrd-Bredbenner C, Kidd T, Brown O, Morrell J, Mosby T. (In Review) Developing Infographic Forecast Reports for Campuses Engaged in GetFruved using the eB4CAST Framework. American Society for Nutrition. Boston, MA. June 2018.

6. Barr ML, Cox S, Brode C, Olfert IM, Chantler PD, Szoka NL, Olfert MD. Preliminary EMR Chart Review of an Appalachian Bariatric Surgery Patient Population. Adolescent Health Research Symposium. Pittsburgh, PA, 2017.

7. Barr, ML, Olfert, MD, Riggsbee K, Kattelmann, KK, Leischner, K, Mathews, AE, Vilaro, M, Colby, SE. Community-Based Participatory Research put into Action and Dissemination: Get Fruved Program. Adolescent Health Research Symposium. Pittsburgh, PA, 2017.

8. Hagedorn RL, Barr ML, Olfert MD. WISH4CAMPUS: Initial Investigation of Food Insecurity Prevalence and Outcomes at West Virginia University. Annual Adolescent and Young Adult Research Symposium. Pittsburgh, PA. May 2017

9. Morris AM, Barr ML, Hagedorn RL, Clark RL, Horacek T, Olfert MD. Characteristics of the Built Environment at West Virginia University. Annual Adolescent and Young Adult Research Symposium. Pittsburgh, PA. May 2017

10. Olfert MD, Hagedorn RL, Famodu OA, Barr ML, King SJ, Colby SE, Franzen-Castle L, Kattelmann K, White A. A Childhood Obesity Prevention Program to Increase Cooking, Eating, and Playing Together in Families: iCook 4-H Study. Annual Adolescent and Young Adult Research Symposium. Pittsburgh, PA. May 2017

11. Olfert MD, Barr ML, Long D, Whanger S, Haggerty T, Weimer M, Doyle D, Cochran J, Maurer MA, Hodder S. Health Outcomes and Feasibility a Personalized Nutrition Technology in Rural and Peri-Urban West Virginia. Adolescent Health Research Symposium. Pittsburgh, PA, 2017.

12. Barr, M. L., Charlier, C. M., Colby, S. E., Greene, G., Bryd-Bredbenner, C., \& Olfert, M. D. (2017). Young Adult Males and Regional Appalachian Differences in Dietary Patterns across US Universities. The FASEB Journal, 31(1 Supplement), 961-25.

13. Barr ML, Famodu OA, Gou G, Colby SE, Olfert MD. Facial Imagery BMI Algorithm correlates with Normal and Overweight Measured BMI. Experimental Biology FASEB American Society of Nutrition Annual Meeting, Abstract \#7895. Chicago, Illinois. April 22-26. 2017. 
14. Barr ML, Beller EL, Colby SE, Morrell J, Kidd T, Riggsbee K, Olfert MD. Young adults physical activity behavior and chronic disease prevention knowledge across Appalachia. Experimental Biology FASEB - American Society of Nutrition Annual Meeting, Abstract \#7991. Chicago, Illinois. April 22-26. 2017.

15. Morris AM, Barr ML, Famodu OA, Colby SE, Zhou W, Hagedorn RL, Riggsbee, Olfert MD. Wellness Characteristics of College Freshmen at West Virginia University. Experimental Biology. Chicago, IL. April 2017.

16. Morris AM, Hagedorn RL, Barr ML, King SJ, Famodu OA, Clark RL, Charlier CM, White A, Colby SE, Kattelmann K, Franzen-Castle L, Olfert MD. Application of a Novel Forecasting and Footprinting Dissemination Framework to a Community Based Childhood Obesity Prevention Program. Experimental Biology. Chicago, IL. April 2017.

17. Hagedorn RL, Barr ML, BS, Famodu OA, Clark RL, Morris AM, Wattick RA, Waanders TR, Olfert MD. Behavior Change Counseling: Training Graduate Dietetic Students in Shortened Motivational Interviewing. Experimental Biology. Chicago, IL. April 2017.

18. Wattick RA, Barr ML, Hagedorn RL, Shelnutt K, Mathews A, Colby SE, Olfert MD. Food Security and Substance Use of College Freshmen. WVU Undergraduate Research Day. Morgantown, WV. April 2017.

19. Morris AM, Barr ML, Famodu OA, Colby SE, Zhou W, Hagedorn RL, Riggsbee, Olfert MD. Wellness Characteristics of College Freshmen at West Virginia University. Van Liere Research Symposium Morgantown, WV. February 2017.

20. Hagedorn RL, Morris AM, Barr ML, Olfert MD. Profile of Food Insecurity Among College Students at West Virginia University and Self-Reported Health Status. Van Liere Research Symposium Morgantown, WV. February 2017.

21. Morris AM, Barr ML, Famodu OA, Hagedorn RL, King SJ, Olfert MD. University Student Auditors Report on Experience and Impact of Campus Environmental Polices. West Virginia Rural Health Conference. Logan, WV. October 2016.

22. Barr ML, Mathews A, Kattelmann K, Colby s, Olfert M. West Virginia University Health Promotion Program: GetFruved. WV Rural Health Conference, Logan, WV. October 19, 2016.

23. Olfert MD, Barr ML, Baus A, Haggerty T, Weimer M, Doyle D, Maurer MA, Cockran J, Hendershot T, Hodder S. Recruitment Effectiveness and Barriers for a Clinical Site Intervention to Track Nutrition Application Usage. SNEB Annual Meeting, San Diego, CA. July 30, 2016.

24. Olfert MD, King SJE, Hagedorn RL, Morris AM, Famodu OA, Barr ML, Morrison P, Colby S, Franzen Castle L, Kattelmann K, White A. Using Tailored Infographics and Narrative Summaries to Empower Communities for Dissemination and Implementation of Programing through eB4CAST: iCook 4-H. SNEB Annual Meeting, San Diego, CA. July 30, 2016.

25. Hagedorn RL, Famodu OA, Barr ML, King SJE, Colby S, Franzen Castle L, Kattelmann K, White A, Olfert MD. Extension Leadership Training Program for Teen Researchers to Deliver Community Based Programing Trhought the Health Science Technology Academy (HSTA). SNEB Annual Meeting, San Diego, CA. July 30, 2016.

26. Famodu OA, Cuff C, Cockburn A, Olfert IM, McFadden JW, Downes ME, Murray PJ, Holaskova I, Barr ML, Colby SE, Morrell J, Olfert MD. Nutrition Intervention to Profile Microbiome and Behaviors in Young Adults at Risk for Metabolic Syndrome: FRUVEDomic Pilot Study. SNEB Annual Meeting, San Diego, CA. July 30, 2016.

27. Morris AM, Barr ML, Famodu OA, Hagedorn RL, King SJE, Olfert MD. University Student Auditors Report on Experience and Impact of Campus Environmental Policies. SNEB Annual Meeting, San Diego, CA. July 30, 2016. 
28. Famodu OA, Olfert MD, Holaskova I, Barr ML, Zhou W, Morrell J, Colby SE. Shortening Pittsburgh Sleep Quality Index Survey Using Factor Analysis. SNEB Annual Meeting, San Diego, CA. July 30, 2016.

29. Barr ML, Olfert MD, Mathews A, Riggsbee K, Leischner K, Kattelmann KK, Colby S. Intervention Planning and Baseline Characteristics of College Students Trained to Implement Wellness on Campus: GetFRUVED Study. SNEB Annual Meeting, San Diego, CA. July 30, 2016.

30. Hanson A, Kattelmann K, Mathews A, Olfert MD, Barr M, Brown O, Horacek T, Kidd T, White A, Violette G, Colby S. An Evaluation of the Relationship between College Students' Cooking Skills, Frequency, and Self-Efficacy and Fruit and Vegetable Intake and Body Mass Index: GetFRUVED Study. SNEB Annual Meeting, San Diego, CA. July 30, 2016.

31. Sowers, MF, Colby SE, Yan W, Zhou W, Olfert MD, Barr ML, Mathew A, Vilaro M, Kattelmann KK, Leischner K, Kidd T, Brown O, Horacek T, White A, Williams J, A Comparison of Peer Mentors' and Mentees' Health Behaviors: Get Fruved Study. SNEB Annual Meeting, San Diego, CA. July 30, 2016.

32. Riggsbee K, Colby SE, Sowers MF, Olfert MD, Barr ML, Kattelmann KK, Kidd T, Horacek T, Brown O, White AA. Social Media and Dietary Patterns Among College Students. SNEB Annual Meeting, San Diego, CA. July 30, 2016.

33. Colby S, Zhou W, Yan W, Dahlman S, Olfert M, Barr M, Kattelmann K, Creager K, Mathews A,Vilaro A, Brown O, Kidd T, Horacek T, White A. Peer Mentoring to Prevent Obesity in First Year College Students: Get Fruved Study. Experimental Biology (EB), American Society of Nutrition (ASN), San Diego, CA. April 2-6, 2016.

34. Barr ML, Olfert MD, Zhou W, Riggsbee K, Mathews AEW, Vilaro M, Kattelmann KK, Leischner K, Crouter S, Morrell JS, Thompson D, White A, Horacek T, Kidd T, Brown O, Colby SE. Fruit and Vegetable Consumption and Physical Activity in Young Adults: Get Fruved Study. Experimental Biology (EB), American Society of Nutrition (ASN), San Diego, CA. April 2-6, 2016.

35. Barr ML, Olfert MD, Zhou W, Riggsbee K, Mathews AEW, Vilaro M, Kattelmann KK, Hanson A, White A, Horacek T, Kidd T, Brown O, Colby SE. Recruitment Strategies Implemented Across a Four-State Lifestyle Intervention: Get Fruved Study. Experimental Biology (EB), American Society of Nutrition (ASN), San Diego, CA. April 2-6, 2016.

36. Olfert MD, Barr ML, Zhou W, Riggsbee K, Mathews AEW, Vilaro M, Kattelmann K, Hanson A, Spurgeon S, Morrell JS, Franzen-Castle L, Byrd-Bredbenner C, White A, Horacek T, Kidd T, Brown O, Colby SE. Sleep and Stress Level of College Students Developing a Health Promotion Intervention: Get Fruved Study. Experimental Biology (EB), American Society of Nutrition (ASN), San Diego, CA. April 2-6, 2016.

37. Bowyer D, Barr ML, Olfert MD. Identifying Effectiveness of Twitter at West Virginia University when Targeting a Large Audience. Undergraduate Research Day at the Capitol (URDC), Charleston, WV, Feb. 25, 2016.

38. Morris AA, Barr ML, Famodu OA, Olfert MD. Thematic Analysis of Feedback from Student Researchers conducting a Healthy Campus Environmental Audit. Undergraduate Research Day at the Capitol (URDC), Charleston, WV, Feb. 25, 2016.

39. Barr ML, White JA, Famodu OA, Olfert MD. 'Get Fruved': Overview, recruitment and training in West Virginia for a peer-led, social marketing campaign aimed at increasing healthier lifestyles on college campuses. Appalachian Translational Research Network (ATRN). Charleston, WV. October 14-16, 2015. (Travel award \$200)

40. Barr ML, White JA, Famodu OA, Olfert MD. 'Get Fruved' Healthy Campus Environmental Audit: Evaluating the Healthfulness of the Built and Food Environments on College Campuses. Appalachian Translational Research Network (ATRN). Charleston, WV. October 14-16, 2015. (Travel award \$200) 
41. Parsley MC, Barr ML, Olfert MD. Analysis of Dosage via Combination Intteraction in iCook 4-H Program. Summer Undergraduate Research Experience Meeting (SURE), Morgantown, WV, July 23, 2015.

42. Olfert M, Famodu O, White J, Barr M, Hagedorn R, Meade R, Colby S, Franzen-Castle L, Aguirre T, Kabala C, Kattelmann K, Mathews D, White A. Blood Pressure and Quality of Life in 9-11 Year Old Youth and Adult Dyad Pairs Over One Year: iCook 4-H. J Nutr Educ Behav 2015; 47(4)S83-84. DOI: http://dx.doi.org/10.1016/j.jneb.2015.04.220

43. Olfert M, Scatterday A, Famodu O, White J, Barr M, Hagedorn R, Meade R, Colby S, Franzen-Castle L, Wilson-Sweebe K, Kattelmann K, Yerxa K, White A. Health Disparate Score Change Over 12 Months: iCook 4-H Study. J Nutr Educ Behav 2015; 47(4), S83. DOI: http://dx.doi.org/10.1016/j.jneb.2015.04.219

44. Famodu O, Olfert I, Kesner D, Buerkle M, White J, Barr M, Downs M, Moore C, Murray P, McFadden J, Cuff C, Colby S, Morrell J, Olfert M. Designing a Nutrition Intervention to Profile Metabolic, Metabolomic, Microbiome and Vascular Health in Young Adults At Risk for Disease: FRUVEDomic Pilot Study. J Nutr Educ Behav 2015; 47(4) S65. DOI: http://dx.doi.org/10.1016/j.jneb.2015.04.171

45. Hagedorn R, White J, Famodu O, Barr M, Hanks S, Chester A, Colby S, Franzen-Castle L, Kattelmann K, White A, Olfert M. Using High School Leaders in Dissemination and Implementation Through the Health Sciences Technology Academy (HSTA): iCook 4-H. J Nutr Educ Behav 2015; 47(4) S38. DOI: http://dx.doi.org/10.1016/j.jneb.2015.04.101

46. Get Fruved Overview Panel Presentation. Society for Nutrition Education and Behavior Annual Meeting. Pittsburgh, PA July 10, 2015.

47. Get Fruved WVU Intervention Presentations (4). Fruved Summit. Knoxville, TN. April 1719, 2015. (Presentations delivered by 25 WVU undergraduate students, 2 graduate students).

48. Barr ML, White JA, Famodu OA, Olfert MD. 'Get Fruved': Recruitment and Training in West Virginia for a Peer-led, Social Marketing Campaign Aimed at Increasing Healthier Lifestyles on College Campuses. Davis College Research and Creativity Expo. Presentation conducted from Davis College of Agriculture, Natural Resources and Design, Morgantown, WV. April 7, 2015.

49. Get Fruved and other National Collegiate 4-H Initiatives. National Collegiate 4-H Conference, Gainesville, FL. March 12-15, 2015. (Presentation and representation by 10 WVU graduate and undergraduate students)

50. Rubino J, Famodu OA, White J, Barr M, Olfert MD. eB4CAST: Evidence-Based Forecasting in Community Program Dissemination. Undergraduate Research Day at the Capital. Charleston, WV March 4, 2015.

51. Hagedorn RL, White J, Famodu OA, Barr M, Olfert MD. Community Research through Teen Implementation. Undergraduate Research Day at the Capital. Charleston, WV March 4, 2015.

52. Famodu O, Olfert I, Kesner D, Buerkle M, White J, Barr M, Downs M, Moore C, Murray P, McFadden J, Cuff C, Colby S, Morrell J, Olfert M. Designing a Nutrition Intervention to Profile Metabolic, Metabolomic, Microbiome and Vascular Health in Young Adults At Risk for Disease: FRUVEDomic Pilot Study. Van Liere Research Symposium Morgantown, WV. February 2015.

53. Barr M, White J, Famodu O, Olfert M. Recruiting in WV for a Peer-led, Social Marketing Campaign That Promotes Health on College Campuses: Get Fruved WV. Van Liere Research Symposium Morgantown, WV. February 2015.

54. White J, Famodu O, Barr M, Hagedorn R, Olfert M. Cooking, Mealtime \& Physical Activities Incorporated in the Home Environment One Year After Initial Intervention: iCook 4-H. Van Liere Research Symposium Morgantown, WV. February 2015. 
55. Famodu OA, Olfert IM, Barr ML, White JA, Warner C, Hagedorn RL, Starrett P, Dehlin M, Hass A, Rubino J, Mathews A, Aromeh L, McFadden JW, Murray PJ, Olfert MD. Nutrition Intervention to Impact Metabolic and Vascular Health. Clinical Translational Science Institute Health Disparity and STEM Meeting. Presentation conducted from Davis College of Agriculture, Natural Resources and Design, Morgantown, WV. Nov. 19, 2014.

56. Barr ML, White JA, Famodu OA, Olfert MD. Get Fruved: Behavioral and Environmental Health Initiative in West Virginia. Clinical Translational Science Institute Health Disparity and STEM Meeting. Presentation conducted from Davis College of Agriculture, Natural Resources and Design, Morgantown, WV. Nov. 19, 2014.

57. Barr ML, Olfert MD, Clarke L, Chertok I. Self-Efficacy in Blood Glucose Monitoring Smoking Cessation and Breastfeeding in Appalachian Women with Gestational or Existing Diabetes during Pregnancy. Undergraduate Research Day at the Capitol (URDC),

Charleston, WV, 2014. 